\title{
Smart Energy Management of Multiple Full Cell Powered Applications
}

\author{
Project Period: \\ Date of Report: \\ August 15, 2005 to May 15, 2007 \\ Recipient: \\ April 23, 2007 (Final Report) \\ Award Number: \\ University of South Alabama \\ DE-FG02-05CH11295 \\ Subcontractor: \\ Radiance Technologies \\ Cost-Sharing Partner: \\ Radiance Technologies \\ Primary Contact: \\ Dr. Mohammad S. Alam (PI/PD) \\ University of South Alabama \\ ECE Department, EEB 75 \\ Mobile, AL 36688-0002 \\ Phone: $251-460-6117$ \\ Fax: 251-460-6028 \\ Email: malam@usouthal.edu
}

DOE Project Officer: Mr. Stephen Waslo

\section{Objectives}

- To demonstrate the most effective design and protection scheme of minigrid power system for multiple fuel cell power plants application

- To define the most economical operational schedule for the multiple fuel cell in terms of electrical, thermal and hydrogen production

- To lay the bases for generation of hydrogen using the photoelectrochemical solar cells

- To develop models for hydrogen production, purification, and storage systems

- To demonstrate that smart energy management and control of a fuel cell power sources when subjected to varying demands of electrical and thermal loads together with demand of hydrogen production. 


\section{Executive Summary}

Fuel cells, as a distributed energy source, are considered as one of the most promising sources of electrical energy that can meet the increasing demand and environmental constraints. To understand how the fuel cell behaves in a multi-unit generation environment, the research team designed a minigrid system with five fuel cells connected in parallel to feed five different neighborhoods. The thermal power, cogenerated from the fuel cells, is used to feed part of the neighborhood thermal load. In addition, the research team developed smart energy management control software to guarantee that the total power consumption of a typical residential home remains below the available power generated from a fuel cell. Generating hydrogen to feed the fuel cells is one of the main objectives of this project. New materials that help in producing hydrogen from water using sunlight are investigated. Another objective of this research is to investigate the application of small power fuel cells for portable applications. The research team investigated the feasibility of using fuel cells to feed the power to a laptop computer. In addition, using storage devices such as supercapacitor with the fuel cell to meet the sharp change in the laptop computer load is also investigated. Based on the economical analysis of the system and experimental results, we infer that a distributed energy system consisting of multiple fuel cells is a viable and feasible option to supply electrical and thermal power to a minigrid system. 


\section{Overview}

In this research project the University of South Alabama research team has been investigating smart energy management and control of multiple fuel cell power sources when subjected to varying demands of electrical and thermal loads together with demands of hydrogen production. This research has focused on finding the optimal schedule of the multiple fuel cell power plants in terms of electric, thermal and hydrogen energy. The optimal schedule is expected to yield the lowest operating cost. Our team is also investigating the possibility of generating hydrogen using photoelectrochemical (PEC) solar cells through finding materials for efficient light harvesting photoanodes. The goal is to develop an efficient and cost effective PEC solar cell system for direct electrolysis of water. In addition, models for hydrogen production, purification, and storage will be developed. The results obtained and the data collected will be then used to develop a smart energy management algorithm whose function is to maximize energy conservation within a managed set of appliances, thereby lowering O/M costs of the Fuel Cell power plant (FCPP), and allowing more hydrogen generation opportunities.

The Smart Energy Management and Control (SEMaC) software, developed earlier, controls electrical loads in an individual home to achieve load management objectives such that the total power consumption of a typical residential home remains below the available power generated from a fuel cell. In this project, the research team will leverage the SEMaC algorithm developed earlier to create a neighborhood level control system. 


\title{
UNIVERSITY OF SOUTH ALABAMA
}

DEPARTMENT OF ELECTRICAL AND COMPUTER ENGINEERING

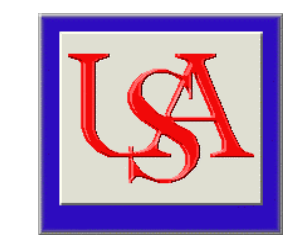

Final Report

(Project Duration: 8/15/05 - 5/15/07)

\section{Smart Energy Management of Multiple Full Cell Powered Applications}

\author{
Submitted by: \\ Dr. Mohammad S. Alam (PI/PD) \\ University of South Alabama \\ ECE Department, EEB 75 \\ Mobile, AL 36688-0002 \\ Phone: $251-460-6117$ \\ Fax: 251-460-6028 \\ Email: $\underline{\text { malam@usouthal.edu }}$
}

April 23, 2007 



\section{CONTENTS}

1. Operational Analysis of Multiple FCPP Based Mini-Grid System

1.1.1. Mini-grid Design and Protection

1.1.2. Representative Residential Load Data Collection

1.1.3. Unmanaged Short-term Scheduling of FCPPs

1.1.4. Thermal Energy Management Based Short-term Scheduling of FCPPs

1.1.5. Hydrogen Management Based Short-term Scheduling of FCPPs

2. Production of Hydrogen Using photoelectrochemical (PEC) Solar Cells

2.1. Modeling and Simulation

2.2. Investigation of Nanostructured Films for Photooxidation of Water

2.3. Development of Smart Materials for Transparent Conduction and Corrosion Resistance of Photoelectrodes Used in PEC Cells

3. Modeling of Hydrogen Production, Purification, and Storage

3.1. Develop a Working Model of a Methane Reformer Operating at Full Steady State Capacity

3.2. Develop a Model of Hydrogen Purification System

3.3. Develop a Model of Hydrogen Compression System

4. Smart Energy Management of FC Application and Energy Conservation

4.1. Energy Conservation Algorithm

4.2. Energy Conservation Hardware

4.3. Pilot Program, Test, and Analysis

5. Neighborhood Level Energy Management

5.1. Algorithm Developed

5.2. Testing

6. Coordination with the Electric cooperative industry

7. Smart energy management and control for $\mathrm{FC}$ based small power application

7.1. Laboratory Experiments

7.2. PEM Fuel Cell System Description

7.3. Simulation Results 


\section{Operational Analysis of Multiple FCPP Based Mini-Grid System}

\subsection{Mini-grid Design and Protection}

\subsubsection{System Design}

The mini-grid consists of 5 neighborhoods and each neighborhood contains a cluster of 10 identical single storied homes. Neighborhoods are fed from proton exchange membrane (PEM) fuel cell power plants (FCPP) with a total capacity of $300 \mathrm{KW}$. The layout of the neighborhoods and the number of FCPPs are the key issues for the design of the mini-grid. In the configuration considered, neighborhoods are fed from multiple-unit FCPPs that are connected to each other in a ring network design. FCPPs are located in the middle of each neighborhood. The distribution design can be divided into primary and secondary distribution systems. The feeder system between the FCPP and the distribution transformers located in the neighborhoods constitutes the primary distribution system. The secondary distribution system relates to the feeder system between the distribution transformer and the homes in the neighborhood. The layout of the neighborhoods is shown in Fig. 1.1.1. The essential factors governing the mini-grid design are: the length of feeders from the FCPP to the neighborhoods, feeder ampacities, voltage drops in the feeders \& transformers, and power loss in the feeder system. The following assumptions are used in the design:

- The designer has complete freedom to decide on the location of neighborhoods for the minigrid community.

- All five neighborhoods are identical and each and every neighborhood has an IEEE-RTS load profile with a peak of $50 \mathrm{~kW}$ [1] to simulate the hourly electrical load profile of the community.

- Hot water usage and space heating rates for the winter season in the region of Atlanta, Georgia [2] is considered to represent the thermal load profile. The summer and spring/fall thermal load data are estimated from the available winter data.

- The thermal load is used along with the electrical load profile to simulate total hourly load profile of the mini-grid community.

- The electric power to each neighborhood is regulated and controlled electronically through the 'Local Energy Management System' (LEMSYS), the 'Micro-grid Energy Management System' (MEMSYS) and 'Neighborhood Energy Management System' (NEMSYS). These controls will, in most instances, maintain a $50 \mathrm{~kW}$ power ceiling for each neighborhood.

- The design will be based on the National Electric Code (2002) [3], and reference will be made to the Articles and Sections of the code throughout the design. Other texts and publications are referenced in the design as well.

\subsubsection{Mini-grid Layout}

The mini-grid layout design is based principally on locating the PEM FCPP in a centralized location with respect to the homes for multiple-unit configuration. The centralized placement of the FCPP is critical because it determines the length of the feeder from the FCPP and/or distribution transformer to the farthest end-user. Besides, the total length of the tie-lines of multiple-unit configuration is also vital in terms of power handling capacity for all possible scenarios. The length of feeder and/or tie-line, and the power carried by them as well as voltage drop in distribution transformers determine the total voltage drop and power loss in the system. 
The sizing or ampacity of the feeder however, is determined in accordance with the NEC code. Figure 1.1.1 shows the layout of the mini-grid under consideration, where each neighborhood is located on its own neighborhood island surrounded by roads on all four sides. The mini-grid community is composed of 5 neighborhood islands each of width $220 \mathrm{ft}$. and $400 \mathrm{ft}$ long. Each neighborhood receives power from its own single-phase distribution transformer with a nominal rating of $2400-120 / 240 \mathrm{~V}$ and $75 \mathrm{kVA}$.

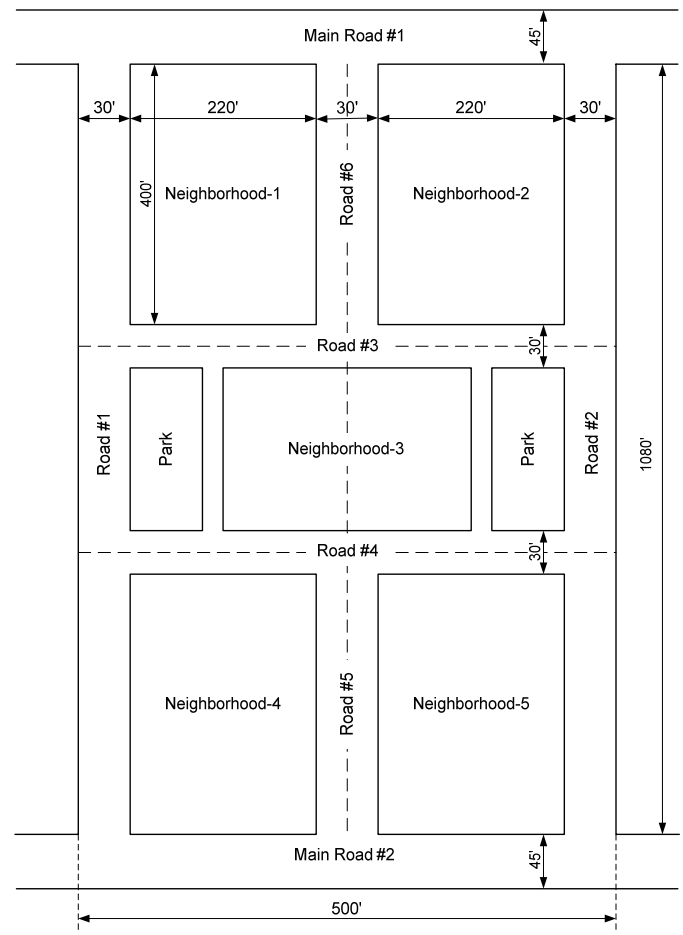

Fig.1.1.1 Mini-grid community layout.

\subsubsection{Multiple FCPP Based Distribution Mini-grid Design}

Single-phase single line diagrams relating to the multiple-unit configuration are shown below. Fig. 1.1.2 is a simplified diagram while Fig. 1.1.3 shows the details of the same configuration. Fig. 1.1.4 shows the $2400 \mathrm{~V}$ neighborhood bus bar along with the local FCPP and the transformer. Although total load demand is assumed to be $250 \mathrm{~kW}$, the sum of FCPP capacities is $300 \mathrm{~kW}$. The additional $50 \mathrm{~kW}$ FCPP generation capacity is provided to meet the system losses if the system is to be operated independent of the grid. The $300 \mathrm{~kW} \mathrm{FCPP} \mathrm{capacity} \mathrm{is} \mathrm{distributed}$ over five FCPPs: $2 \times 25 k W+2 \times 75 k W+1 \times 100 k W$, totaling $300 \mathrm{~kW}$.

It may be mentioned that all FCPPs come with step up transformers that provide 2400 volt AC. The $100 \mathrm{~kW}$ FCPP unit, located in neighborhood-3, represents the utility grid tie point. A step 
down distribution transformer with rated voltages of 2400-240/120 V is shown in Fig. 1.1.5. To allow for the adjustment of the supply voltage to the end-users, taps are provided.

The longest length of the feeder plus lateral is taken as $1895 \mathrm{ft}$. This length includes the path for the worst case condition starting from the middle FCPP unit (neighborhood-3) to the distribution transformer of neighborhood-5 in the counter-clockwise direction or to the distribution transformer of neighborhood-2 in the direction of clockwise. Since the maximum power needs to be carried is $200 \mathrm{~kW}$ in the extreme case the feeders must be sized accordingly. The next issue to be addressed is the type of cable appropriate for this application. Since the operating voltage level is the $2.4 \mathrm{kV}$, Article 310.60 of [3] suggests that MV type cable should be used.

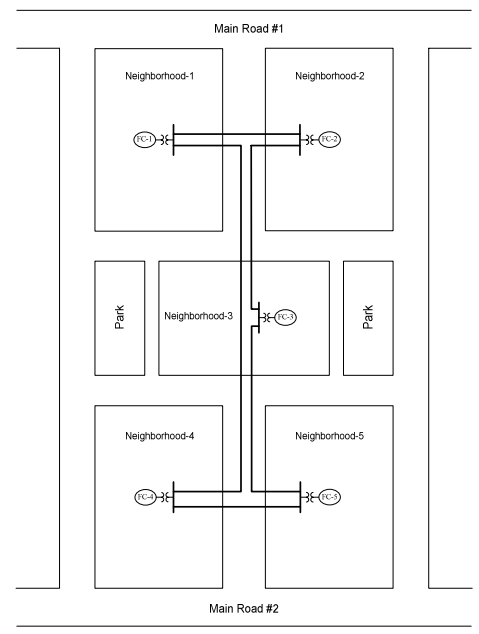

Fig. 1.1.2 Single line diagram of the mini-grid feeder system for the multiple-unit configuration.

To determine the size of the cables the current loading must be known. As indicated earlier, the worst case would be when a neighborhood at a distance of $1895 \mathrm{ft}$ will be allowed to draw the full $200 \mathrm{~kW}$ at $2400 \mathrm{~V}$. Assuming a power factor of 0.95 lagging, the current is, $200000 /(2400 \times 0.95)=87.719 \mathrm{~A}$. This current is considered to be continuous. Hence, according to Article 310.15 of [3], the design load current will be $1.25 \times 87.719=109.64 \mathrm{~A}$. The minimum over current device rating for the $100 \mathrm{~kW}$ FCPP must be 110A. This is in accordance with Article 240.6 of [3]. Article 310.60 of [3] lists the types of conductors rated for the medium voltage range (2001 to 35000 volts). According to this article, ampacities for such conductors should be selected from the Tables 310.67 through 310.86. Since our concern is single-insulated copper conductors directly buried in earth, the cable must be taken from Table 310.81 of [3] from the column marked $90^{\circ} \mathrm{C}$. The voltage drop calculations (appearing later) indicate that the conductor size should be \#4 AWG so as to limit the voltage drop to less than $5 \%$. From the table, the maximum allowable current rating for this conductor size of Type MV-90 is 180A. In this design, full load current in the worst case is $87.719 \mathrm{~A}$, which is expected to produce a conductor temperature much less than $60^{\circ} \mathrm{C}$. This design also satisfies the requirement of Article $110.14(\mathrm{C})(1)(\mathrm{a})$ of [3], which indicates that if the design load current is less than 100A, the 
ampacity of conductors with higher than $60^{\circ} \mathrm{C}$ temperature ratings should not go beyond the ampacity level determined for such conductors. So the outcome of the design so far determines the type and size of the feeder to be a two single insulated conductors, type MV-90, \#4 AWG copper cable, directly buried.

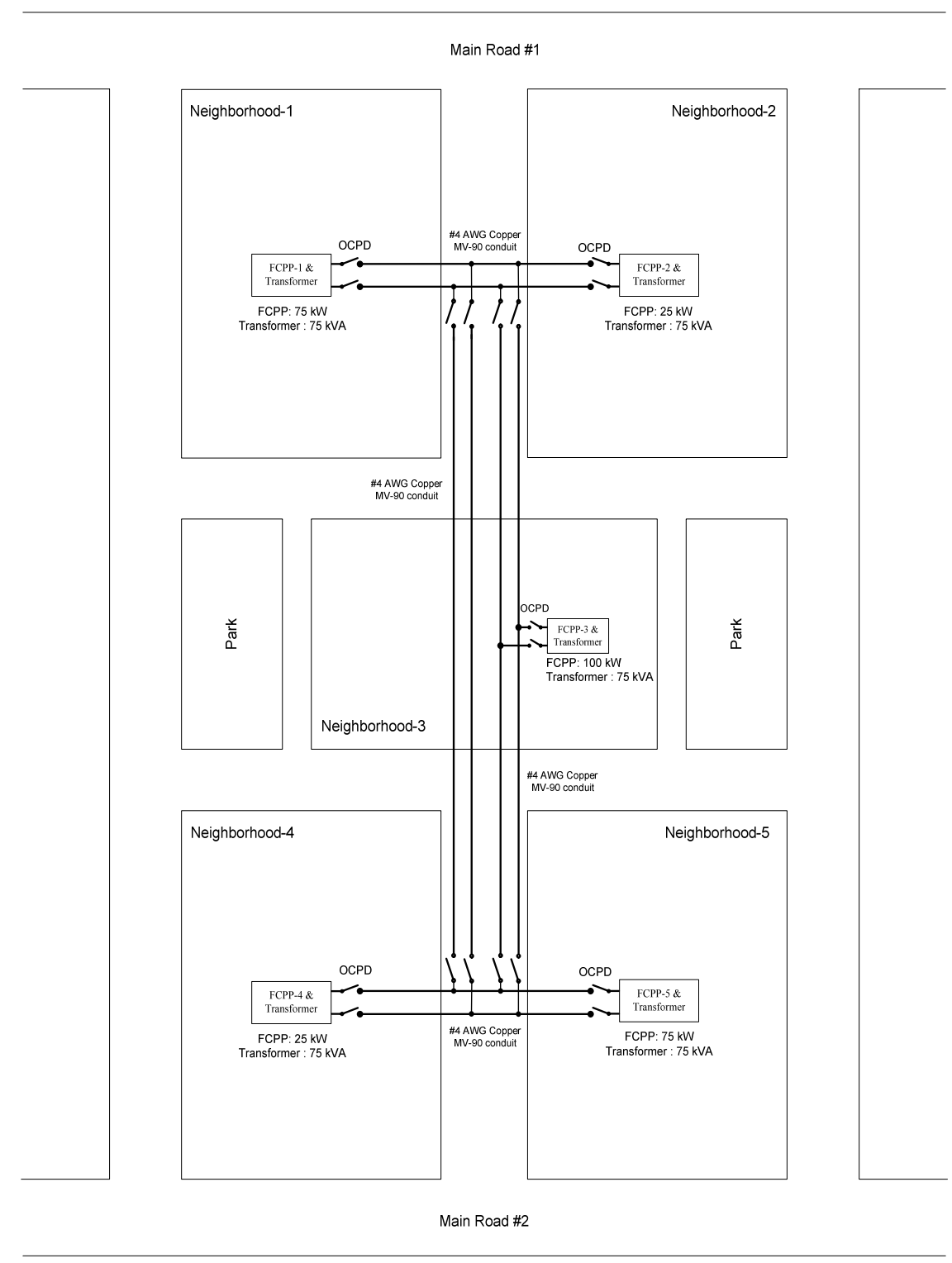

Fig. 1.1.3 Single-phase mini-grid feeder system for multiple-unit configuration. 
When calculating the voltage drop, the impedance of the $75 \mathrm{kVA}$ transformer as well as the feeder must be taken into account. As indicated in the single-unit design, percentage resistance and reactance value of $75 \mathrm{kVA}$ distribution transformer are $0.8(\% \mathrm{r})$ and $1.2(\% \mathrm{x})$, which yields the same voltage drop $(1.134 \%)$.

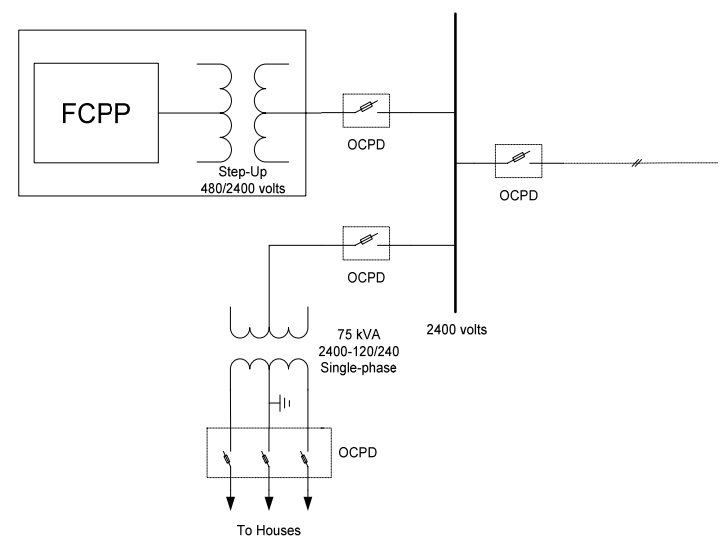

Fig. 1.1.4 Diagram of connections showing local FCPP, transformer and bus bars for a multipleunit configuration.

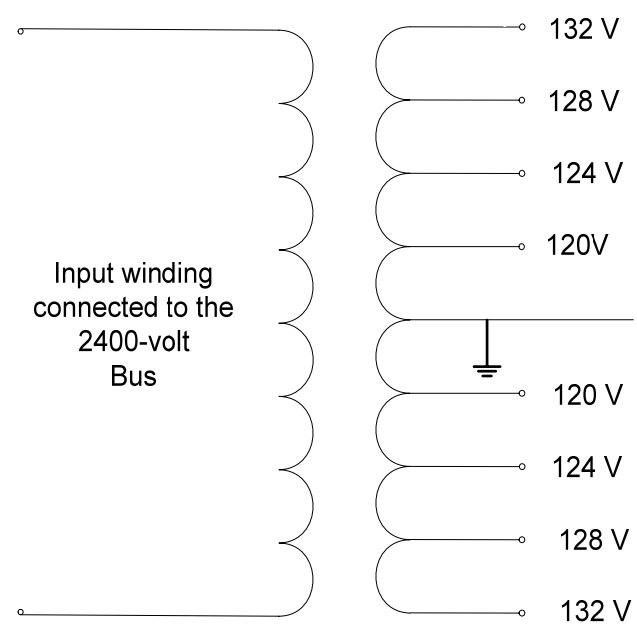

Fig. 1.1.5 A $75 \mathrm{kVA}$ transformer with secondary taps $(\% \mathrm{r}=0.8, \% \mathrm{x}=1.2)$ for multiple-unit configuration. 
The cable resistance and reactance per $1000 \mathrm{ft}$. is obtained from [3]. The values for \#4 AWG are, resistance $=0.31 \mathrm{ohm} / 1000 \mathrm{ft}$. and reactance $=0.048 \mathrm{ohm} / 1000 \mathrm{ft}$. Thus, for a total length of $1895 \mathrm{ft}$ as shown in Fig. 1.1.6, we have:

$\mathrm{R}_{\text {Feeder }}=2 \times 0.31 \times \frac{1895}{1000}=1.1749 \mathrm{ohm}$ and $\mathrm{X}_{\text {Feeder }}=2 \times 0.048 \times \frac{1865}{1000}=0.18192 \mathrm{ohm}$ The $\quad$ voltage

drop in the $1895 \mathrm{ft}$. feeder line can be calculated as,

$$
\mathrm{v}_{\mathrm{D}}=87.719 \times[1.1749 \times \cos (-18.2)-0.18192 \times \sin (-18.2)]=102.88 \mathrm{~V},
$$

and the percent voltage drop as,

$$
\mathrm{v}_{\mathrm{D}} \%=\frac{102.88}{2400} \times 100=4.28(\text { Percent drop in the line })
$$

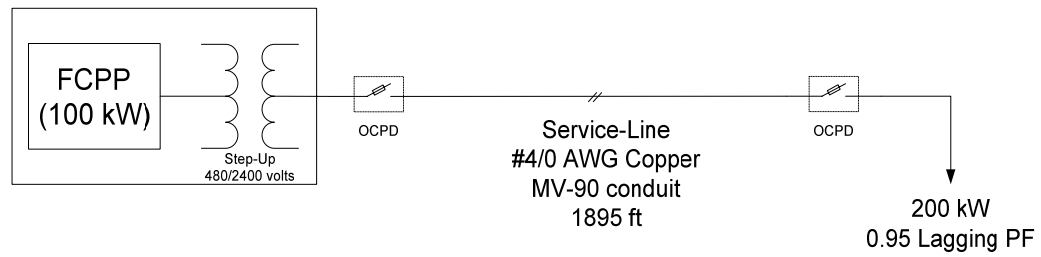

Fig. 1.1.6 Single line diagram showing the FCPP and the feeder.

Now the total voltage drop is the summation of line and transformer voltage drop, which is $\mathbf{V}_{\text {Drop }}=\% 4.28+\% 1.134=\% 5.414 \mathrm{~V}$. The magnitude of the drop is $227 \mathrm{~V}$ in the $2400 \mathrm{~V}$ system. The total power loss in the feeder system supplying all five neighborhood for the extreme case is, $\mathrm{P}_{\text {Feeder }}=1.1749 \times 87.719^{2}=9040$ watts $=9.04 \mathrm{~kW}$. Assuming a transformer efficiency of $95 \%$ for a loading of $50 \mathrm{~kW}$, the total loss in the transformers is determined as,

$$
5 \times 50000 \cdot\left[\frac{1-0.95}{0.95}\right]=13160 \text { watts }
$$

\subsubsection{Mini-grid Protection}

The layout and configuration of the mini-grid with multiple fuel cell power plants (FCPP) was developed in Phase III of the project. In Phase IV, the focus is to develop a reliable protection scheme that would afford protection to the mini-grid from overcurrent and lightning as well as address issues relating to safety, namely grounding. The work that is being reported here relates to the above.

\subsubsection{Overcurrent Protective Devices (OCPDs)}

Overcurrent protection is provided by a system of well-designed Over Current Protective Devices (OCPDs) placed strategically in the mini-grid. OCPDs are series connected. 


\subsection{Location of OCPDs in the Mini-grid}

The first task in providing overcurrent protection is to determine the location of the OCPDs in the mini-grid. This was done keeping in mind two factors: electrical protection to the system and safety for personnel working on the system. While the local bus system in each neighborhood has the same basic layout in all neighborhoods, the ratings of the FCPPs being different require that OCPD ratings be different. This requires separate calculations for individual FCPP OCPDs. Neighborhood 3 on the other hand has a link with the commercial grid distribution system at 2400 VAC.

The locations of the individual OCPD are shown in the mini-grid layout, Fig. 1.1.7 The choice of location of the OCPDs is based on providing isolation of different zones of the mini-grid. The isolation can be achieved by simply operating the Load Break Switches, which are basically isolator switches whenever maintenance is desired. During overcurrent or fault conditions the OCPDs will be able to automatically isolate the faulted zones for repair and replacement.

\subsection{Selection of the Technology Relating to OCPDs}

The technology used in designing OCPDs depends on the system voltage and current. For multi$\mathrm{kV}$ and multi-Amp circuits Oil Circuit Breakers are commonly used. For medium voltage systems $(13.8 \mathrm{kV})$ Vacuum Interrupters are used. Since the mini-grid voltage selected is $2.4 \mathrm{kV}$, it is simpler and economical to use a combination of Load Break Switches and fuses.

Load Break Switches are manually operated switches that are housed in metal enclosures and placed in series with the line. The operation of these switches involves the closing and opening of spring-loaded contactors. The contactors are rated for the desired voltage and current. In series with the Load Break Switches are placed the fuses which are overcurrent protective devices

\subsection{Fuse Characteristics}

Fuses for power system use are manufactured to incorporate certain desired characteristics. Since OCPDs will be used to protect the feeders as well as the transformers, the important characteristic that fuses must possess is to have some time delay so as to absorb the inrush current surge of the transformers at the instant of switching on. The inrush current will instantaneously rise to its highest value during the first half cycle (approximately $0.01 \mathrm{sec}$.). To accommodate this inrush current the time-current withstand values of at least 12 times primary rated current for 0.1 second and 25 times for 0.01 second are chosen. The delay characteristics are based on time-current charts provided by the manufacturers of the fuses. In the design suggested, Type J or AJT time delay fuses may be used.

\subsection{Determination of OCPD Ratings}

While time delay for the fuses of the OCPDs are based on the inrush current characteristics of the transformers, the overload interrupting value of the fuse is governed by the National Electric Code and ANSI standards. For the interrupting current ratings of the fuses therefore relevant sections of the NEC and ANSI standard have been consulted. Tables are provided listing all the OCPDs in the system and their current ratings.

Fuse ratings for transformer protection: As mentioned in the design of the mini-grid, there are a total of five single-phase transformers. Each transformer is rated, $75 \mathrm{KVA}, 2400 / 240 / 120 \mathrm{~V}$. The rated primary and secondary currents are $31.25 \mathrm{~A}$ and $312.5 \mathrm{~A}$. As indicated above, the 
National Electric Code gives the guidelines for the determination of ratings of fuses for the primary and secondary sides of transformers. Table 450.3(A) indicates that for supervised locations the primary fuse rating should be $250 \%$ of the rated current of the primary while the secondary fuse rating should be $125 \%$ of the rated secondary current. The minimum fuse rating for the primary is therefore $2.5 \times 31.25=78 \mathrm{~A}$ while the secondary fuse rating is $390 \mathrm{~A}$. For accommodating the in-rush current, the time-delay characteristics of the primary fuses are determined as follows: $12 \times 31.25=375 \mathrm{~A}$ for $0.1 \mathrm{sec}$. and $25 . \mathrm{x} 31.25=781.25 \mathrm{~A}$ for $0.01 \mathrm{sec}$. The closest rating for the primary fuse is $100 \mathrm{~A}$. The time-delay curves shown in Fig. 1.1.8 below indicates that the $100 \mathrm{~A}$ fuse will withstand a current of $375 \mathrm{~A}$ for about 37 seconds and a current of $781.25 \mathrm{~A}$ for about 0.03 second. The secondary closest fuse rating will be $450 \mathrm{~A}$ (current limiting non-time delay fuse.)

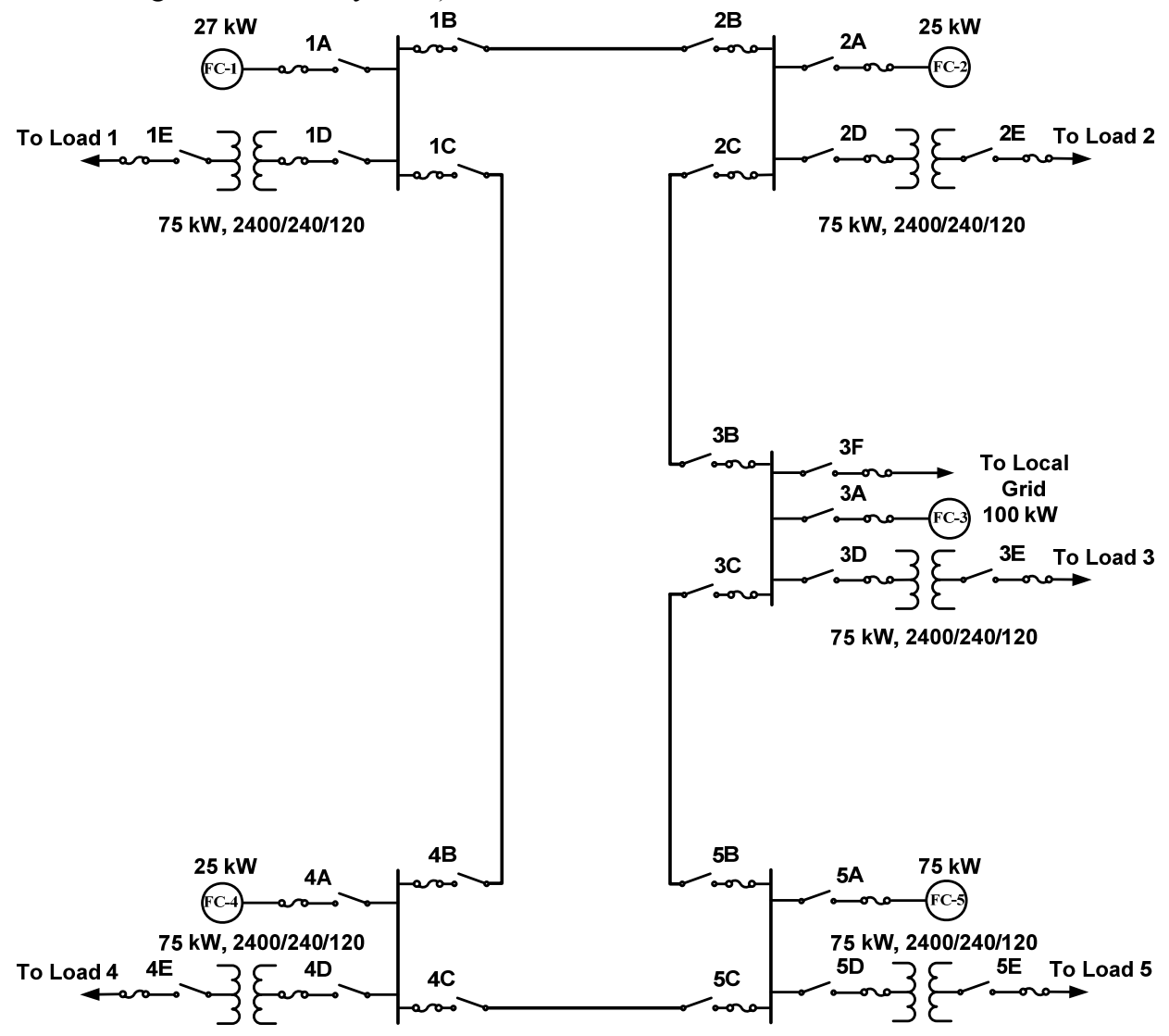

Fig. 1.1.7 Locations of the individual OCPD 


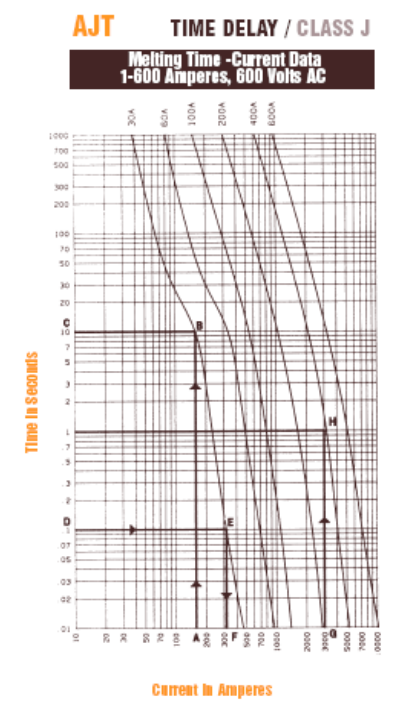

Fig. 1.1.8 time-delay curves

Fuse ratings for feeder lines: The design of the mini-grid specifies the feeder cables as MV-90, \#4 AWG copper cables. The continuous load current of the feeder is $87.72 \mathrm{~A}$, and the design load current is $1.25 \times 87.72=109.64$ A. In accordance with the National Electric Code Article 240.6, the minimum overcurrent protective device must be rated equal to the design load current of 109.64 A. The standard fuse rating is therefore $110 \mathrm{~A}$ (current limiting non-time delay fuse.) Table 1.1.1 lists the load break switches while Table 1.1.2 shows the fuse ratings.

Fuse ratings for the FCPP units: The load break switch and the fuse for the FCPP are located as shown earlier in Fig 1.1.7. When the local transformer is turned on it will draw its primary inrush current from the local bus. Since the local FCPP is nearest to the local bus, it will be called upon to deliver most of the inrush current. Assuming that the FCPPs are capable of supplying the inrush current from their on-board batteries, the fuses must be rated to supply these inrush currents. It is clear therefore that the type of fuse needed is similar to those used for the protection of transformers, namely time-delay fuses. There are three separate $\mathrm{KW}$ ratings of the FCPPs used in the system $-100 \mathrm{KW}, 75 \mathrm{KW}$ and $25 \mathrm{KW}$. The minimum fuse rating of the fuse it takes is $125 \%$ of the rated current. Based on this requirement, the minimum fuse ratings for these units are: $100 \mathrm{KW}-53 \mathrm{~A} ; 75 \mathrm{KW}-39 \mathrm{~A}$ and $25 \mathrm{KW}-13 \mathrm{~A}$. Going back to Fig. 1.1.7 and allowing for the surge currents for the times following switching namely, 0.01 and 0.1 second, the fuse ratings for the three units would be: $100 \mathrm{KW}-100 \mathrm{~A} ; 75 \mathrm{KW}-60 \mathrm{~A}$ and 25 KW-30 A.

\subsubsection{System Grounding}

Grounding is essential for the protection of equipment and personnel. It also prevents overvoltage during lightning. Ground electrodes are necessary in the vicinity of equipment such as transformers, switchgear, fuel cell power generating units etc. In such cases the metallic body or case of the unit is connected to the ground electrode to protect personnel from receiving an 
electric shock should the metallic case becomes live as a result of a fault in the unit. Also, to meet the code requirements, certain points in the electrical system must be grounded.

Transformer grounding: The center point of the secondary winding which is rated $240 / 120 \mathrm{~V}$ is required to be grounded as per Section 250.20(B)(1) of the National Electric Code. The ground is also needed to accommodate the lightning arrester that is installed on the $2400 \mathrm{~V}$ feeder line on the primary side. The setup is illustrated in Fig. 1.1.9.

Fuel Cell grounding: The FCPP may be located in the same general area as the neighborhood transformer. However, for purposes of grounding it is preferable to ground the metal case or tank locally using a separate grounding electrode. This is illustrated in Fig. 1.1.10.

Table 1.1.1 Load break switches

\begin{tabular}{|c|c|c|}
\hline Location & $\begin{array}{c}\text { Voltage } \\
(\mathbf{V})\end{array}$ & $\begin{array}{c}\text { Continuous } \\
\text { Current (A) }\end{array}$ \\
\hline 1A & 2400 & 41.11 \\
\hline 1B & 2400 & 110 \\
\hline 1C & 2400 & 110 \\
\hline 1D & 2400 & 40 \\
\hline 1E & 240 & 400 \\
\hline 2A & 2400 & 13.7 \\
\hline 2B & 2400 & 110 \\
\hline 2C & 2400 & 110 \\
\hline 2D & 2400 & 40 \\
\hline 2E & 240 & 400 \\
\hline 3A & 2400 & 55 \\
\hline 3B & 2400 & 110 \\
\hline 3C & 2400 & 110 \\
\hline 3D & 2400 & 40 \\
\hline 3E & 240 & 400 \\
\hline 3F & 2400 & 164.5 \\
\hline 4A & 2400 & 13.7 \\
\hline 4B & 2400 & 110 \\
\hline 4C & 2400 & 110 \\
\hline 4D & 2400 & 40 \\
\hline 4E & 240 & 400 \\
\hline 5A & 2400 & 41.11 \\
\hline 5B & 2400 & 110 \\
\hline 5C & 2400 & 110 \\
\hline 5D & 2400 & 40 \\
\hline 5E & 240 & 400 \\
\hline & & \\
\hline
\end{tabular}


Grounding electrode conductor: The conductor that provides the connection between the point of grounding in the system and the grounding electrode is called the grounding electrode conductor. The conductor must be bare copper and protected wherever necessary by a conduit to prevent physical damage. The size of the conductor is determined from Table 250.66 of the National Electric Code. In accordance with this code, the conductor size is determined based on the size of the ungrounded service entrance conductor. In the mini-grid system design, the 2400 $\mathrm{V}$ feeder cable was sized \#4 AWG. According to the above mentioned table, the grounding electrode conductor size is determined to be \#8 AWG copper conductor.

Table 1.1.2 Fuse rating

\begin{tabular}{|c|c|c|c|}
\hline Location & Fuse Type & Fuse Current Rating (A) & Fuse Voltage (V) \\
\hline 1A & AJT Class J & 60 & 2400 \\
\hline 1B & Non Time Delay & 110 & 2400 \\
\hline 1C & Non Time Delay & 110 & 2400 \\
\hline 1D & AJT Class J & 100 & 2400 \\
\hline 1E & Non Time Delay & 450 & 240 \\
\hline 2A & AJT Class J & 30 & 2400 \\
\hline 2B & Non Time Delay & 110 & 2400 \\
\hline 2C & Non Time Delay & 110 & 2400 \\
\hline 2D & AJT Class J & 100 & 2400 \\
\hline 2E & Non Time Delay & 450 & 240 \\
\hline 3A & AJT Class J & 100 & 2400 \\
\hline 3B & Non Time Delay & 110 & 2400 \\
\hline 3C & Non Time Delay & 110 & 2400 \\
\hline 3D & AJT Class J & 100 & 2400 \\
\hline 3E & Non Time Delay & 450 & 240 \\
\hline 3F & Non Time Delay & 200 & 2400 \\
\hline 4A & AJT Class J & 30 & 2400 \\
\hline 4B & Non Time Delay & 110 & 2400 \\
\hline 4C & Non Time Delay & 110 & 2400 \\
\hline 4D & AJT Class J & 100 & 2400 \\
\hline 4E & Non Time Delay & 450 & 240 \\
\hline 5A & AJT Class J & 60 & 2400 \\
\hline 5B & Non Time Delay & 110 & 2400 \\
\hline 5C & Non Time Delay & 110 & 2400 \\
\hline 5D & AJT Class J & 100 & 2400 \\
\hline 5E & Non Time Delay & 450 & \\
\hline & & & 240 \\
\hline
\end{tabular}

Made electrode: The National Electric Code also specifies the size and form of the grounding electrode. Section 250.52(A)(5) requires a pipe electrode or conduit no smaller than $3 / 4$ inch and at least 8 feet in length. In addition, a rod has to be at least $5 / 8$ inch in diameter and $8 \mathrm{ft}$. in length. The outer surface of any pipe or electrode must be galvanized or coated to prevent corrosion. The rod has to be copper-clad steel ground rod. In accordance with Section 250.53(G) the rod and pipe must be driven vertically to a depth of 8 feet. The rod may also be buried 
horizontally in a trench at least 30 inches below ground level. In all cases the electrode must be in direct contact with the earth for a length of at least 8 feet. The code requires that the electrode to earth resistance must not be more than $25 \mathrm{ohms}$.

Use of Relays in the System: A careful study of the size of the system suggests that the minigrid is small in size relative to the commonly found regional grids. Any form of relay protection is therefore uncalled for. The ring feeder design provides sufficient reliability of supply. Another aspect is the cost of relay protection. In general, relay protection system requires greater capital outlay and increased maintenance cost. These can be avoided if the fuse protection system is selected as was done in this case.

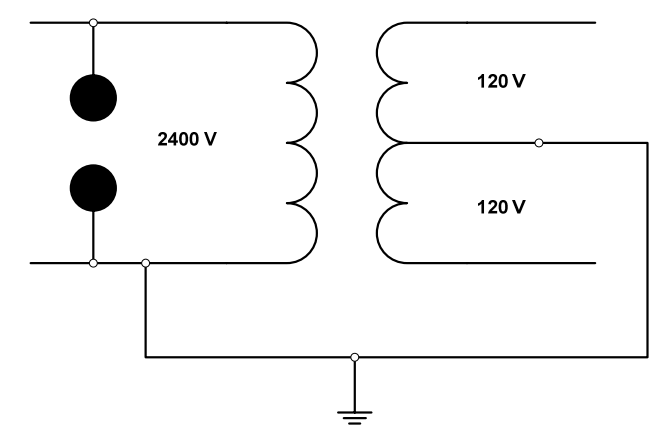

Fig. 1.1.9 Transformer grounding

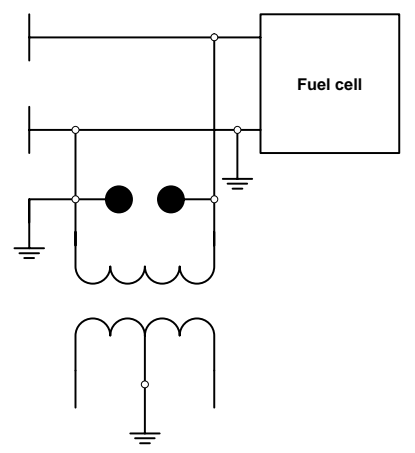

Fig. 1.1.10 Fuel cell grounding

\subsection{Representative Residential Load Data Collection}

Eight domestic dwellings have been identified. At each house two days of data has been collected. The data includes the active and reactive power, voltage and current for each phase. A sampling time of one minute is used. The collected data is used to simulate the actual load of the five neighborhoods.

\subsection{Unmanaged Short-Term Scheduling of FCPPs}

Due to high efficiency and low emission and noise, fuel cell is among the most promising sources of electrical and thermal energy for distributed generation. Due to low working temperature (80$100^{\circ} \mathrm{C}$ ), fast start up, extremely low emission, and very low noise among different type of fuel cells, PEM fuel cell power plants (FCPP) are the best candidates for residential and isolated load applications. With cost effective operational strategies, the use of FCPPs is expected to become widespread in the near future, in spite of their current high capital cost.

In distributed generation system fuel cells and many different types of generators, such as microturbines, solar cells, and wind energy can be connected in parallel to share the same load. This research focuses on solving the short term scheduling problem of multiple FCPPs connected in parallel to supply electric and thermal energy to a microgrid community. Short-term scheduling of FCPPs problem is a hard combinatorial mixed integer optimization problem to 
determine the optimum schedule of generating units and the output electrical and thermal power from each unit while satisfying a set of system and unit constraints. Finding the optimal short term scheduling of FCPPs is very important, since it could mean significant annual financial savings in electric and thermal power generating costs.

Several solution techniques have been applied to solve the short term scheduling problem for conventional generators. These include deterministic, meta-heuristic, and hybrid approaches. Deterministic approaches include the priority list method [4], dynamic programming [5], Lagrangian Relaxation (LR) [6], integer/mixed-integer programming [7], [8], and the branch-andbound methods [9]. Due to the mixed binary and continuous variable nature, of the short term scheduling problem traditional optimization techniques may miss the optimal solution. In addition, dimensionality of the problem limits the application of traditional optimization techniques to small size system. Recently, meta-heuristic approaches became popular in the effort to overcome shortcomings of traditional optimization techniques. Techniques such as genetic algorithms [10], [11], seeded memetic algorithms [12], evolutionary programming [13], simulated annealing [14], and tabu search [15] have been widely investigated to solve the short term scheduling problem. These methods can accommodate more complicated constraints and are claimed to produce solutions of improved quality. In this research a hybrid technique based on the evolutionary programming (EP) and hill climbing $(\mathrm{HC})$ technique is used. During the solution process of the short term scheduling problem of the FCPPs, the EP is used to search for the optimal solution, while the $\mathrm{HC}$ technique is used to watch for the solution feasibility.

\subsubsection{Problem Formulation}

The objective of the FCPPs short term scheduling problem is to determine the output level of units in each time stage that yield the minimum total cost while satisfying the problem constraints. Since the microgrid system is connected in parallel with the local grid, power trade between microgrid and the local grid is permitted. In this case, the power balance constraint is not applicable. The FCPPs short term scheduling problem is described as follows.

The objective function: is the sum of the cost of producing/buying electrical and thermal energy to satisfy the system electrical/thermal load, maintenance, operation and startup cost.

$$
\begin{aligned}
\operatorname{Min} & C_{n 1} T \sum_{j} \sum_{i}\left(\frac{P_{i j}+P_{a i}}{\eta_{i j}}\right) v_{i j}+C_{e l, p} T \sum_{j} \max \left(L_{e l, j}-\right. \\
& \left.\sum_{i} P_{i j} V_{i j}, 0\right)-C_{e l, s} T \sum_{j} \max \left(\sum_{i} P_{i j} v_{i j}-L_{e l, j}, 0\right)+ \\
& \left.\sum_{j}\left(S C_{i j}+O M_{i j}\right)\right]+C_{n 2} T \sum_{j} \max \left(L_{t h, j}-\sum_{i} P_{t h, j}, 0\right)
\end{aligned}
$$

Subject to:

(a) Real power operating limits of FCPP

$$
v_{i, j} P_{i}^{\min } \leq P_{i, j} \leq v_{i, j} P_{i}^{\max }, \quad j \in T H ; i \in N
$$

(b) Minimum uptime and downtime of the unit

$$
\left(T_{i(j-1)}^{o n}-M U T_{i}\right)\left(v_{i(j-1)}-v_{i j}\right) \geq 0.0, \quad j \in T H ; i \in N
$$




$$
\left(T_{i(j-1)}^{\text {off }}-M D T_{i}\right)\left(U_{i j}-U_{i(j-1)}\right) \geq 0.0, \quad j \in T H ; i \in N
$$

(c) Unit ramp constraints

$$
\begin{gathered}
P_{i j}-P_{i(j-1)} \leq \Delta P_{u_{i}}, \quad j \in T H ; i \in N \\
P_{i(j-1)}-P_{i j} \leq \Delta P_{D_{i}}, \quad j \in T H ; i \in N
\end{gathered}
$$

where,

$N \quad$ number of generating units,

$\mathrm{TH}$ the total time horizon (h),

$P_{i, j} \quad$ real power output of unit $i$ at interval $j(\mathrm{~kW})$,

$v_{i, j} \quad$ control variable, with

$v_{i, j}=\left\{\begin{array}{ll}0 & \text { if unit } i \text { is off at stage } j \\ 1 & \text { if unit } i \text { is on at stage } j\end{array}\right.$,

$S C_{i, j}$ the startup costs incurred during the transition of unit $i$ from "off" to "on" during stage $j$,

$\mathrm{SC}_{\mathrm{i}, \mathrm{j}}=\alpha_{i}+\beta_{i}\left(1-e^{-\frac{t_{\mathrm{i} e d}}{\tau_{i}}}\right)$,

$\alpha_{i}, \beta$ : hot and cold start up cost of ith FCPP respectively

$t_{i \text { off }} \quad$ the time the ith FCPP has been off (h),

$\tau_{i} \quad$ cooling time constant of the ith FCPP (h)

$T \quad$ length of time interval (h),

$P_{a i} \quad$ power for auxiliary devices of unit $i(\mathrm{~kW})$,

$\eta_{i j} \quad$ fuel cell efficiency of unit $i$ at interval $j$,

$C_{e l, p} \quad$ tariff for purchasing electricity $(\$ / \mathrm{kWh})$,

$C_{e l, s} \quad$ tariff for selling electricity $(\$ / \mathrm{kWh})$,

$L_{e l, j} \quad$ electrical load demand at interval $j(\mathrm{~kW})$,

$C_{n 2}$ fuel price for residential loads $(\$ / \mathrm{kWh})$,

$L_{t h, j} \quad$ thermal load demand at interval $j(\mathrm{~kW})$,

$P_{\text {thi,j }} \quad$ thermal load produced from unit $i$ at interval $j(\mathrm{~kW})$,

$P_{i}^{\min } \quad$ minimum power limit of unit $i(\mathrm{~kW})$,

$P_{i}^{\max } \quad$ maximum power limit of unit $i(\mathrm{~kW})$,

$\Delta P_{u i} \quad$ upper limit of the ramp rate of unit $i$,

$\triangle P_{D i} \quad$ lower limit of the ramp rate of unit $i$,

$T^{\text {on }} \quad$ FCPP on-time (number of intervals),

$T^{\text {off }} \quad$ FCPP off-time (number of intervals),

$M U T_{i}$ minimum up-time of unit $i$ (number of intervals),

$M D T_{i}$ minimum down-time of unit $i$ (number of intervals),

$O M_{i} \quad$ operation and maintenance cost of unit $i$,

The first term of the objective function (1.3.1) is the daily overall fuel cost for the FCPPs (\$). The second term is the daily cost of electrical energy purchased if the demand exceeds the electrical energy produced from the FCPPs $(\$)$. The third term is the daily income from the electrical energy sold if the electrical energy produced from the FCPPs exceeds the demand (\$). The fifth term is the start up and maintenance costs of the FCPPs (\$).The last term is the daily cost of purchased gas for residential thermal loads if the thermal energy produced is not enough to meet the thermal energy demand (\$). 
In PEM FCPPs thermal energy is recovered mainly from the reformer. The recovery from the stack is neglected due to the lower operating temperature $\left(70-80^{\circ} \mathrm{C}\right)$. This research considers thermal load (space heating and hot water) as part of the loading of the PEM FCPP along with electric loads. The thermal load is satisfied by utilizing the recovered thermal energy from the FCPPs, and if necessary through the direct use of natural gas. At full load conditions, the FCPPs produce thermal energy approximately equal to the electrical energy [16]. In [16], experimentally determined efficiency and thermal to electrical energy ratio curves have been developed. The efficiency and the thermal to electrical energy ratio are functions of the part load ratio, PLR (PLR $=$ electrical generated power/maximum power). Mathematical expressions to approximate the curves have been developed in [16]. Due to the lack of information of efficiency and electrical to thermal energy ratio curves of different FCPPs, different curves similar to those presented in [16] have been extrapolated. Those curves are used to calculate the recovered thermal power and the efficiency of each FCPP at each interval. The efficiency and thermal to electrical ratio as functions in the PLR can be written as:

$$
\begin{aligned}
\eta_{i j}= & K_{5} P L R_{i, j}^{5}+K_{4} P L R_{i, j}^{4}+K_{3} P L R_{i, j}^{3}+ \\
& K_{2} P L R_{i, j}^{2}+K_{1} P L R_{t, j}+K_{o} \\
r_{T E i, j}= & R_{4} P L R_{i, j}^{4}++R_{3} P L R_{i, j}^{3}+R_{2} P L R_{i, j}^{2}+ \\
& R_{i} P L R_{i, j}+R_{o}
\end{aligned}
$$

where, $\eta_{i, j}$ is the efficiency of FCPP $i$ at time interval $j, P L R_{i, j}$ the part load ratio of unit $i$ at time interval $j, r_{T E i, j}$ the thermal energy to electrical energy ratio of unit $i$ at time interval $j$. The thermal power recovered from the fuel cell $i$ at interval $j$ according to electric power outputs $P_{i, j}$ and auxiliary power $P_{a i}$ can be calculated as follows:

$$
P_{t h(i, j)}=r_{T E i, j}\left(P_{i, j}+P_{a i}\right)
$$

\subsubsection{Evolutionary Programming (Ep)-Based Solution Methodology}

Evolutionary programming (EP) can be traced back to early 1950's when Turing discovered a relationship between machine learning and evolution. During the 1980's, advances of computer technology permitted the use of evolutionary programming to solve difficult real-world optimization problems [17]-[19]. The general scheme for solving optimization problems using evolutionary programming can be summarized as follows:

Initialization: An initial population ( $m$ individual) of uniform randomly distributed solution is selected. In this step random values are assigned to the schedule of the FCPPs and the power output from each unit. The random schedule and the output power from each unit must satisfy the problem constraints.

Mutation: A Gaussian random variable is added to all the current generation individuals using the following equation with uniform probability.

$$
S_{i+m, j}=S_{i, j}+N\left(0, \beta_{i} v\left(S_{i}\right)+z_{j}\right) \quad j=1, \ldots, k
$$


where $m$ is the number of individuals in the current generation, $v\left(S_{i}\right)$ is the fitness score, $S_{i}$ is the $j$ th element of the ith individual, $N\left(\mu, \sigma^{2}\right)$ is the Gaussian random variable with mean $\mu$ and variance $\sigma^{2}, \beta_{i}$ is a constant of probability to scale $v\left(S_{i}\right), z_{j}$ is an offset to guarantee a minimum amount of variance, $i$ is individual number, and $k$ is number of variables in each individual. During this step new $m$ individuals are produced from the previous $m$ individuals.

Competition: A probabilistic selection scheme is used to assign a weight to each offspring individual according to a comparison between current individual and a randomly chosen one. The weights are calculated as follows:

$$
W_{i}=\sum_{j=1}^{N} W_{i, j}
$$

where $N$ is the competition number generated randomly, and $W_{i, j}$ is either 0 or 1 depending on the competition of the individual with another individual selected randomly from the population. The value of $W_{i, j}$ can be calculated as follows:

$$
W_{i, j}=\left\{\begin{array}{rr}
1 & \text { if } v\left(S_{i}\right) \leq v\left(S_{p}\right) \\
0 & \text { otherwise }
\end{array}\right.
$$

where $p=\left[2 m u_{1}+1\right], p \neq i, u_{1} \sim U(0,1)$

During the competition step, $m$ individuals with the highest value of weight are selected to move to the next generation, where the $m$ individuals are used as initial individuals for the next generation. The process is terminated when there is more improvement in the objective function, or when the number of generation reaches a predetermined value.

The above mentioned EP procedure is used to search for the optimal schedule and electrical power output from each FCPP. During the solution process, the new individuals generated from the mutation step may not satisfy the system constraints. In this situation, instead of rejecting the infeasible solution, the $\mathrm{HC}$ technique [20] is used to test the neighborhood of the available infeasible solution. If one feasible solution is obtained during the $\mathrm{HC}$ technique search, the infeasible solution is moved to the feasible one. Using the $\mathrm{HC}$ technique to watch for the infeasibility of the new solutions, reduces the time needed to find the optimal solution. In addition, it reduces the probability of trapping at a local optimum.

\subsubsection{Tests and Results}

A PC with $3.6 \mathrm{GHz}$ Intel Pentium 4 processor with 3GBytes RAM was used to solve the short term scheduling problem of a five FCPP system. The FCPPs capacities are given in Table 1.3.1, where $x_{0}$ is the initial status of the FCPPs (negative means down and positive means up). The FCPPs efficiency and thermal to electrical energy ratio coefficients are given in Tables 1.3.2, and 1.3.3. The IEEE-RTS load profile with a peak of $250 \mathrm{~kW}$ [21] is used to simulate the hourly electrical load profile of the system. In this test system, the weekly, daily and hourly peak load values are given in percent of annual, weekly and daily peak loads, respectively. The winter hot water usage and space heating load for Atlanta, Georgia [16] is used to estimate the thermal load profile. The thermal load is used along with the electrical load profile to simulate total hourly operation of the FCPPs. Other system cost and parameters are given in Table 1.3.4. 
TABLE 1.3.1 FCPPS DATA

\begin{tabular}{ccccccccccc}
\hline \hline Unit & $P^{\max }$ & $P^{\min }$ & $t_{\text {up }}$ & $t_{\text {down }}$ & $x_{0}$ & $\alpha$ & $\beta$ & $\tau$ & $\Delta P_{u i}$ & $\Delta P_{D i}$ \\
\hline 1 & 100 & 25 & 6 & 4 & -2 & 0.02 & 20 & 6 & 50 & 50 \\
2 & 75 & 15 & 3 & 3 & 5 & 0.01 & 15 & 4 & 40 & 40 \\
3 & 75 & 15 & 5 & 2 & 2 & 0.01 & 15 & 4 & 40 & 40 \\
4 & 25 & 7 & 4 & 3 & -4 & 0.01 & 10 & 3 & 15 & 15 \\
5 & 25 & 7 & 6 & 5 & -2 & 0.01 & 10 & 3 & 15 & 15 \\
\hline
\end{tabular}

TABLE 1.3.2 FCPPS EFFICIENCY COEFFICIENTS

\begin{tabular}{ccccccc}
\hline Unit & $K_{5}$ & $K_{4}$ & $K_{3}$ & $K_{2}$ & $K_{1}$ & $K_{o}$ \\
\hline 1 & 0.9333 & -2.9996 & 3.6513 & -2.0704 & 0.4723 & 0.3947 \\
2 & 0.9033 & -2.9996 & 3.6503 & -2.0704 & 0.4623 & 0.3747 \\
3 & 0.9033 & -2.9996 & 3.6503 & -2.0704 & 0.4623 & 0.3747 \\
4 & 0.9443 & -2.9996 & 3.6503 & -2.1704 & 0.4723 & 0.3847 \\
5 & 0.9443 & -2.9996 & 3.6503 & -2.1704 & 0.4723 & 0.3847 \\
\hline \hline
\end{tabular}

TABLE 1.3.3 FCPPS THERMAL TO ELECTRICAL RATIO COEFFICIENTS

\begin{tabular}{cccccc}
\hline \hline Unit & $R_{4}$ & $R_{3}$ & $R_{2}$ & $R_{1}$ & $R_{0}$ \\
\hline 1 & 1.1785 & -1.9949 & 1.5005 & -0.2917 & 0.6838 \\
2 & 1.0585 & -1.9739 & 1.5005 & -0.2817 & 0.6838 \\
3 & 1.0585 & -1.9739 & 1.5005 & -0.2817 & 0.6838 \\
4 & 1.0585 & -1.9739 & 1.5005 & -0.3817 & 0.6838 \\
5 & 1.0585 & -1.9739 & 1.5005 & -0.3817 & 0.6838 \\
\hline \hline
\end{tabular}

TABle 1.3.4 Cost And Evolutionary Programming Parameters

\begin{tabular}{lc}
\hline Length of time interval, $T(\mathrm{~h})$ & 0.25 \\
Price of natural gas for FCPP, $c_{n 1}(\$ / \mathrm{kWh})$ & 0.04 \\
Tariff for purchasing electricity, $c_{e l, p}(\$ / \mathrm{kWh})$ & 0.13 \\
Tariff for selling electricity, $c_{e l, s}(\$ / \mathrm{kWh})$ & 0.08 \\
Fuel price for residential loads, $c_{n 2}(\$ / \mathrm{kWh})$ & 0.06 \\
Maximum number of evolutionary generation & 20000 \\
Number of individuals & 150 \\
\hline \hline
\end{tabular}

Using the given thermal and electrical load, the short term scheduling problem for a system of five FCPPs connected in parallel to feed the thermal and electrical load requirement of a five neighborhoods is solved. The thermal energy retrieved from the FCPPs is used to partially/fully satisfy the thermal load. During the interval where the produced thermal power from the FCPPs is less than the load, the system uses natural gas to satisfy the mismatch in the thermal load. In addition, the system can sell or buy electric energy from the local utility grid.

The FCPPs unit schedule over a 24 hours time horizon is shown in Table 1.3.5. The schedule shows the on/off periods for each FCPP, where each period represents 15 minutes. 
TABLE 1.3.5 FCPP 24 HOURS SCHEDULE

\begin{tabular}{|c|c|c|c|c|c|c|c|c|c|c|c|c|c|c|c|c|}
\hline FCPP & Off & On & $\begin{array}{c}\text { Off } \\
3-16\end{array}$ & $\begin{array}{c}\text { On } \\
17-24\end{array}$ & $\begin{array}{c}\text { Off } \\
25-29\end{array}$ & $\begin{array}{c}\text { On } \\
\text { - } 37-37\end{array}$ & $\begin{array}{c}\text { Off } \\
38-42\end{array}$ & $\begin{array}{c}\text { On } \\
43-50\end{array}$ & $\begin{array}{c}\text { Off } \\
51-55\end{array}$ & $\begin{array}{c}\text { On } \\
56-68\end{array}$ & $\begin{array}{c}\text { Off } \\
69-72\end{array}$ & $\begin{array}{c}\text { On } \\
73-89\end{array}$ & $\begin{array}{c}\text { Off } \\
90-93\end{array}$ & $\begin{array}{c}\text { On } \\
94-96\end{array}$ & Off & On \\
\hline 1 & & $\begin{array}{c}3-12 \\
1-3\end{array}$ & $\begin{array}{c}13-16 \\
4-7\end{array}$ & $\begin{array}{c}17-24 \\
9-10\end{array}$ & $\begin{array}{l}25-29 \\
11-13\end{array}$ & $\begin{array}{l}30-37 \\
14-16\end{array}$ & $\begin{array}{l}38-42 \\
17-20\end{array}$ & $\begin{array}{r}43-50 \\
21-24\end{array}$ & $\begin{array}{r}51-55 \\
25-28\end{array}$ & $\begin{array}{l}56-68 \\
29-31\end{array}$ & $\begin{array}{r}69-72 \\
32-34\end{array}$ & $\begin{array}{l}73-89 \\
35-37\end{array}$ & $\begin{array}{l}90-93 \\
38-40\end{array}$ & $\begin{array}{l}94-96 \\
41-43\end{array}$ & & \\
\hline 2 & & $\begin{array}{l}1-3 \\
1-3\end{array}$ & $\begin{array}{l}4-7 \\
4-6\end{array}$ & $9-10$ & $11-13$ & 14-16 & $17-20$ & $21-24$ & 25-28 & 29-31 & $\begin{array}{l}32-34 \\
38-40\end{array}$ & $35-37$ & $38-40$ & 41-43 & 44-46 & $\begin{array}{l}47-56 \\
55-61\end{array}$ \\
\hline 3 & & $1-3$ & $4-6$ & $7-12$ & 13-14 & $15-20$ & $21-22$ & $23-28$ & 29-31 & $32-37$ & $38-40$ & $41-45$ & $46-47$ & 48-52 & 53-54 & $55-61$ \\
\hline 4 & & $1-6$ & $7-13$ & 14-18 & $19-21$ & $22-25$ & $26-29$ & $30-34$ & $35-39$ & $40-44$ & $45-47$ & $48-52$ & 53-56 & $57-62$ & $63-66$ & $67-72$ \\
\hline 5 & $1-4$ & $5-11$ & $12-16$ & $17-24$ & $25-30$ & $31-36$ & $37-41$ & $42-47$ & $48-52$ & $53-60$ & $61-69$ & $70-76$ & $77-84$ & $85-90$ & $91-96$ & \\
\hline FCPP & Off & On & Off & On & Off & On & Off & On & Off & On & Off & On & Off & On & Off & On \\
\hline 1 & & & & & & & & & & & & & & & & \\
\hline 2 & $57-60$ & $61-65$ & $66-68$ & $69-76$ & $77-79$ & $80-85$ & $86-88$ & $89-92$ & 93-96 & & & & & & & \\
\hline 3 & $62-66$ & $67-72$ & 73-74 & $75-80$ & $81-82$ & $83-87$ & $88-89$ & $90-96$ & & & & & & & & \\
\hline 4 & 73-75 & 76-81 & $82-84$ & $85-88$ & $89-91$ & $92-95$ & 96 & & & & & & & & & \\
\hline 5 & & & & & & & & & & & & & & & & \\
\hline
\end{tabular}

Table 1.3.6 shows the system daily cost based on the gas and the energy prices given in Table 1.3.4. To satisfy the mismatch in thermal energy the system uses $1688 \mathrm{kWh}$ of natural gas. Comparing the purchased and the sold energy to the local utility, the net cost is $\$ 19.80$, which is equivalent to $152.31 \mathrm{kWh}$. The individual power output from FCPPs is shown in Fig. 1.3.1. The total electric generation/load is shown in Fig. 1.3.2. The total trade with the local utility grid is shown in Fig. 1.3.3. The total thermal generation/load is shown in Fig. 1.3.4.

TABLE 1.3.6 DAILY SyStem CosT

\begin{tabular}{ll}
\hline Fuel cost & $\$ 403.99$ \\
Purchased electricity cost & $\$ 69.10$ \\
Sold electricity income & $\$ 49.30$ \\
Residential natural gas cost & $\$ 101.28$ \\
O\&M cost & $\$ 18.08$ \\
Startup cost & $\$ 137.85$ \\
Total cost & $\$ 681.00$ \\
\hline
\end{tabular}

It is clear from Figs. 1.3.3 and 1.3.4 that the system was able to satisfy the electric load requirement. For the thermal load Fig. 1.3.4, the system produces thermal power less than the load in the high demand periods (0:00-7:45 and 17:45-23:45). During the low demand period (11:45-17:45) the system produces thermal power more than the load requirement. The excess thermal energy during this period is wasted.

\subsubsection{Conclusions}

This part of the research presents a mathematical formulation of the short term scheduling of multi FCPPs connected in parallel in a microgrid to supply electrical and thermal power load of multi-neighborhoods. The objective function of the short term scheduling problem includes the production cost, the cost of buying natural gas to satisfy the thermal load, the power trade with the local utility grid, and the startup and maintenance cost. A hybrid technique based on evolutionary programming and hill climbing technique is used to solve the short term scheduling problem of a multi FCPP system. Test results presented indicate the viability of the mathematical model of the FCCPs short term scheduling problem and the use of the evolutionary programming to obtain near global optimal solution for the problem. 

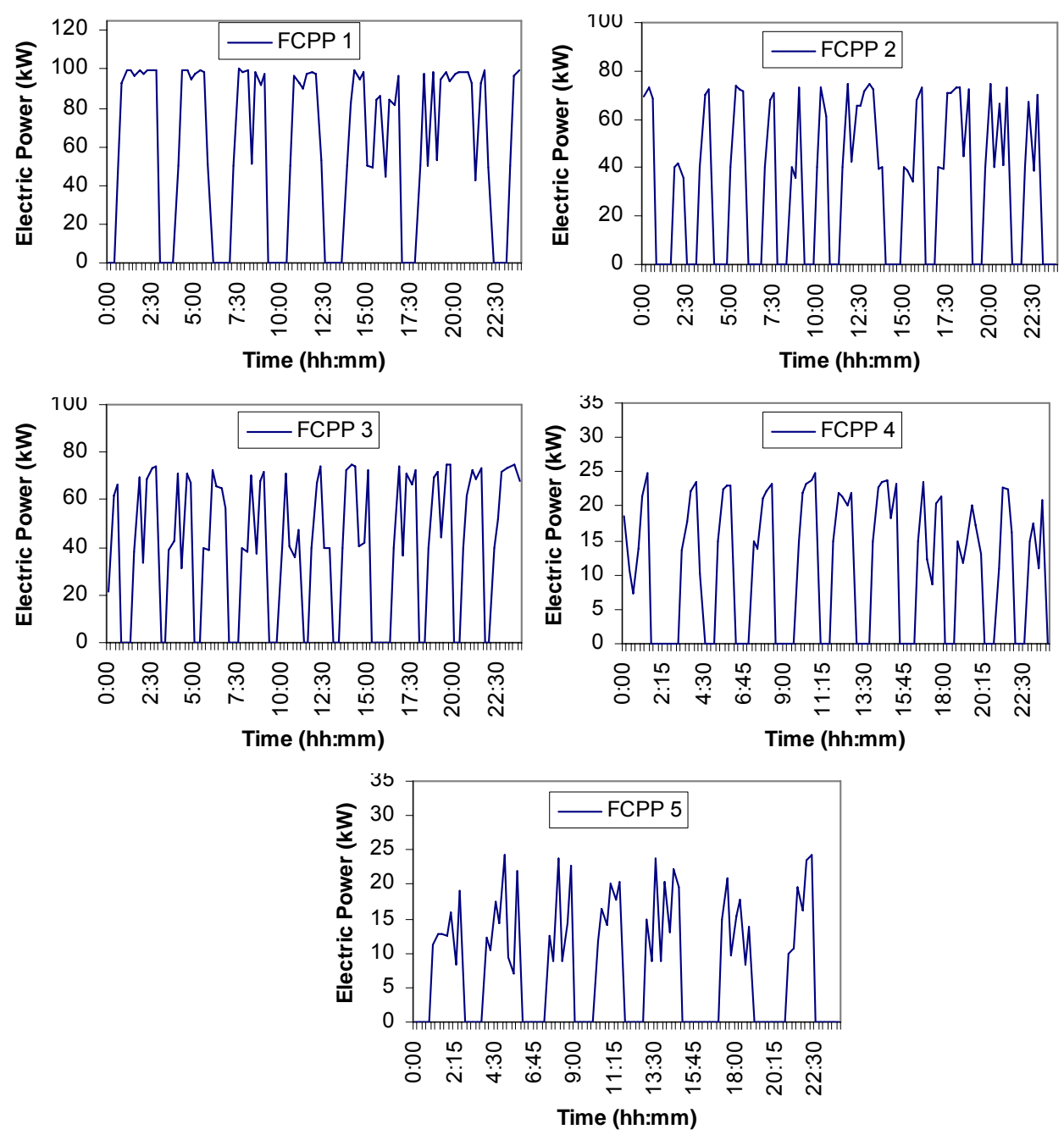

Fig. 1.3.1 Electric power output from each FCPP

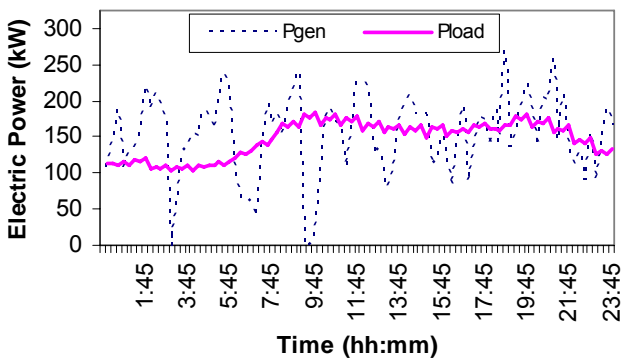

Fig. 1.3.2 Electric power generation/load 


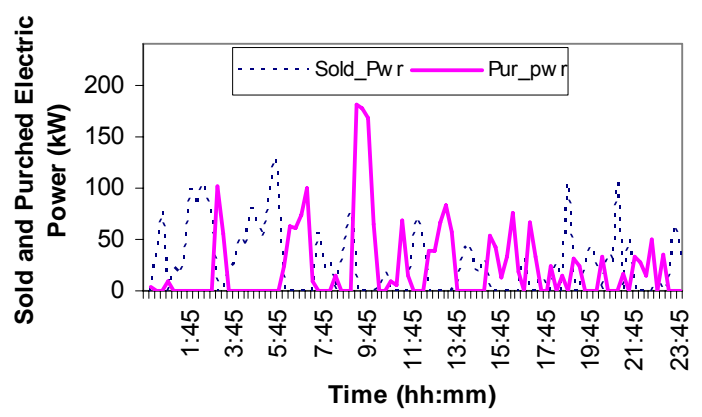

Fig. 1.3.3 Electric power trade with the local grid

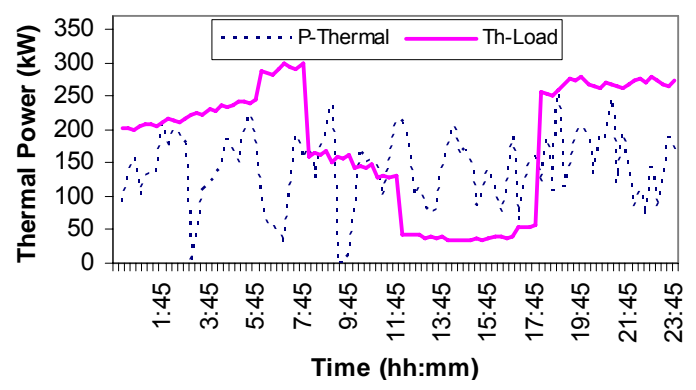

Fig. 1.3.4 Thermal power generation/load

\subsection{Thermal Energy Management Based Short Term Scheduling of FCPPs}

Two methane reformer systems will operate independently from the fuel cell systems. Each reformer is capable of operating the entire $300 \mathrm{~kW}$ electrical power and will deliver a constant amount of thermal energy to a thermal reclamation system. A proposed design for utilizing thermal energy from the reformers to reclaim hot water for domestic use has been developed. The hot water will be delivered to the homes at a temperature of approximately 65 to 70 degrees centigrade for use in space heating and domestic hot water. For hot water delivery, the minigrid system is divided into communities of 10 houses as shown in Fig. 1.4.1. Each community would receive hot water from the reformer heat exchangers.

Hot water from the reformer heat exchanger exit is directed into two storage tanks, each providing storage for five residences, as shown in Fig. 1.4.2. A pump capable of supplying the required flow rate and pressure is attached to each tank. The return line from each half of the grid enters a mixing valve where make-up water is added to replace the volume of water removed from the system by the residents. The water is then pumped through a radiator, which allows the water to be cooled, if necessary, to maintain the proper supply temperature at the inlet of the fuel cell heat exchanger. A connection from the central storage tank to the low-pressure line provides a closed loop system, allowing the system to be full at all times. A bypass line connecting the two 
systems is added for maintenance purposes. If the supply pump on one side of the system should need maintenance, the other pump can be routed to supply both sides with hot water.

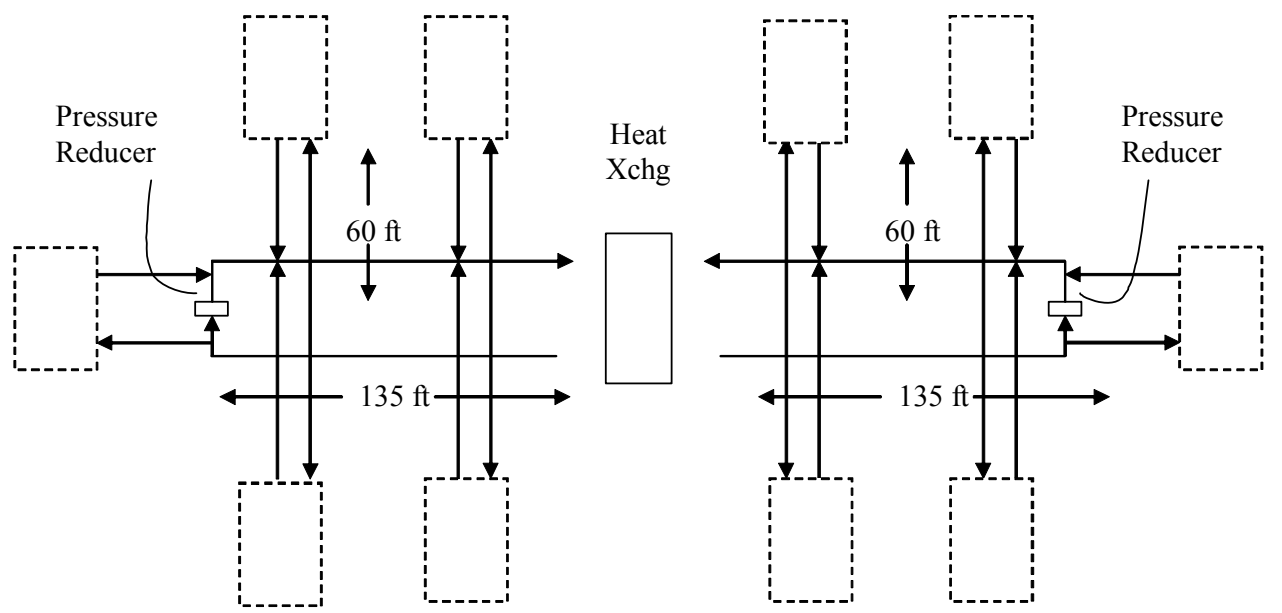

Fig. 1.4.1 Community hot water distribution.

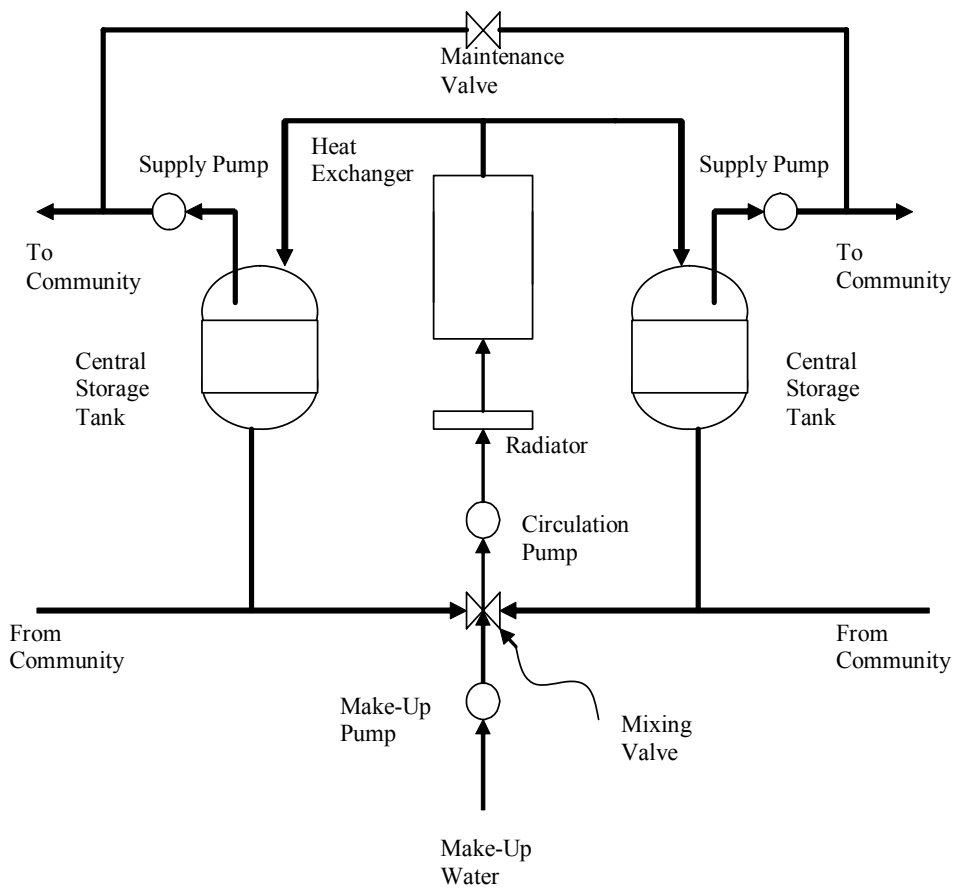

Fig. 1.4.2 Community hot water storage and flow management. 
Figure 1.4.3 shows a proposed residential delivery system. For each residence, there is a local circulation tank that is maintained at a water temperature of approximately $80^{\circ} \mathrm{C}$ by a local circulating pump. The circulation tank is used to supply hot water to the residence at approximately $60^{\circ} \mathrm{C}$. The water from the primary loop is mixed with cold water from the residence to reduce the temperature to that required for household use. If the circulation tank temperature cannot be maintained at the required delivery temperature, electrical heating elements are used for auxiliary heating.

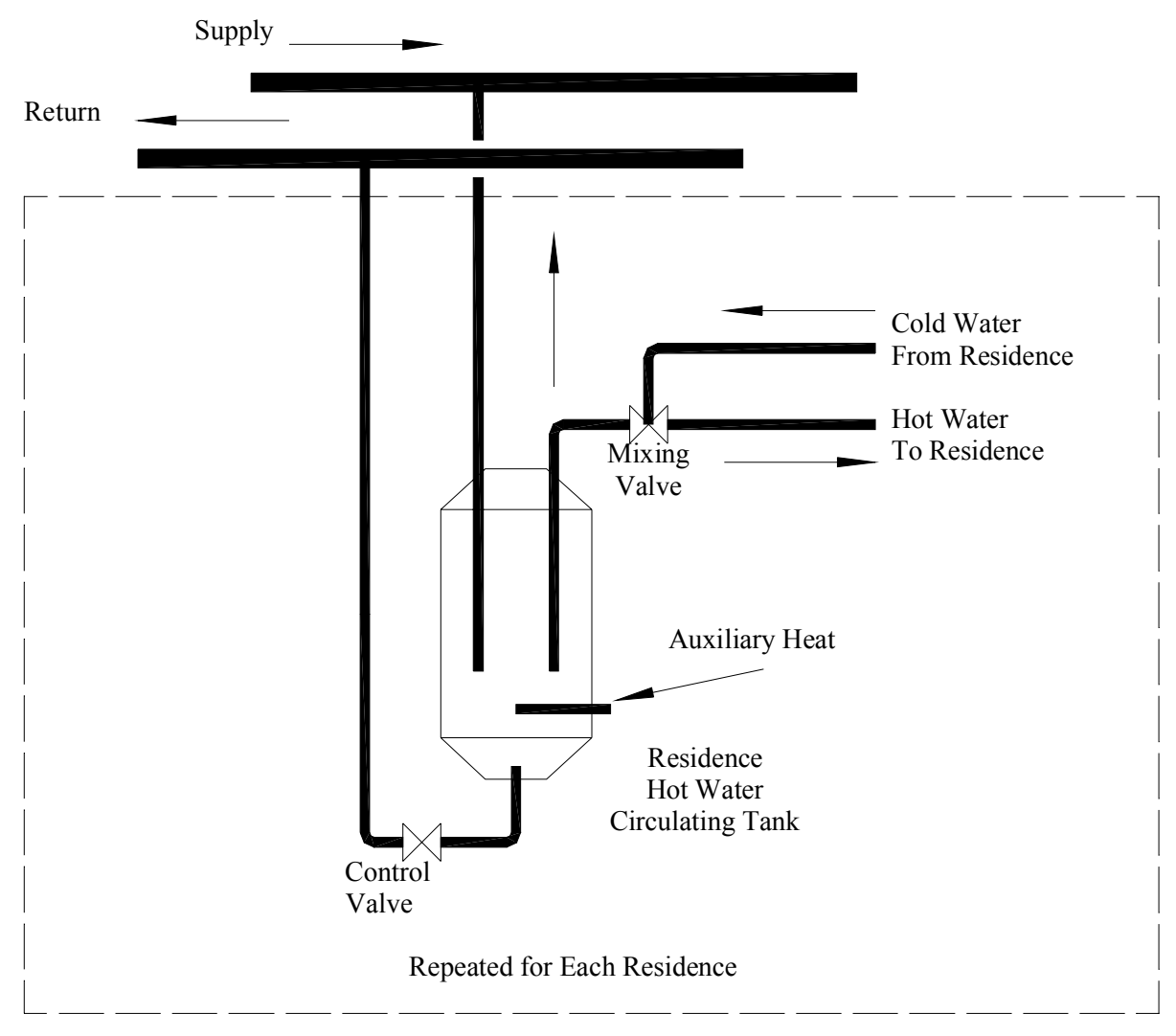

Fig. 1.4.3 Residential hot water delivery system.

Since the reformers operate at steady state and do not ramp up and down as electrical load changes, it is expected that the main problem in short term thermal management will be rejection of excess heat from the reformer systems when domestic thermal demand is low. A heat rejection system for the reformers must be sized to meet maximum load. This should not present an insurmountable problem, since there are many ways to perform the task, including liquid to liquid heat exchangers, radiators, and cooling towers. The particular solution chosen must take into account patterns of use and the climate in the minigrid location. 


\subsection{Hydrogen Management Based Short Term Scheduling of FCPPs}

In order to guarantee a continued supply of hydrogen to the five FCPPs making up the generation system of the mini-grid it is envisioned that two methane reformers will feed two tanks located strategically along the hydrogen feeder system. Feeder lines to the five FCPPs will be connected to the feeder system. Hydrogen poses unique problems for storage and distribution. Being a gas with the lowest molecular weight of any gas it is capable of leaking at a faster rate than all other gases. Hydrogen leaks at a rate 2.8 faster than methane and 3.3 times faster than air. Since hydrogen is highly volatile safety is paramount in the design of the hydrogen storage and distribution system. Also, there is the possibility of detonation when hydrogen is mixed with air. When ignited the flame produced is almost invisible. Hydrogen must not be allowed to concentrate in a confined space. Fortunately, when exposed to the atmosphere this gas disperses more rapidly than any other gas and in a practical storage and distribution system the concentration levels necessary for ignition or detonation are not likely to be reached.

It is advisable to use two methane reformers and two storage tanks to allow for the shutting down of one tank and one reformer for refilling and maintenance purposes. Of course, each system must then be capable of supplying the peak and sustained energy requirements of the mini-grid for the period of the shutdown. Hence, the detailed sizing of the tanks and feeder lines will be dependent, not only on the shut down period, but also on the nature and types of loads, the scheduling strategy adopted and the energy management algorithm employed.

In order to accurately determine the nature and type of loads encountered in a residential setting the following measurements were made, on each phase, for ten different households over a forty eight hour period at one minute intervals, namely, the current, the voltage the active power, the reactive power, the apparent power and the power factor. Fig. 1.5.1 shows a representative chart of the data, showing active power in one phase versus time over a 24 hour period.

This data can be used to generate a typical load profile for a neighborhood of ten homes. This will allow previously developed energy management algorithm to be tested and tuned. The data can be extrapolated from a neighborhood of ten homes to a community of fifty homes by a variety of schemes and when used, in conjunction with the scheduling optimizer, will permit a realistic determination of the optimal load scheduling, over a twenty four hour period, for each generator. This scheduling profile will translate directly into a scheduling profile for the hydrogen demand for each generator and hence the entire hydrogen demand for the entire microgrid system.

Total real power in Watts, for nine households, located in Mobile Alabama, were measured, using a sampling rate of one minute, during the summer of 2006. Three samples are shown in Figs. 1.5.2 - 1.5.4.

The data is recorded from midnight to midnight at one minute intervals. Little activity takes place during the night but there is about $6 \mathrm{~kW}$ of usage in the morning hours for about one hour. Usage increases during the afternoon to about $6 \mathrm{~kW}$, with a peak of $14 \mathrm{~kW}$ at about $6 \mathrm{PM}$. Usage then decreases until late evening. Figs. 1.5.3 and 1.5.4 show the power demands for the second and third households, respectively. From the data obtained a composite power demand, for the minigrid, over a twenty four hour period was derived. Figure 1.5.5 shows this curve. The average 
power demand over the 24 hour period is $121 \mathrm{~kW}$. If we assume that the amount of power purchased equals the amount of power sold then $121 \mathrm{~kW}$ must be supplied from the two hydrogen tanks over each 24 hour period. If we further assume that the tanks are refilled twice a year and that $1 \mathrm{~kW}$ of output power consumes $0.25 \mathrm{ft}^{3} / \mathrm{min}$ of hydrogen, then we will require a total capacity of $7,949,700 \mathrm{ft}^{3}(121 \mathrm{~kW} * 60 \mathrm{~min} /$ hour*24 hours/day*365/2 days/6months*0.25 $\mathrm{ft}^{3} / \mathrm{min} / \mathrm{kW}$ ). Hence, each tank would require a capacity of approximately 4 MCF. Each supply line must be capable of supplying approximately $300 \mathrm{~kW}$ of peak power corresponding to a flow rate of $75 \mathrm{ft}^{3} / \mathrm{min}$ of hydrogen. The actual tank and pipe sizing depends on the pressure and temperature specified for the system.

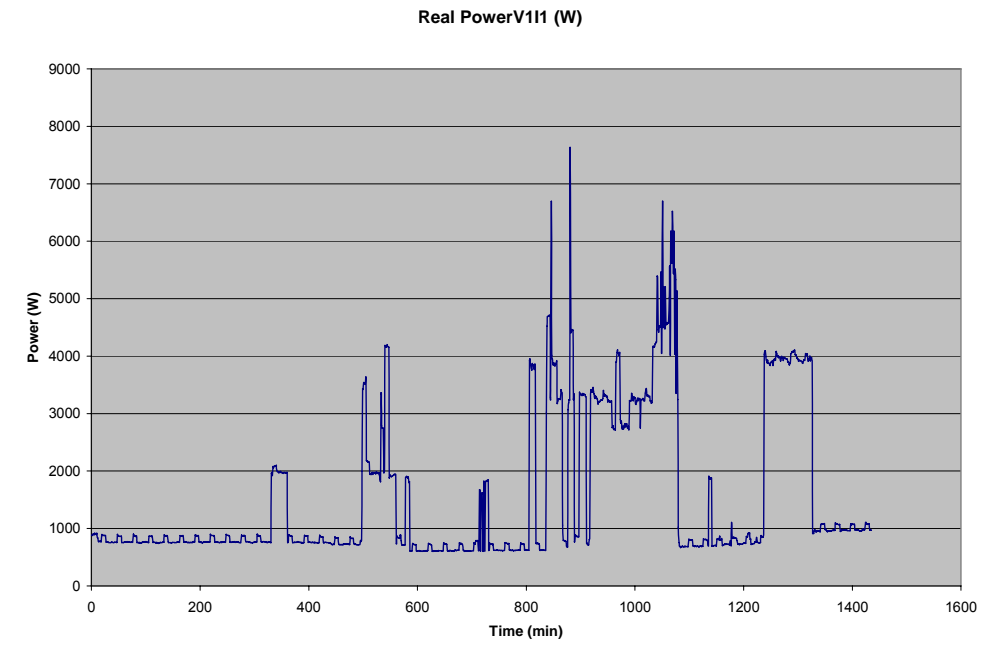

Fig. 1.5.1 Typical residential real power load profile over a 24 hour period at 1 min intervals.

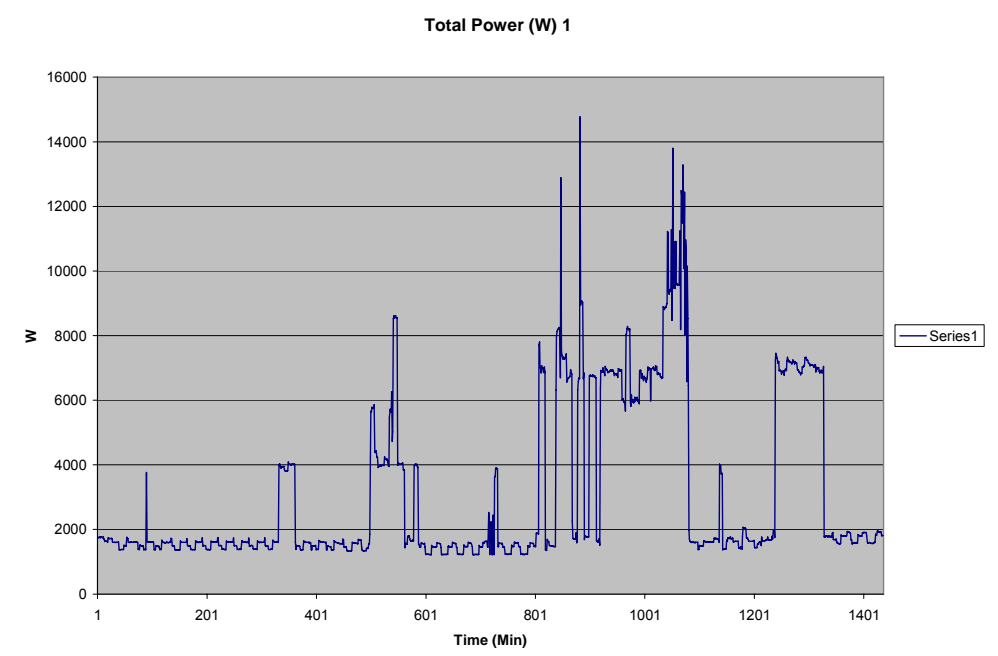

Fig. 1.5.2 Total power in Watts over a 24 hour period for home 1 
Figure 1.5.6 shows the same data as Fig. 1.5.5, except that the sampling interval has been increased from one minute to fifteen minutes. Figure 1.5.6 is considerably smoother than Fig. 1.5.5 and the peak value reached is considerably less, $250 \mathrm{~kW}$ versus over $300 \mathrm{~kW}$ for the one minute sampling. The average power for both figures is the same and hence the design, outlined above, remains valid.

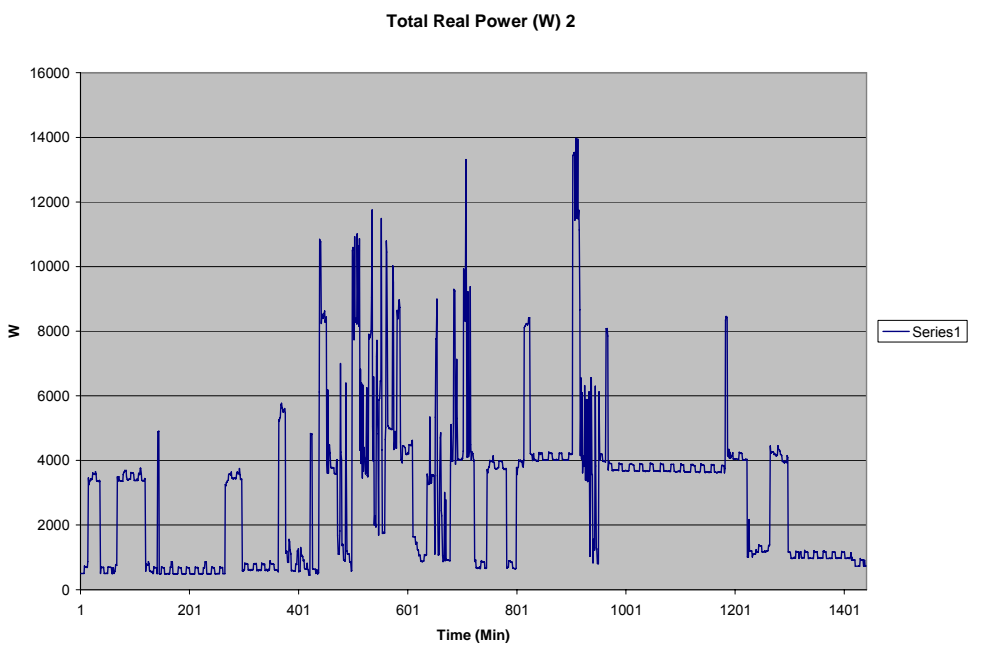

Fig. 1.5.3 Total power in Watts over a 24 hour period for home 2

Total Power (W) 6

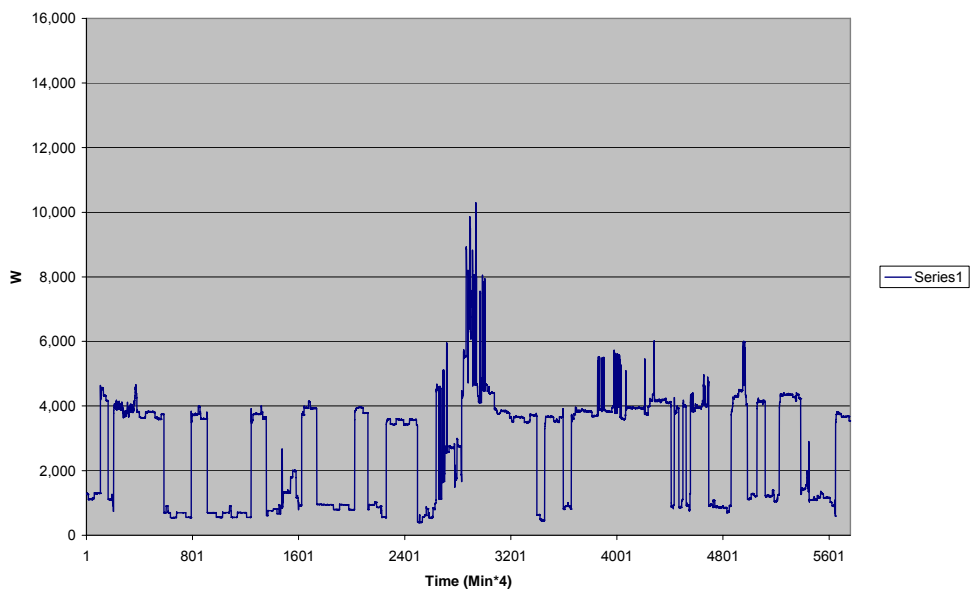

Fig. 1.5.4 Total power in Watts over a 24 hour period for home 3 


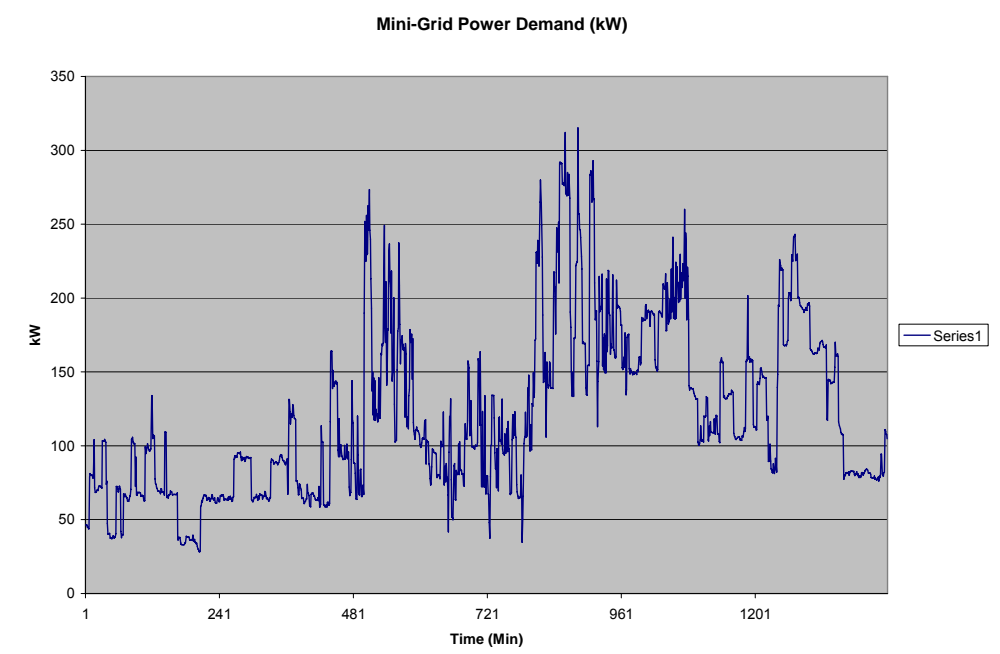

Fig. 1.5.5 Total power demand in Watts over a 24 hour period for a grid of 50 homes

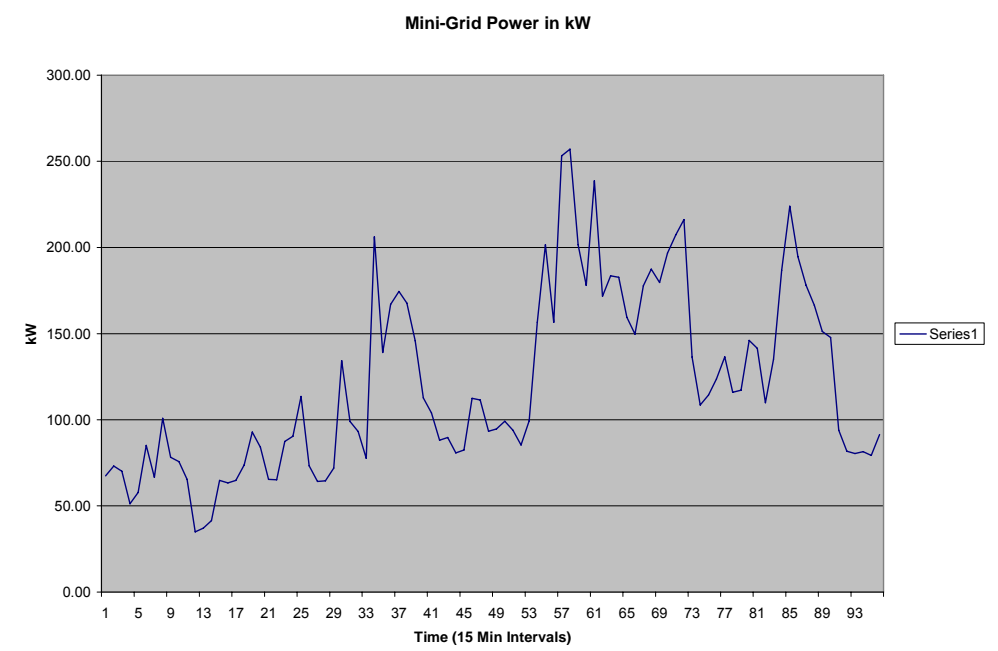

Fig. 1.5.6 Mini grid power demand in kW using 15 min interval sampling

\section{Production of Hydrogen Using Photoelectrochemical (PEC) Solar Cells}

One of the widely technique used to produce hydrogen is the photoelectrochemical (PEC) method. In PEC, hydrogen is produced using direct electrolysis of water using sunlight as an energy source. The input energy available from the Sunlight is fed into the electrolysis cell which, under certain conditions, can split the water and produce hydrogen. Several stringent criteria have to be fulfilled simultaneously for the direct electrolysis of water. The bandgap of the semiconductor material should be between $1.4 \mathrm{eV}$ and $1.8 \mathrm{eV}$; the band energetics of the semiconductor must overlap the water redox potentials; the charge transfer from the metal to the electrolyte should occur quickly; and the material should be stable in the aqueous electrolyte solution. Many materials may fulfill some of these criteria, though no single material fulfills all 
the criteria simultaneously. In this project, we investigated the electrochemical properties of an advanced material, InN, for its possible use in direct water splitting. The main goal of this work is to investigate novel materials suitable for PEC hydrogen production. The efficiency of photoelectrodes is a key factor in PEC hydrogen production; the higher the efficiency, the lower the cost of hydrogen production. Extensive work to increase the efficiency of already established materials has showed interesting results. In an alternative approach, novel promising materials are being investigated.

Recently, group III nitrides have received a great deal of attention in PEC hydrogen production. $\mathrm{GaN}$ and InGaN are promising materials for direct water splitting. Among these nitrides, another least studied material is InN, which is also an interesting material for direct water splitting. Different values of the bandgap of $\mathrm{InN}$ are reported by various authors. The band energetics of $\mathrm{InN}$ are also positioned in favor of direct water splitting. This motivated us to investigate the photoresponse of $\mathrm{InN}$ for photoelectrochemical hydrogen production. We used a Density Functional Theory code, Vienna Ab initio Simulation Package (VASP) to calculate the structural and electronic properties of InN. Total binding energy, lattice constants, density of states and the band-structure of $\mathrm{InN}$, the basic properties of a semiconductor material, are calculated.

Pulsed Laser Deposition is used to grow the InN thin films. So far, the photoelectrochemical investigation of $\mathrm{InN}$ grown by direct Pulsed Laser Deposition has not been reported. The knowledge of photocurrent onset potential and/or flat-band potential, and the photocurrent density is important in understanding the photoelectrochemical behavior of any material. We measured the current potential characteristics of $\mathrm{InN}$ in the dark and under illumination. Growth parameters will be varied and their effect on photo response will be studied with the intent of optimization. In addition, the effect of background gas and pressure is also investigated.

\subsection{Modeling and Simulation}

Theoretical simulation has been a popular approach in material science and engineering, where the precise control over the parameters at the atomic level is not possible in practical situations. A wide variety of methods are being used to predict the properties of atoms, molecules, and solids. $\mathrm{Ab}$ initio calculations are the first principles calculations which employ basic properties of materials. In this research, we report the ab initio calculations of the structural and electronic properties of InN.

The structural and electronic structure calculations in this research are performed using Vienna $A b$ initio Simulation Package (VASP) [22][23]. VASP is a complex simulation package for the atomic and electronic structure calculation of molecules and crystals. It contains a large set of pseudopotentials or PAW potentials for the density functional calculations of the properties of any material. So, the electron-ion interaction can be represented by either PAW or PP method. A large number of settings and parameters are available in VASP to tailor the calculation according to the needs. It allows the user to specify the type of exchange-correlation approximation among various methods in either generalized gradient algorithm or local density approximation.

We have used the ultrasoft pseudopotential (US-PP) approach for density functional theory within linear density approximation to calculate the structural properties of InN. For electronic structure calculations, US-PP and pseudopotentials with self interaction correction, as implemented in VASP, were used. The Perdew-Wang functional was used for the approximation 
of exchange-correlation energy. For correct structural predictions of InN, the indium $4 \mathrm{~d}$ electrons were considered as valence electrons. Monkhorst and Pack [24] grid were used to generate kpoints for the integration over the Brillouin zone.

\subsubsection{Structural Properties}

The bulk modulus, pressure derivative of bulk modulus, and lattice constant were calculated by fitting the energy vs. volume data to the Murnaghan equation of state [25]. The total energy vs volume for zincblende and wurtzite InN is shown in Fig. 2.1.1. The total energy of wurtzite was slightly greater than zincblende structure. The lattice constant, the bulk modulus, and its pressure derivative, determined from these energy-volume dependence graphs are summarized in Table 2.1.1.

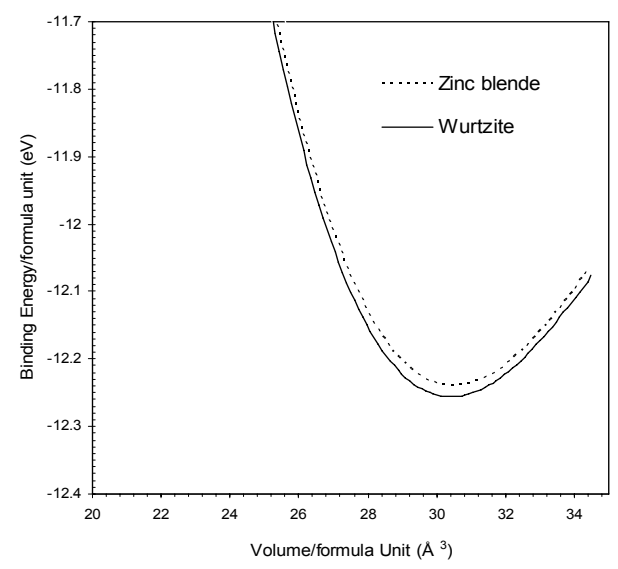

Fig. 2.1.1 Comparison of total energy vs. volume for zb- and w- InN.

The calculated lattice constants, 4.968 for the zincblende, and $\mathrm{a}=3.511, \mathrm{c} / \mathrm{a}=1.62$ for the wurtzite, were in good agreement with previous calculations [26]. The lattice constant of $\mathrm{zb}-\mathrm{InN}$ was within $0.4 \%$ from the experimental value of 4.986 .

The bulk modulus of zb-InN was found to be 138.57 and that of w-InN was 140.724. The measured value of bulk modulus is 138.87 for zb-InN and 140.72 for w-InN. Due to the difficulty in the growth of high quality InN, the measured values of bulk modulus from the experiments are somehow tentative. Moreover, it was shown that the bulk modulus may be reduced by the correction due to photon vibrational energy [27], which justifies the reliability of our calculations. Since these calculated structural properties of $\mathrm{InN}$ match with the other previous calculations, they can be used whenever the experimental data are not available.

Table 2.1.1 Structural properties of zinc blend and wurtzite InN.

\begin{tabular}{|l|l|l|l|l|l|}
\hline & Total Energy $(\mathrm{eV})$ & Volume $\left(\AA^{3}\right)$ & Bulk modulus & $\mathrm{B}^{1}$ & Lattice Constant \\
\hline Zinc Blende & -12.2435 & 30.5524 & 138.87 & 4.10 & 4.968 \\
\hline Wurtzite & -12.255 & 30.4966 & 140.7239 & 4.30 & $\mathrm{a}=3.511, \mathrm{c} / \mathrm{a}=1.62$ \\
\hline
\end{tabular}




\subsubsection{Electronic Properties}

Recently, there has been a controversy over the bandgap of $\mathrm{InN}$. A wide range of bandgap values are reported from the experimental measurements. Similarly, in theoretical calculation, depending on the methods employed in the calculations, different values of bandgap energies of $\mathrm{InN}$ are reported. Using full relativistic linear augmented plane wave method within LDA, Ramos et al. calculated the bandgap energy of InN to be $-0.48 \mathrm{eV}$ [28]. Using GGA, similar negative bandgap was reported [29]. A positive gap value of $+0.43 \mathrm{eV}$ was reported using LDA plus selfinteraction correction method [30]. Using quasi-particle correction, the obtained value of bandgap was $0.52 \mathrm{eV}$, and using both quasi-particle and self-interaction correction, it was reported to be $1.31 \mathrm{eV}[30]$. The bandstructure and density of states of zinc blende $\mathrm{InN}$ were calculated using DFT-LDA. The bandstructure calculated using LDA is shown in Fig. 2.1.2(a). The bandstructures were calculated within the theoretical lattice constant of LDA. The obtained bandgap was negative, due to the well known bandgap error of LDA. There was an overlap of the valence and conduction bands near the gamma point. This is because the self-interaction of the electrons leads to the severe underestimation of the bandgap energy of semiconductors. Only the methods that correct the exchange-correlation or the electron-ion interaction give rise to positive bandgap energy. To address this problem, self-interaction corrected pseudopotentials of the In- $4 \mathrm{~d}$ electrons are used. The resulting bandstructure is shown in Fig. 2.1.2(b). The bandgap was calculated to be $+0.45 \mathrm{eV}$.
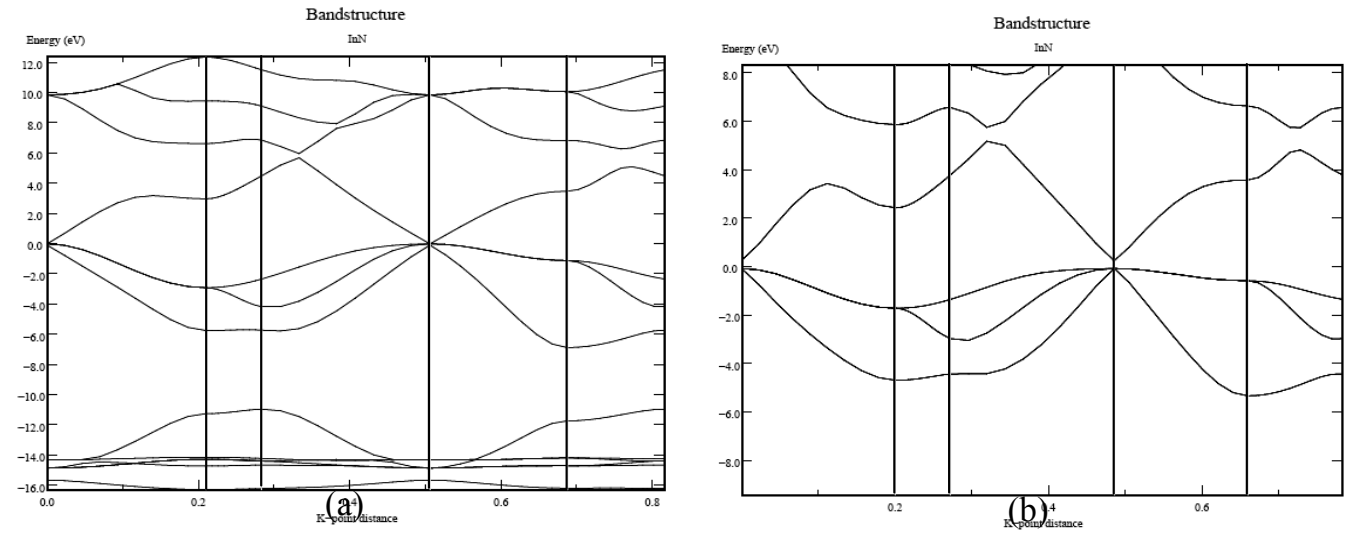

Fig. 2.1.2 Bandstructure of zb-InN calculated using (a) DFT-LDA and (b) SIC pseudopotential. The bandgap was widened with SIC pseudopotentials.

Density of states is another important electronic property of solids. It shows the conduction and valence band electron's energy distribution, which is essential to analyze the photoemission spectrum and dielectric function of materials. Fig. 2.1.3 shows the total density of states of $\mathrm{InN}$ calculated using DFT-LDA, with self-interaction corrected pseudopotentials. We have calculated the total density of states to verify the bandstructure calculations. The difference between the conduction and valence band energy, the bandgap of the material, is found consistent with the one from bandstructure calculation. It is clear from the figure that the total density of states for the unoccupied levels (conduction band) is gradually increased with small slope from the gamma point. This implies that the probability of electrons to occupy the energy states near the bottom of conduction band is very low, unlike the valence band maximum. 
Hence in simulation work, we have performed $a b$ initio calculations to predict structural and electronic properties of InN. It is realized that lack of sufficient experimental data preclude the in-depth analysis of the results. The correct values of lattice constant, bulk modulus, and pressure derivative of bulk modulus ensures the reliability of the method of calculation. The electronic properties were calculated on the calculated theoretical lattice constant. The bandgap value of $\mathrm{InN}$ is less than the recently predicted values using quasiparticle corrections. Due to the limitation of the software, we could not use this method in our calculations. However, SIC corrected bandgap is a reasonable prediction of bandgap of InN. It also provides a basis for further calculations to understand the effect of doping on the bandgap of InN. Moreover, the obtained value of the bandgap is able to absorb the major portion of the solar spectrum.

Density (states/eV)

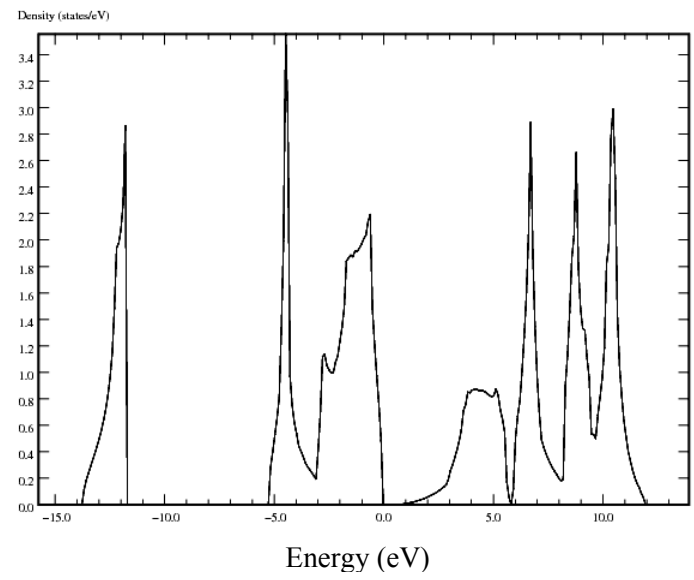

Fig. 2.1.3 Total density of states of zinc blende InN.

\subsection{Investigation of Nanostructured Films for Photooxidation of Water}

Pulsed Laser Deposition was used for the deposition of thin films. The InN films were deposited on sapphire and silicon substrates for structural characterization. For photoelectrochemical measurements, the films were deposited on conductive glass coated with fluorine doped $\mathrm{SnO}_{2}$. The thin film deposition process was carried out in a high vacuum chamber. Some of the films were also grown on nitrogen ambient. Research grade $\mathrm{N}_{2}$ was introduced into the deposition chamber through the leak valves. The gas pressure inside the vacuum chamber was 8.5 mTorr. The substrate temperature was maintained at $525^{\circ} \mathrm{C}$ for sapphire and silicon substrates. For $\mathrm{SnO}_{2}$ coated glass substrates, the temperature was maintained at $500{ }^{\circ} \mathrm{C}$ to preserve the conductive coating.

$\mathrm{InN}$ is available only in powder form. The standard method of hot pressing does not work for $\mathrm{InN}$ because of its low dissociation temperature (around $550{ }^{\circ} \mathrm{C}$ ). The target was prepared by pressing the InN powder on the custom made target holder under a pressure of approximately $6 \times 10^{4} \mathrm{~N}$. The diameter of the target was $1 \mathrm{~cm}$ and several $\mathrm{mm}$ thick. 
The sapphire substrates were first dipped in TriChloroEthylene (TCE) solution for five minutes. The procedure was followed by ultrasonically cleaning the substrates with acetone and methanol for 3 minutes each. Then the substrates were rinsed with deionized (DI) water for three minutes. Other substrates were cleaned ultrasonically with acetone and methanol for 5 minutes each and then rinsed with DI water. The substrates were carefully inspected before being loaded into a substrate heater under an optical microscope, which was used to check for any contamination. The cleaning procedure was repeated if needed.

\subsubsection{Analysis of InN Grown on Sapphire Substrates}

Sapphire is the most widely used substrate for the epitaxial growth of InN. There is large lattice mismatch between InN and c-plane sapphire, of approximately $29^{\circ}$. The vast lattice mismatch can cause a high density of structural defects. Such a large lattice mismatch is the root of structural defects in the InN films. The c-plane sapphire substrates were heated at $800{ }^{\circ} \mathrm{C}$ for one hour in the nitrogen environment. This will create a thin layer of aluminum nitride on the top of $\mathrm{Al}_{2} \mathrm{O}_{3}$ substrates. This surface nitridation process will significantly improve the crystallinity of the $\mathrm{InN}$ film forming AlN buffer layer between the substrate and the epilayer [31]. The temperature of the substrate was maintained at $525{ }^{\circ} \mathrm{C}$ during the deposition. The pulse energy of $175 \mathrm{~mJ}$ was used. Two different numbers of pulses were used for $\mathrm{InN}$ thin film deposition on sapphire substrates.

Fig. 2.2.1 shows the SEM images of InN grown for 5000 pulses at $5 \mu \mathrm{m}$ range and $2 \mu \mathrm{m}$ range. The magnified SEM image reveals the crystal/grain structure of the film. The surface was flat and uniform. The particulate density in this case was less than the film grown for 2000 pulses. Moreover, the size of the InN particulates was relatively smaller. No misfit dislocation was observed, as in previous sample. The SEM figure reveals that this is high quality film. As we can see in the magnified image (Fig. 2.2.2 b), the surface morphology contained highly oriented grains of uniform sizes.
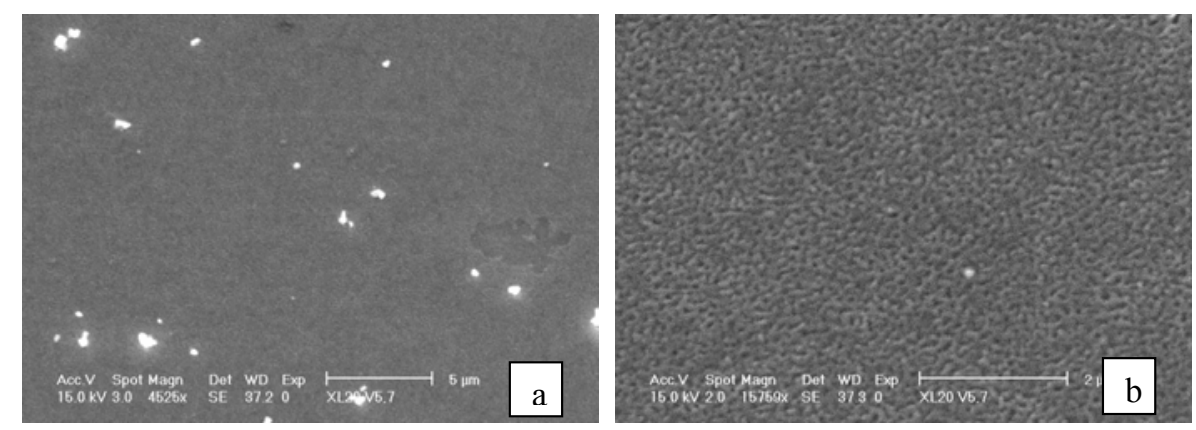

Fig. 2.2.1 SEM image of InN grown on C-axis Sapphire for 5000 pulses at $175 \mathrm{~mJ}$ beam energy a) $5 \mu \mathrm{m}$ range b) $2 \mu \mathrm{m}$ range. The film was smooth with only few particulates on the surface.

The XRD pattern of InN grown under the above mentioned conditions for 5000 pulses on Sapphire is shown on Fig 2.2.2. The XRD pattern shows a strong peak of $\mathrm{InN}$ at around $2 \theta$ of $30.8^{\circ}$. This peak is associated with (0002) InN. Also, other smaller InN peaks were obtained at $32.3^{\circ}$ and $51.2^{\circ}$. The peak at $51.3^{\circ}$ is assigned to be $\operatorname{InN}(2110)$. 


\subsubsection{Analysis of InN Grown on Silicon Substrates}

Indium nitride film was also grown on silicon (100) substrates. The films were grown using 175 $\mathrm{mJ}$ of pulse energy at $525^{\circ} \mathrm{C}$ of substrate temperature. The surface morphology of the film shown in Fig. 2.2.3 was smooth, containing less particulate density on the surface. However, the pitting still appeared on the surface. The InN film grown for 5000 pulses, while maintaining other growth parameters same as above, is shown in Fig. 2.2.4. The film was smooth and contained only few particulates on the surface. The surface pitting was also diminished in this case. The magnified SEM image reveals the grain structure of the film in detail. The size of the grain was in nanometer range, thus maintaining a remarkably flat, smooth and regular surface.

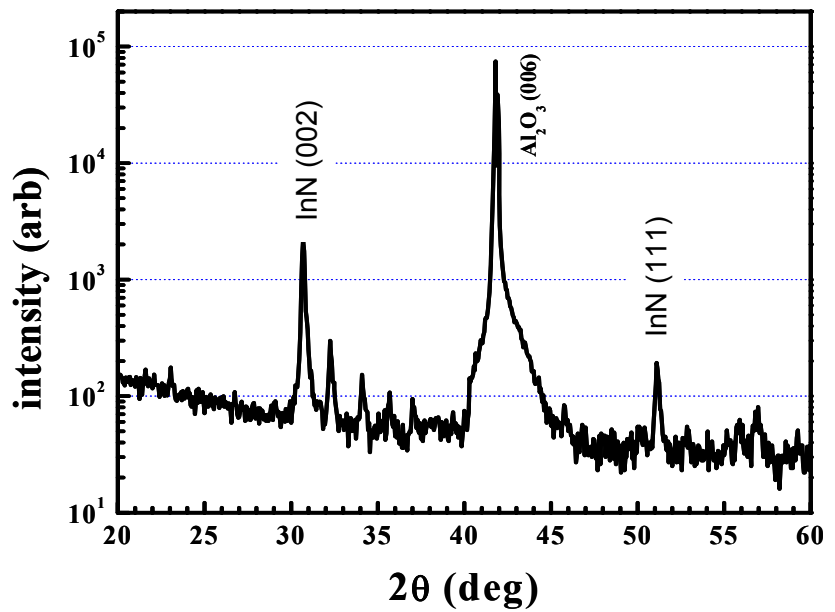

Fig. 2.2.2 X-ray diffraction pattern of $\mathrm{InN}$ grown on $\mathrm{Al}_{2} \mathrm{O}_{3}$. The XRD pattern shows the presence of polycrystalline $\mathrm{InN}$.
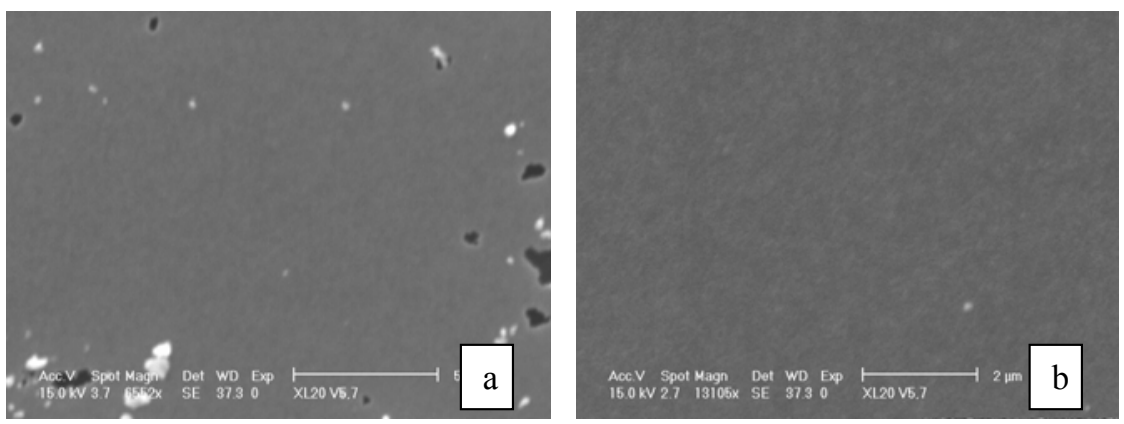

Fig. 2.2.3 SEM image of InN grown on Si for 2000 pulses at $175 \mathrm{~mJ}$ beam energy a) $5 \mu \mathrm{m}$ range b) $2 \mu \mathrm{m}$ range. 

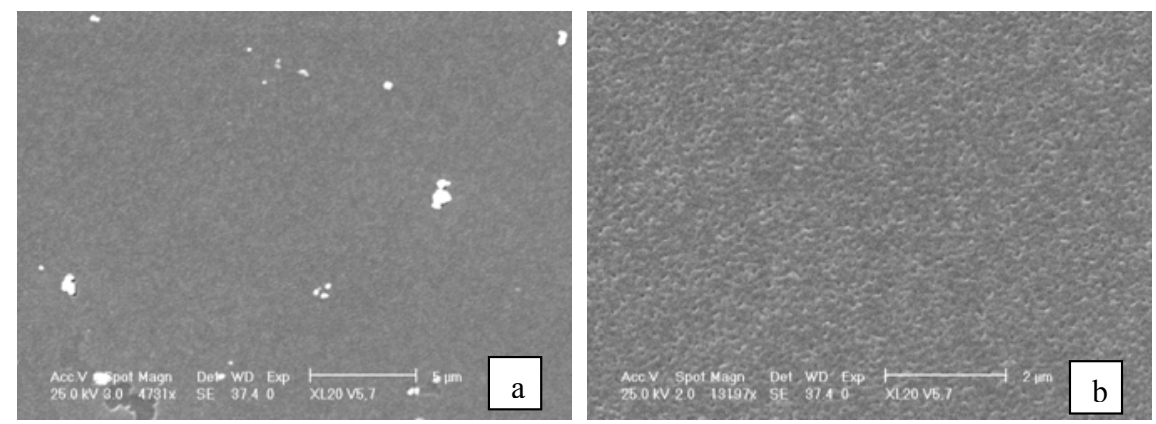

Fig. 2.2.4 SEM image of InN grown on Si for 5000 pulses at $175 \mathrm{~mJ}$ beam energy

a) $5 \mu \mathrm{m}$ range b) $2 \mu \mathrm{m}$ range. The film was a high quality film with smooth surface morphology and with only few particulates.

The XRD pattern of the film grown on Si (100) for 5000 pulses is shown in Fig. 2.2.5. The InN peaks for silicon substrate were very similar to those obtained for InN on sapphire. The InN peaks at $30.8^{\circ}$ and $51.2^{\circ}$ are assigned to $\operatorname{InN}(002)$ and $\operatorname{InN}(111)$. The XRD results along with the SEM figures indicate the successful high quality growth of InN.

\subsubsection{Photoelectrochemical Measurements}

The Photocurrent measurements are important in determining the characteristics of a semiconductor for its use in photoelectrochemical hydrogen production. We have performed the photocurrent and dark-current measurements of different InN electrodes grown using Pulsed Laser Deposition. Different conditions were tested with the intent of finding optimum growth conditions for the photoelectrodes. The pulse energy, number of pulses and the background environment in the vacuum chamber were varied, and the photoresponse of the as-grown films were observed.

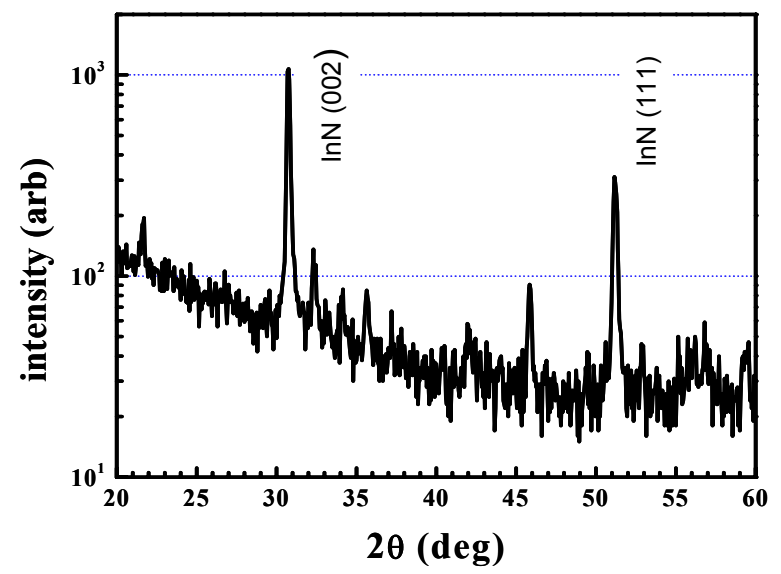

Fig. 2.2.5 X-ray diffraction pattern of InN grown on Si (0001). 


\subsection{Development of Smart Materials for Transparent Conduction and Corrosion Resistance of Photoelectrodes Used in PEC Cells}

For the photoelectrochemical characterization of the $\mathrm{InN}$ film, the electrodes were prepared by depositing InN on conducting glass substrate (fluorine doped tin oxide coated glass). The sheet resistance of the glass substrate was $8 \Omega / \square$, where $\square$ denotes the sheet resistance. The substrates were cut into small rectangular pieces. The sides of the conducting substrate were covered by metal clip throughout the deposition. This holds the thick glass substrate well on the substrate heater and also keeps that space from deposition to maintain electrical contact in the electrode. The electrical connection was established by making contact with the uncoated substrate surface with copper wire and silver paste. The back surface and the edges of the electrode were sealed with epoxy resin. The experimental conditions of the deposition of InN film for electrode preparation are summarized in Table 2.3.1.

Table 2.3.1 Summary of growth parameters for photoelectrode preparation.

\begin{tabular}{|l|l|}
\hline Laser fluence & $175 \mathrm{~mJ}-225 \mathrm{~mJ}$ \\
\hline Number of pulses & $3000-7000$ \\
\hline Substrate temperature & $500{ }^{\circ} \mathrm{C}$ \\
\hline Pressure & $8.5 \mathrm{mTorr}$ \\
\hline Repetition rate & $1 \mathrm{~Hz}$ \\
\hline Target rotation & No \\
\hline
\end{tabular}

\subsubsection{Variation in Pulse Energy}

Fig. 2.3.1(a) shows the dark-current density versus applied potential (voltage as a function of saturated calonel electrode, denoted as V vs SCE) of the InN sample prepared using $175 \mathrm{~mJ}$ of pulse energy. The electrodes were scanned from $-0.6 \mathrm{~V}$ to $+0.6 \mathrm{~V}$. It is observed that the current is positive on the anodic potentials implying the n-type behavior of the InN electrodes. This is attributed to the nitrogen vacancies present in the film. Nitrogen vacancies are the native defects present in the InN film that donate electrons in the conduction band. In addition, nitrogen antisite and impurities like oxygen might have donated the charge carriers.

The photocurrent of this film as a function of applied potential (V vs SCE) is shown in Fig. 2.3.1(b). Since the current density around the observed onset potential was fairly low, it is hard to precisely locate the onset potential. The photocurrent onset potential for $\mathrm{InN}$ was roughly estimated at around $-0.2 \mathrm{~V}$ vs SCE. The onset potential of the anodic photocurrents and flat-band potential should, ideally, position at the same point for n-type semiconductor [32]. However, in real situations, massive recombination causes the onset potential to move from flat-band potential.

The onset potential and the open-circuit potential were coincided at the same potential. In other words, the photocurrent started to flow as soon as the positive dark current started to flow. A small increase in photocurrent was observed until $+0.25 \mathrm{~V}$, and thereafter the photocurrent were found to increase rapidly along with the dark current. The sharp increase in photocurrent is attributed to the oxidation; the iodide might have converted into tri-iodide. No photocurrent could be observed beyond $+0.4 \mathrm{~V}$ due to the dominance of dark current. 
The photocurrent density of InN films prepared using different values of pulse energy is shown in Fig. 2.3.2. The photocurrent for the $200 \mathrm{~mJ} \mathrm{InN}$ sample was found to be greater than that of the $175 \mathrm{~mJ}$ and $225 \mathrm{~mJ}$ sample. The photocurrent onset potential for the $175 \mathrm{~mJ}$ and $225 \mathrm{~mJ}$ samples was located around $-0.2 \mathrm{~V}$ vs SCE, while that of $200 \mathrm{~mJ}$ sample was located around $-0.3 \mathrm{~V}$ vs SCE. It is difficult to analyze the difference in the onset potential for different samples. The InN films contained some oxygen, and the different amount of oxygen incorporation for different samples could be the ground of the difference. Also, the direction of the scanning of the electrode may cause the discrepancy. A detailed examination of the electrodes is necessary before reaching any conclusion.

As already mentioned, this onset potential is only a rough estimation of flat-band potential. Due to very small current around flat-band potential, it is difficult to find the exact location of the onset potential. At higher positive potential, due to the strong band bending and wide enough space-charge regions for the separation of light generated electrons and holes, the photocurrent is higher.

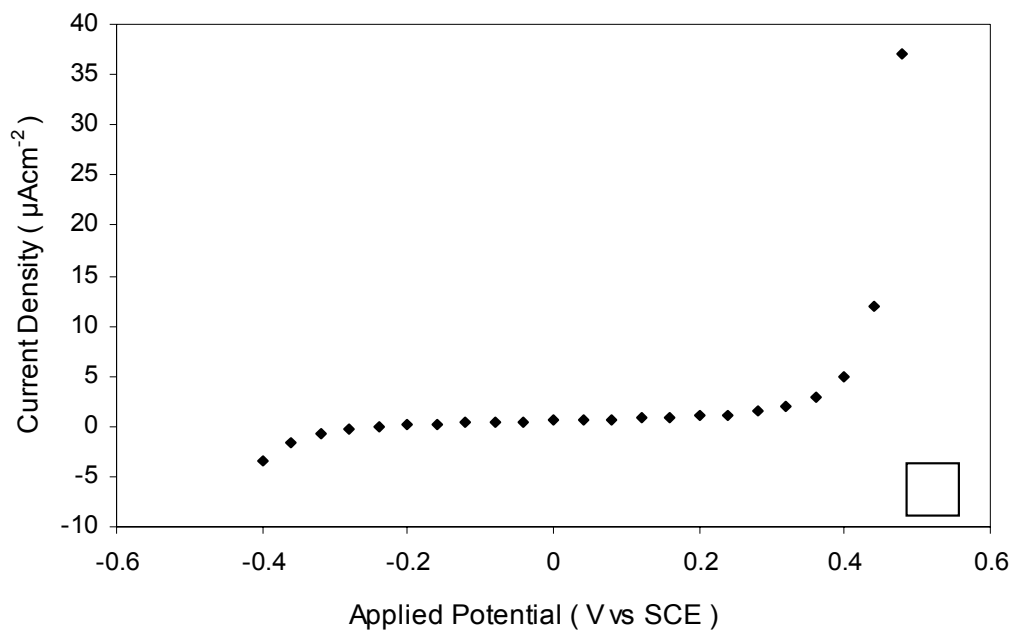




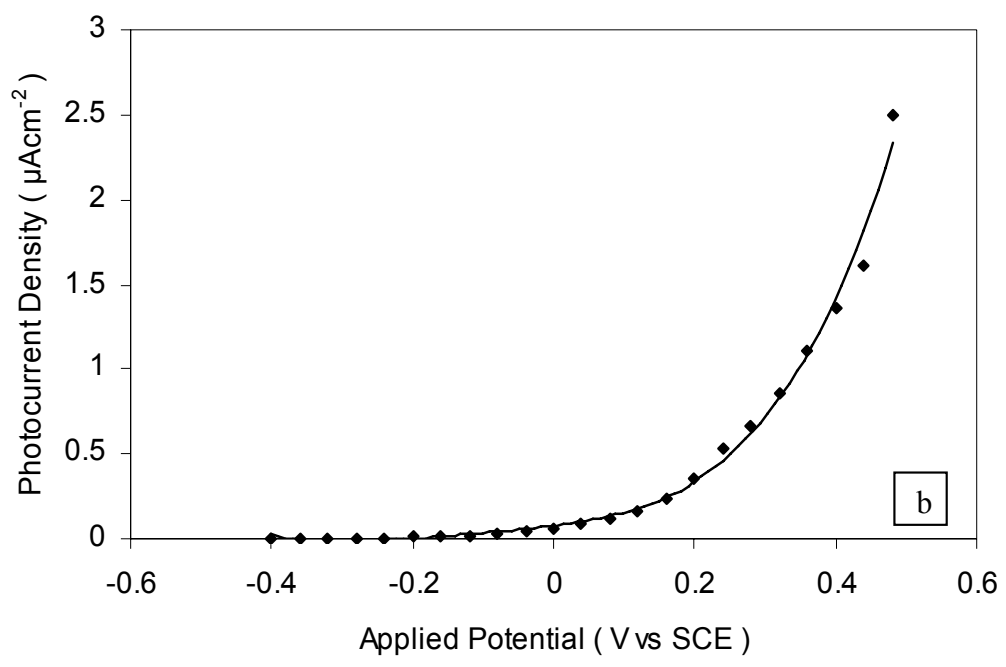

Fig. 2.3.1 Current-potential curves for InN electrode grown for 7000 pulses using $175 \mathrm{~mJ}$ pulse energy: (a) measured in dark, and (b) photocurrent.

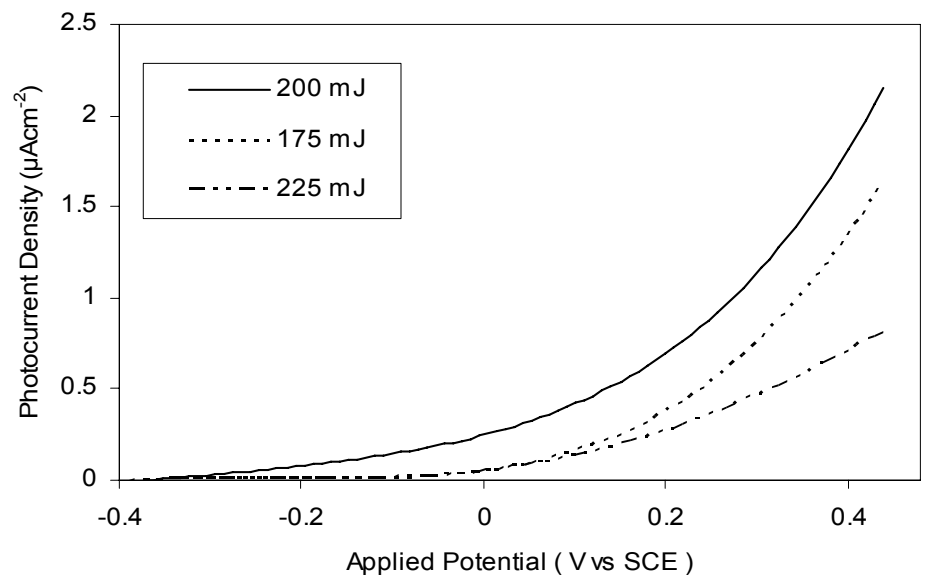

Fig. 2.3.2 Photocurrent-potential curves for InN electrodes, grown for 7000 pulses, for different pulse energy.

\subsubsection{Variation in Number of Pulses}

In the previous section, an optimum in laser pulse energy was found at $200 \mathrm{~mJ}$. We proceed, in this section, varying the number of pulses while keeping the pulse energy at its optimum. The 
optimum in the number of pulses is found at 5000 pulses as shown in Fig. 2.3.3. The photocurrent obtained at a given applied potential for the sample prepared using 5000 laser pulses was significantly higher than the photocurrent for the 3000 and 7000 pulses.

One plausible explanation for this is that for a small number of pulses, the film thickness was not enough to absorb a sufficient number of incident photons. As the film thickness was increased, more and more incident photons were absorbed in the film and photocurrent started to rise. However, with the increase in number of pulses, the increased thickness of the film consequently increased the resistivity of the film. The increased resistivity of the film meant the decreased photocurrent. Also, the different oxygen incorporation in the film could cause the change in photo response.

\subsubsection{Variation in Background Conditions}

We have also observed the effect of background gas in the photo response of the InN films. The samples were prepared for the optimum conditions, as mentioned in the previous sections. One of them was deposited in $8.5 \mathrm{mTorr}^{\mathrm{N}_{2}}$ in the background and the other in $2.5 \times 10^{-6}$ Torr vacuum. As shown in Fig. 2.3.4, the photo response of the sample prepared in the nitrogen ambient was better than that of the sample prepared in high vacuum. The exact reason behind this is still unknown.

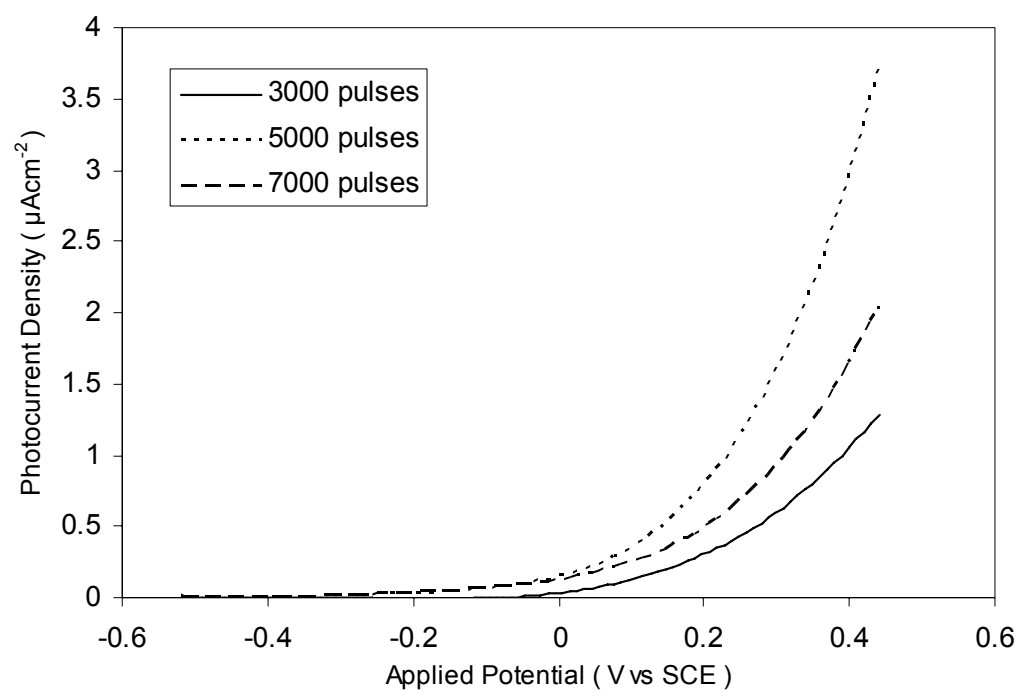

Fig. 2.3.3 Photocurrent-potential curves for InN electrodes, grown using $200 \mathrm{~mJ}$ of pulse energy for different number of pulses. The sample grown for 5000 pulses showed better photoresponse than others. 


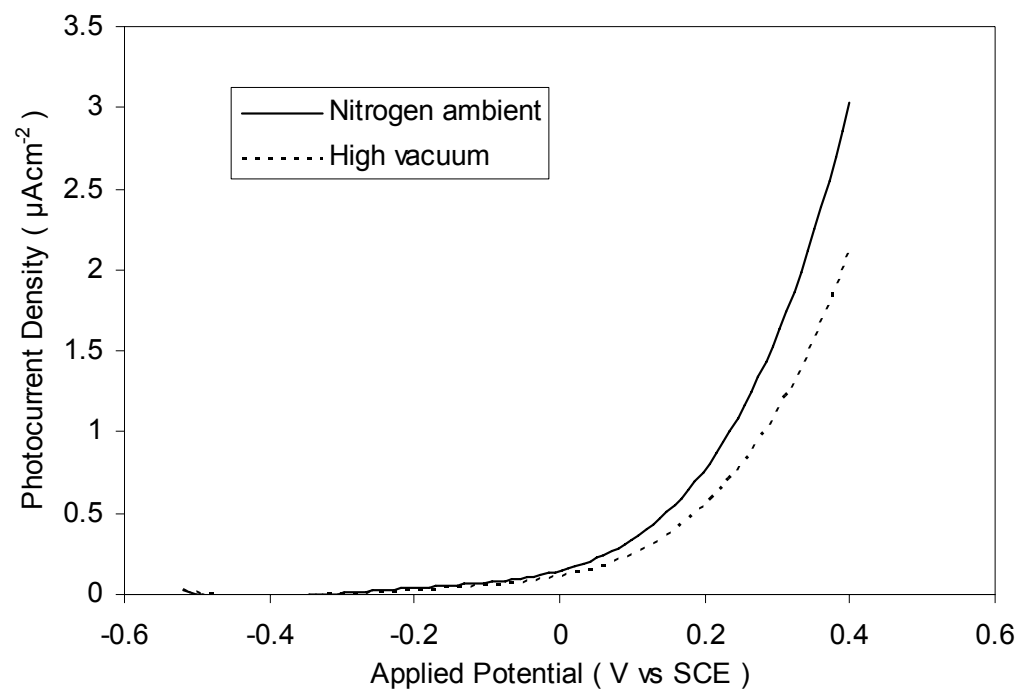

Fig. 2.3.4 Photocurrent-potential curves for $\mathrm{InN}$ electrodes grown under different background environment. The photoresponse of the film grown in nitrogen ambient was better than that of the film grown in high vacuum.

\subsubsection{Stability}

The stability of the electrode is an important criterion of the material to be used in PEC hydrogen production. The stability directly determines the cost of the hydrogen production. For commercial realization of any electrode, it should be stable for thousands of hours of operation. Short operating lifetime of electrode increases the cost of hydrogen production by demanding more electrodes for a given period of operation. The InN film was found stable in the aqueous electrolyte solution. The SEM images of the film before and after two hours of operation in KI solution is shown in Fig. 2.3.5. It is noted that these images were of the different area of the same electrode. No significant decomposition or corrosion of the surface was observed. The white particles on the surface are assumed to be the potassium iodide from the electrolyte. Hence it is expected that InN film is stable in the electrolyte solution.
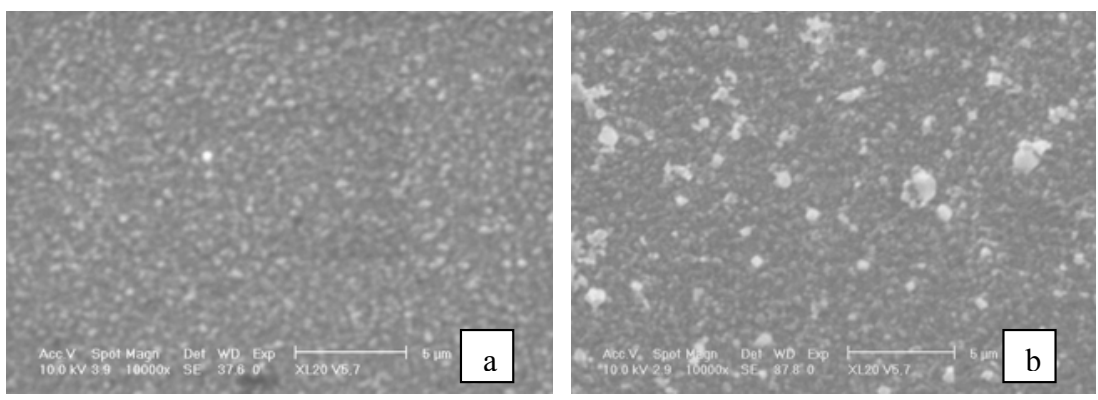

Fig. 2.3.5 SEM image of InN grown on TEC8 glass for 7000 pulses at $175 \mathrm{~mJ}$ beam energy: (a) as grown, and (b) after 2 hours of operation. 


\subsubsection{Discussions}

We have successfully grown $\mathrm{InN}$ in a varieties of substrates such as $\mathrm{Si}$, sapphire, and conductive glass. To our knowledge, this is the first successful deposition of InN on Si using direct PLD. PLD is a flexible and cost-effective thin film method with only a few, easy-to-control growth parameters. The qualities of the films were confirmed by SEM and XRD characterization results. Initial experiments showed very rough surface with low crystalline quality. After performing series of experiments with different growth parameters, the film quality was significantly improved. A smooth, regular surfaced film with only few particulates was achieved. The pulse energy was explored to be the important parameter in improving the surface morphology of the films. By decreasing the pulse energy, the particulate density on the film surface was reduced. An optimum in the pulse energy was found at $175 \mathrm{~mJ}$. The pulse repetition rate, also, had significant impact on the film quality. It is noted that low density of the target material prohibited using higher pulse frequency. Had the density of target was higher, higher pulse frequency could be used. Moreover, the surface nitridation of the substrates also aided to improve the smoothness of the film by creating an intermediate layer between the substrate and the grown films. The XRD pattern of the film reveals the high quality polycrystalline growth of $\operatorname{InN}$.

With reference to the foregoing observations mentioned in the previous section, it is clear that InN has a potential to be used in PEC hydrogen production. By investigating the photoresponse of films grown for different pulse energy and number of pulses, optimum growth condition for the better photo response of the films was obtained. There was no clear trend between these growth parameters and the photo response of the film. At $200 \mathrm{~mJ}$ of pulse energy and 5000 number of pulses, maximum photocurrent density of several $\mu \mathrm{A} / \mathrm{cm}^{2}$ was achieved. The films were found stable in the electrolyte solution for several hours of operation. However, for its use in commercial hydrogen production, an in-depth analysis of the semiconductor surfaceelectrolyte junction is needed.

The observed photocurrent was not conspicuous in the present scenario. The goal set by US department of Energy (DOE) is to achieve 14\% solar to hydrogen conversion efficiency by 2015 . To achieve $15 \%$ efficiency, photocurrent in the range of at least $\mathrm{mA}$ should be achieved. Already established materials such as $\mathrm{TiO}_{2}, \mathrm{WO}_{3}$ have better photo response than $\mathrm{InN}$, although still not able to fulfill the DOE goal. The cost of material is also important factor that determines its possible use in hydrogen production. If the material is expensive, the cost of the PEC system, and hence the cost of hydrogen will be high. This is one of the reasons for searching novel materials, which are cheap, stable in aqueous solution, and have better photo response. In this search, our work will have significant impact by opening new possibilities of using $\mathrm{InN}$ in direct water splitting.

\subsubsection{Conclusions}

The InN films were successfully grown on varieties of substrates such as $\mathrm{Si}$, sapphire, and conductive glass. With the aid of SEM and XRD, the samples were observed to have good surface morphology and crystalline quality. The InN samples were observed to be photoactive. The photo response of the InN films grown for different growth parameters was observed. No clear trend between the pulse energy and the photo response of the film was evident. Similarly, the effect of film thickness on the photocurrent was not in regular trend. An optimization in these growth parameters for the better photo response was found. The observed photocurrent was in the range of $\mu \mathrm{A} / \mathrm{cm}^{2}$. Although the observed current is low to have an immediate, significant impact 
on PEC hydrogen production, it establishes a sound basis for the further investigations to increase the photo response of InN films.

\section{Modeling of Hydrogen Production, Purification and Storage}

3.1 Methane Reformer

A Plug Power GenSys 5C fuel cell generator was used in this research to obtain operational data for the simulation work. The GenSys is an integrated heat and power production system that consists of three major subsystems. In the first subsystem, methane is converted to hydrogen-rich fuel, known as reformate, that provides hydrogen to the proton exchange membrane (PEM) fuel cell subsystem. The PEM cell subsystem converts the hydrogen to electrical energy. The third subsystem is a series of heat exchangers that manages the reformer and PEM cell temperatures and provides a means of extracting heat energy from the system to increase the overall efficiency.

The GenSys $5 \mathrm{C}$ is designed to operate as a stand-alone system, independent of the power grid, providing a maximum of $5 \mathrm{~kW}$ of electrical energy. Instrumentation built into the system monitors a wide variety of parameters, including temperatures, pressures, flow rates, and electrical power. Experimental data from the GenSys was used to develop an ASPEN model of the fuel processing subsystem.

\subsubsection{Fuel Processing System Description}

The fuel processing subsystem is shown in block diagram form in Fig. 3.1.1. Since hydrogen is a non-traditional fuel, it must be produced from readily-available materials. In this system, natural gas, which is primarily methane, is converted to hydrogen by the process of steam reforming. Each component of the system is described below [33].

Sulfur Removal - Before the methane is processed, mercaptan is removed by an adsorptive bed. Mercaptan is added to commercial natural gas as an odorant and must be removed because sulfur compounds act as a poison to the platinum anode catalyst in the PEM fuel cell assembly. After sulfur removal, the methane is combined with air to form a process stream. The air flow is metered to provide 1 mole of oxygen for every 2 moles of methane.

Humidifier - The process stream is humidified in preparation for steam methane reforming. The humidifier temperature is regulated to provide 4 moles of saturated water vapor for every mole of methane. This ratio is referred to as the "steam-to-carbon ratio" (SCR) and is a critical control parameter.

HX1 - The humidified process stream is preheated by heat recovered from the system exhaust using HX1, a gas-to-gas heat exchanger.

SMR - The steam methane reformer (SMR) primary steam reforming reaction is as follows:

$$
\mathrm{H}_{2} \mathrm{O}+\mathrm{CH}_{4} \rightarrow 3 \mathrm{H}_{2}+\mathrm{CO}
$$

This reaction is endothermic, with $\Delta \mathrm{H}=206 \mathrm{~kJ} / \mathrm{mol}$. The SMR contains a catalyst bed that is maintained at a temperature of about $750 \mathrm{C}$. The gas composition of the outlet of the SMR is approximately $40 \%$ hydrogen and approximately $15 \%$ carbon monoxide (CO). 
HX2 - The temperature of the process stream is reduced from approximately $750 \mathrm{C}$ to approximately $400 \mathrm{C}$ by $\mathrm{HX} 2$, a gas-to-gas heat exchanger. The excess heat is recovered to preheat the humidified process stream.

HTS - The high-temperature shift (HTS) reactor's primary function is to reduce the level of CO in the outlet of the SMR. Carbon monoxide acts as a poison to the platinum anode catalyst in the fuel cell and must be reduced to PPM levels before the reformate can be used in the fuel cell. The HTS operates at a temperature of about $400 \mathrm{C}$ over a metal oxide catalyst bed. The primary reaction is known as the water-gas shift reaction, described as follows:

$$
\mathrm{CO}+\mathrm{H}_{2} \mathrm{O} \rightarrow \mathrm{CO}_{2}+\mathrm{H}_{2}
$$

This reaction is exothermic, with $\Delta \mathrm{H}=-41 \mathrm{~kJ} / \mathrm{mol}$. The gas composition of the outlet of the HTS is approximately $55 \%$ hydrogen and $3 \% \mathrm{CO}$.

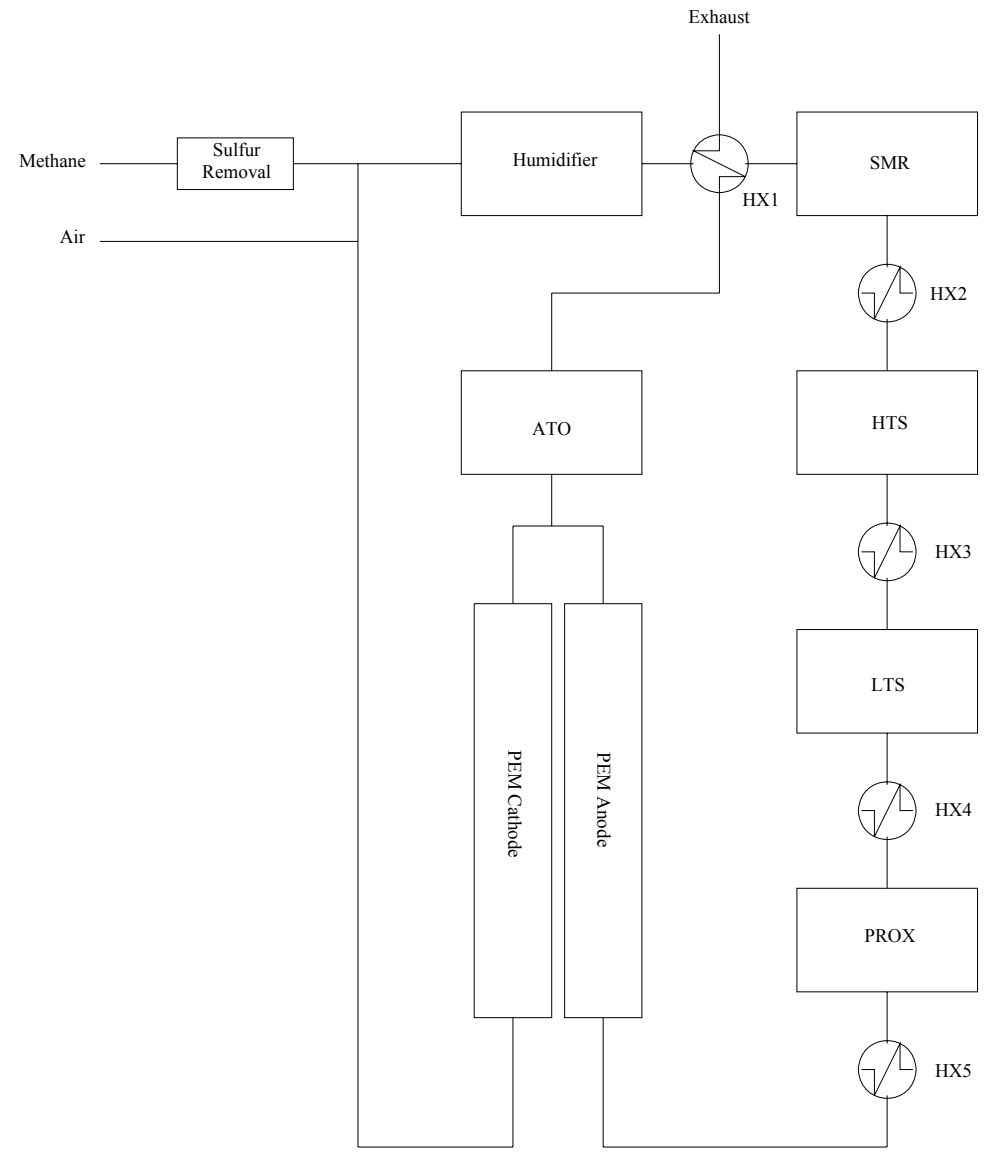

Fig. 3.1.1 Reformer Block Diagram. 
HX3 - Since the water-gas shift reaction is exothermic, heat management must be done to prevent the formation of $\mathrm{CO}$ in preference to reduction of $\mathrm{CO}$. HX3 is a gas-to-gas heat exchanger that reduces the outlet temperature of the HTS from approximately $400 \mathrm{C}$ to approximately $200 \mathrm{C}$.

LTS - The low temperature shift (LTS) reactor performs another stage of the water-gas shift reaction at about half of the temperature of the HTS. This further reduces the $\mathrm{CO}$ level, resulting in an outlet composition of approximately $55 \%$ hydrogen and less than $0.25 \% \mathrm{CO}$.

HX4 - The outlet temperature of the LTS is reduced from approximately $200 \mathrm{C}$ to approximately $140 \mathrm{C}$ by HX4, a gas-to-liquid heat exchanger. The liquid loop contains ethylene glycol.

PROX - The preferential oxidizer (PROX) reduces the level of $\mathrm{CO}$ in the stream from approximately $0.25 \%$ to less than 50 PPM. Additional air is introduced into the PROX to oxidize $\mathrm{CO}$ by the following reaction:

$$
\mathrm{CO}+\frac{1}{2} \mathrm{O}_{2} \rightarrow \mathrm{CO}_{2}
$$

This reaction is conducted over a catalyst and is exothermic, with $\Delta \mathrm{H}=-283 \mathrm{~kJ} / \mathrm{mol}$. The temperature must be carefully controlled to prevent the undesirable reaction:

$$
\mathrm{H}_{2}+\frac{1}{2} \mathrm{O}_{2} \rightarrow \mathrm{H}_{2} \mathrm{O}
$$

which has $\Delta \mathrm{H}=-242 \mathrm{~kJ} / \mathrm{mol}$, and reduces the amount of hydrogen in the reformate. Temperatures less than $150 \mathrm{C}$ tend to favor the oxidation of $\mathrm{CO}$, so the temperature is controlled by regulating the amount of oxygen provided to the PROX. The outlet composition of the PROX is approximately $70 \%$ hydrogen, $<50 \mathrm{PM} \mathrm{CO}$, and $30 \%$ inerts, which includes water vapor, nitrogen, methane, and carbon dioxide.

HX5 - The outlet temperature of the PROX is reduced from approximately $150 \mathrm{C}$ to approximately $80 \mathrm{C}$ by the gas-liquid heat exchanger HX5. The liquid loop contains ethylene glycol. The reformate from HX5 is suitable for processing by the anode of the PEM fuel cell assembly. The hydrogen in the reformate is catalytically split into $\mathrm{H}^{+}$ions and electrons by a platinum membrane separating the PEM cell anode and cathode. The reaction is as follows:

$$
H_{2} \rightarrow 2 H^{+}+2 e^{-}
$$

The anode and cathode are separated by a proton exchange membrane (PEM), which is an electrical insulator that allows the $\mathrm{H}^{+}$ions to permeate through to the cathode. The electrons are then available to do electrical work, after which they combine with the hydrogen ions and oxygen at the cathode according to the following reaction: 


$$
\frac{1}{2} \mathrm{O}_{2}+2 \mathrm{H}^{+}+2 e^{-} \rightarrow \mathrm{H}_{2} \mathrm{O}
$$

ATO - Since there is a small amount of hydrogen and unreacted methane in the anode outlet of the PEM fuel cell, the anode tail gas oxidizer (ATO) recovers the heat energy by two exothermic reactions:

$$
\mathrm{H}_{2}+\frac{1}{2} \mathrm{O}_{2} \rightarrow \mathrm{H}_{2} \mathrm{O}
$$

with $\Delta \mathrm{H}=-242 \mathrm{~kJ} / \mathrm{mol}$, and

$$
\mathrm{CH}_{4}+2 \mathrm{O}_{2} \rightarrow \mathrm{CO}_{2}+2 \mathrm{H}_{2} \mathrm{O}
$$

with $\Delta \mathrm{H}=-802.5 \mathrm{~kJ} / \mathrm{mol}$

The ATO operating temperature is approximately $650 \mathrm{C}$ with an outlet composition of nitrogen, carbon dioxide, and water vapor, which is routed to the system exhaust through HX1. The system exhaust temperature is approximately $80 \mathrm{C}$.

\subsubsection{System Data}

The GenSys fuel cell was connected to a variable load system and was configured to run independently from the power grid. Data was obtained at a variety of load conditions. Figures 3.1.2 through 3.1.7 show representative real-time data profiles from April 21, 2006. The system was stabilized at approximately $2 \mathrm{~kW}$ and was operated over a 1-hour period with resistive loads from zero to $3.25 \mathrm{~kW}$.

In Fig. 3.1.2, the DC power provided by the stack and the AC power provided to the load are shown. The reformer controller and system electronics consume approximately 300 to 500 watts of the energy generated, so there is a discrepancy between the DC power produced by the PEM stack and the AC output power to the load. The DC power from the stack is converted to AC power by an inverter, which operates at approximately $99 \%$ efficiency. Fig. 3.1.3 shows the flow of methane and air into the reformer system. The system air blower provides combustion air for reformer startup, combustion air to the ATO, oxygen to the PROX, and oxygen to the PEM cathode.

Figure 3.1.4 shows the individual reformer stage temperatures. The individual stage temperatures are managed by a series of heat exchangers. Much of the system thermal energy is utilized to preheat reactants entering the SMR and to support the endothermic SMR reaction, but a proportion of the thermal energy is available from a customer heat exchanger. This heat exchanger has an ethylene glycol loop that can be used to heat water for space heating and domestic hot water. In the experiments performed in this research, the heat energy was not utilized and was rejected to the atmosphere through a radiator.

Figure 3.1.5 shows the relationship between power output and hydrogen flow to the anode. The utilization efficiency of hydrogen in a typical PEM cell is approximately $80 \%$. As can be see from the graph, the GenSys PEM stack develops approximately $2.5 \mathrm{~kW}$ of electrical energy at a hydrogen flow rate of approximately 40 standard liters per minute (SLPM). 


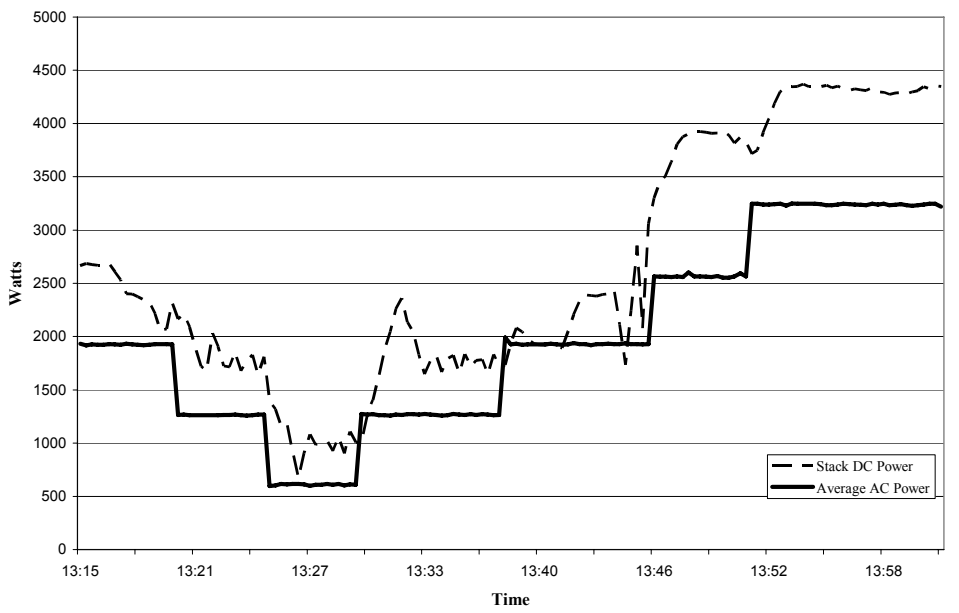

Fig. 3.1.2 System power output.

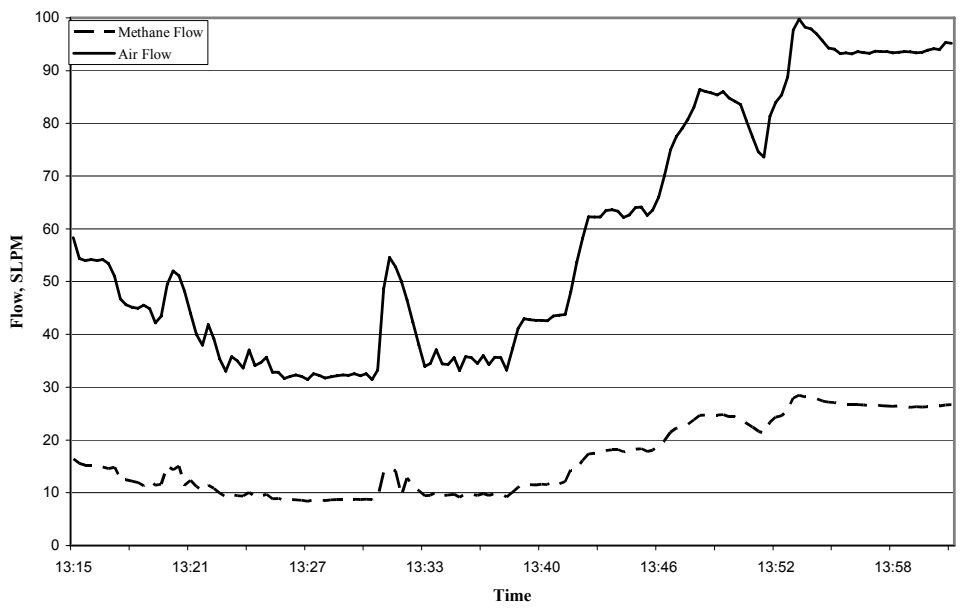

Fig. 3.1.3 Reformer inlet flows. 


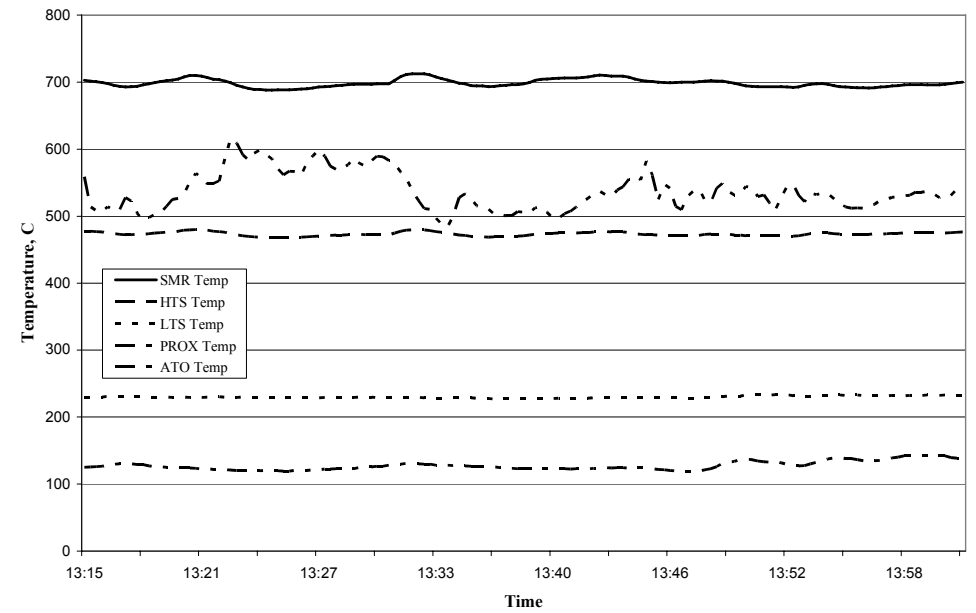

Fig. 3.1.4 Reformer stage temperatures.

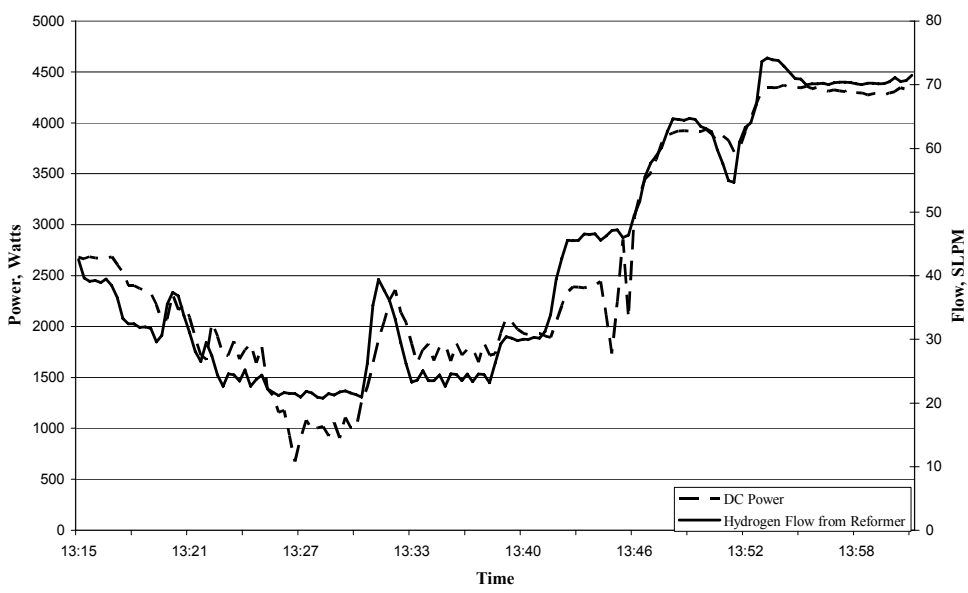

Fig. 3.1.5 Hydrogen flow and DC power output. 


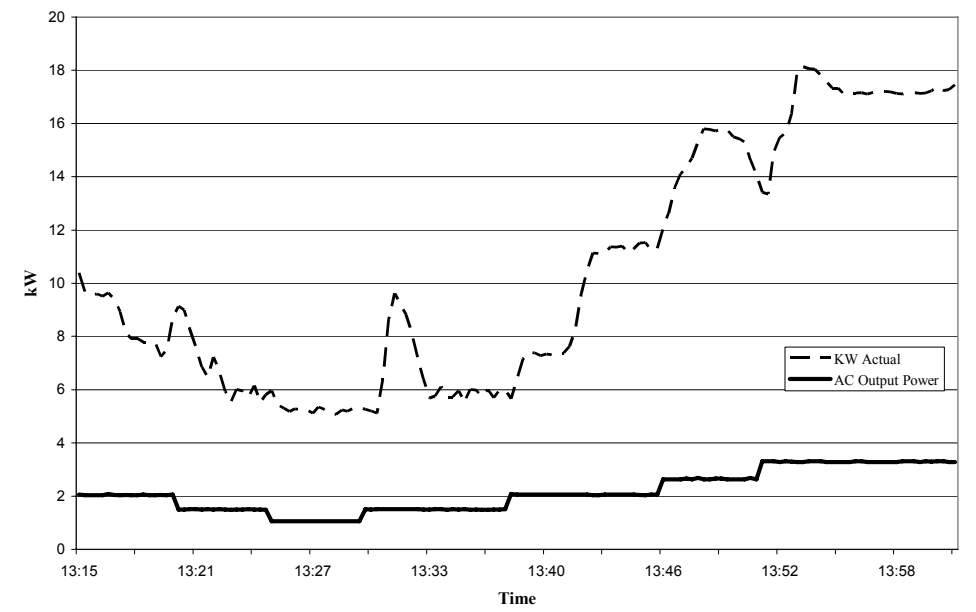

Fig. 3.1.6 - Total combined thermal/electrical power and electrical output power.

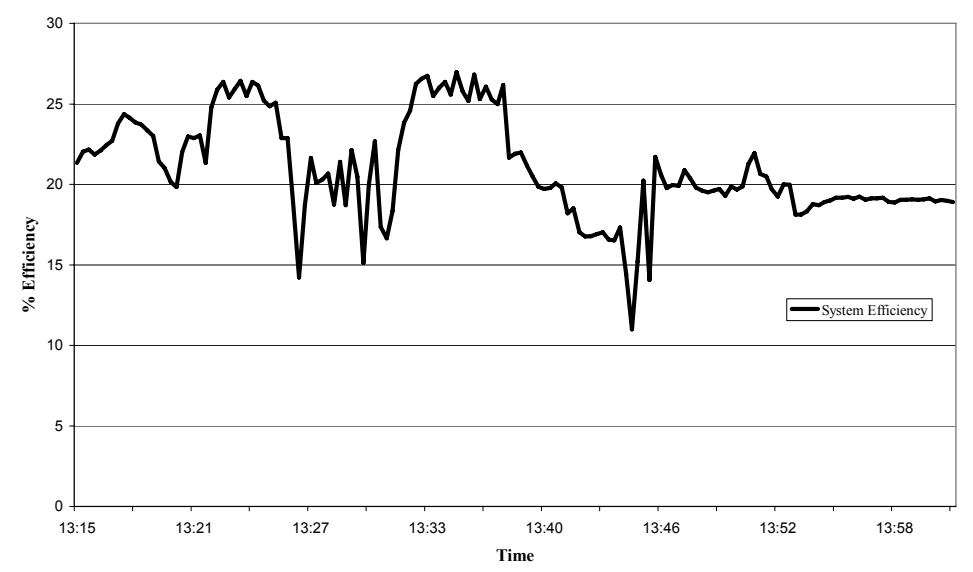

Fig. 3.1.7 System thermodynamic efficiency.

Figure 3.1.6 shows the thermodynamic efficiency of the system. Only about $20 \%$ of the total available energy from the methane is reclaimed as electrical energy. This efficiency can be significantly increased by making use of the available thermal energy as "sensible heat," but the problem with a PEM system is the relatively low temperature of operation, which makes the temperature differential between the system and the ambient temperature low. The problem with this is that steam generation is not feasible. The heat energy can only be realistically reclaimed as hot water for space heating or domestic use. When heat reclamation is done, the system is said to be operating in combined heat and power (CHP) mode, which roughly doubles the system efficiency to approximately $40 \%$. 


\subsubsection{ASPEN Reformer Model}

A reformer model was developed in ASPEN using the parameters from the GenSys reformer. Run data from the Gensys was taken at a variety of power output levels over the duration of a three year operating period. Since the proposed minigrid system will utilize two reformers, the models were scaled up to appropriate flow rates. Although some assumptions had to be made, it is believed that the scaled-up model will give a reasonable estimate of the hydrogen production, thermal energy production, and energy consumption of a stand-alone steam methane reformer. Table 3.1.1 summarizes the data from a representative ASPEN simulation.

Table 3.1.1 ASPEN Reformer Simulation Data.

\begin{tabular}{|c|c|c|c|c|c|c|c|c|c|c|c|}
\hline Substream: MIXED & CH4 Feed & H2O FEED & O2 FEED & SMR OUT & SMR HX OUT & HTS OUT & HTS HX OUT & LTS OUT & LTS HX OUT & PROX OUT & PROX BOTTOM \\
\hline $\mathrm{H} 2 \mathrm{O}$ & $0.000 \mathrm{E}+00$ & $4.000 \mathrm{E}+02$ & $0.000 \mathrm{E}+00$ & $3.015 \mathrm{E}+02$ & $3.015 \mathrm{E}+02$ & $2.243 \mathrm{E}+02$ & $2.243 \mathrm{E}+02$ & $2.041 \mathrm{E}+02$ & $2.041 \mathrm{E}+02$ & $6.270 \mathrm{E}+01$ & $1.414 \mathrm{E}+02$ \\
\hline $\mathrm{CH} 4$ & $1.000 \mathrm{E}+02$ & $0.000 \mathrm{E}+00$ & $0.000 \mathrm{E}+00$ & $1.473 \mathrm{E}+00$ & $1.473 \mathrm{E}+00$ & $1.473 \mathrm{E}+00$ & $1.473 \mathrm{E}+00$ & $1.473 \mathrm{E}+00$ & $1.473 \mathrm{E}+00$ & $1.472 \mathrm{E}+00$ & $8.030 \mathrm{E}-04$ \\
\hline $\mathrm{H} 2$ & $0.000 \mathrm{E}+00$ & $0.000 \mathrm{E}+00$ & $0.000 \mathrm{E}+00$ & $2.956 \mathrm{E}+02$ & $2.956 \mathrm{E}+02$ & $3.728 \mathrm{E}+02$ & $3.728 \mathrm{E}+02$ & $3.929 \mathrm{E}+02$ & $3.929 \mathrm{E}+02$ & $3.929 \mathrm{E}+02$ & $7.181 \mathrm{E}-03$ \\
\hline $\mathrm{CO}$ & $0.000 \mathrm{E}+00$ & $0.000 \mathrm{E}+00$ & $0.000 \mathrm{E}+00$ & $9.854 \mathrm{E}+01$ & $9.854 \mathrm{E}+01$ & $2.137 \mathrm{E}+01$ & $2.137 \mathrm{E}+01$ & $1.193 \mathrm{E}+00$ & $1.193 \mathrm{E}+00$ & $0.000 \mathrm{E}+00$ & $0.000 \mathrm{E}+00$ \\
\hline $\mathrm{CO} 2$ & $0.000 \mathrm{E}+00$ & $0.000 \mathrm{E}+00$ & $0.000 \mathrm{E}+00$ & $0.000 \mathrm{E}+00$ & $0.000 \mathrm{E}+00$ & $7.717 \mathrm{E}+01$ & $7.717 \mathrm{E}+01$ & $9.735 \mathrm{E}+01$ & $9.735 \mathrm{E}+01$ & $9.830 \mathrm{E}+01$ & $2.414 \mathrm{E}-01$ \\
\hline $\mathrm{O} 2$ & $0.000 \mathrm{E}+00$ & $0.000 \mathrm{E}+00$ & $1.000 \mathrm{E}+00$ & $0.000 \mathrm{E}+00$ & $0.000 \mathrm{E}+00$ & $0.000 \mathrm{E}+00$ & $0.000 \mathrm{E}+00$ & $0.000 \mathrm{E}+00$ & $0.000 \mathrm{E}+00$ & 4.231E-01 & 1.135E-04 \\
\hline Total Flow lbmol/hr & $1.000 \mathrm{E}+02$ & $4.000 \mathrm{E}+02$ & $1.000 \mathrm{E}+00$ & $6.971 \mathrm{E}+02$ & $6.971 \mathrm{E}+02$ & $6.971 \mathrm{E}+02$ & $6.971 \mathrm{E}+02$ & $6.971 \mathrm{E}+02$ & $6.971 \mathrm{E}+02$ & $5.558 \mathrm{E}+02$ & $1.417 \mathrm{E}+02$ \\
\hline Temperature $\mathrm{F}$ & $6.800 \mathrm{E}+01$ & $6.800 \mathrm{E}+01$ & $6.800 \mathrm{E}+01$ & $1.292 \mathrm{E}+03$ & $8.960 \mathrm{E}+02$ & $8.960 \mathrm{E}+02$ & $4.280 \mathrm{E}+02$ & $4.280 \mathrm{E}+02$ & $2.480 \mathrm{E}+02$ & $1.200 \mathrm{E}+02$ & $1.200 \mathrm{E}+02$ \\
\hline Pressure psi & $1.500 \mathrm{E}+01$ & $1.500 \mathrm{E}+01$ & $1.500 \mathrm{E}+01$ & $1.500 \mathrm{E}+01$ & $1.500 \mathrm{E}+01$ & $1.500 \mathrm{E}+01$ & $1.500 \mathrm{E}+01$ & $1.500 \mathrm{E}+01$ & $1.500 \mathrm{E}+01$ & $1.500 \mathrm{E}+01$ & $1.500 \mathrm{E}+01$ \\
\hline Enthalpy Btu/lbmol & $-3.211 \mathrm{E}+04$ & $-1.230 \mathrm{E}+05$ & $-6.306 \mathrm{E}+01$ & $-4.220 \mathrm{E}+04$ & $-4.546 \mathrm{E}+04$ & $-4.723 \mathrm{E}+04$ & $-5.101 E+04$ & $-5.151 E+04$ & $-5.292 \mathrm{E}+04$ & $-4.141 \mathrm{E}+04$ & $-1.222 \mathrm{E}+05$ \\
\hline
\end{tabular}

The system components are as identified in Fig. 3.1.1 and as described in Section 3.1.1. The data is normalized to an inlet flow of $100 \mathrm{lbmol} / \mathrm{hr}$ of methane. The reformate composition at each reformer stage is summarized in Table 3.1.2.

Table 3.1.2 Reformer stream composition at each stage.

\begin{tabular}{|l|c|c|c|c|}
\hline Component, mol\% & SMR OUT & HTS OUT & LTS OUT & PROX OUT \\
\hline $\mathrm{H} 2 \mathrm{O}$ & 43.25 & 32.18 & 29.28 & 11.28 \\
\hline $\mathrm{CH} 4$ & 0.21 & 0.21 & 0.21 & 0.26 \\
\hline $\mathrm{H} 2$ & 42.40 & 53.47 & 56.37 & 70.69 \\
\hline $\mathrm{CO}$ & 14.14 & 3.07 & 0.17 & 0.00 \\
\hline $\mathrm{CO} 2$ & 0.00 & 11.07 & 13.97 & 17.69 \\
\hline $\mathrm{O} 2$ & 0.00 & 0.00 & 0.00 & 0.08 \\
\hline
\end{tabular}

Reformer Sizing - The proposed minigrid will operate from a total of five fuel cell units. The nominal power outputs are $100 \mathrm{~kW}, 75 \mathrm{~kW}, 75 \mathrm{~kW}, 25 \mathrm{~kW}$, and $25 \mathrm{~kW}$, so each reformer must be capable of providing enough hydrogen to operate at a peak capacity of $300 \mathrm{~kW}$. In the GenSys $5 \mathrm{~kW}$ system, the AC output power is lower than the DC power from the PEM stack due to the electrical requirements of the system. In the larger systems, the $\mathrm{AC}$ requirements are expected to be a much smaller fraction of the DC output power.

Simulation data for AC power scheduling to the minigrid is shown in Fig. 3.1.8. Hydrogen consumption at peak output power must be capable of supporting a $300 \mathrm{~kW}$ load. Since maintenance considerations require the ability to shut down one reformer with no effect on 
hydrogen supply to the power grid, each reformer must independently be able to supply enough hydrogen to operate the entire grid.

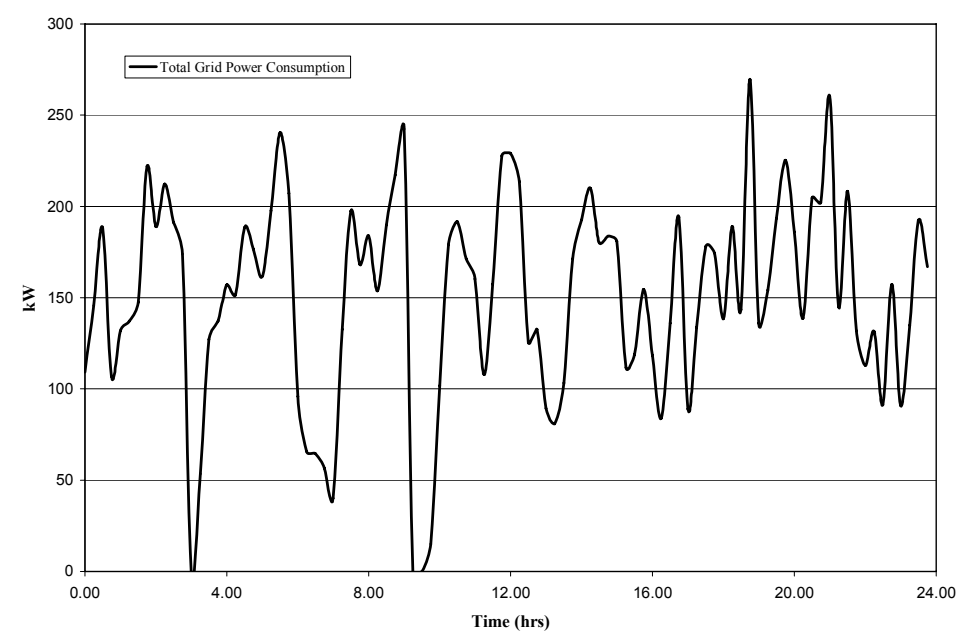

Fig. 3.1.8 Typical minigrid power demand.

The total power use over a typical 24-hour period was integrated to give total power consumption. This figure was used to calculate 24-hour methane consumption and hydrogen production from the ASPEN reformer model. Results are summarized in Table 3.1.3.

Table 3.1.3 Total daily power, methane, and hydrogen demand.

\begin{tabular}{|c|c|c|c|c|}
\hline AC Pwr & CH4 & H2 & CH4 & H2 \\
\hline kWh & lbmol & lbmol & cuft & cuft \\
\hline 3,582 & 211 & 507 & 75,890 & 182,136 \\
\hline
\end{tabular}

The 24-hour full capacity of the power grid is $7,200 \mathrm{kWh}$, so the scenario presented in Fig. 3.1.8 shows the grid operating at approximately $50 \%$ capacity. For a reformer operating at full capacity, the hydrogen production would be 365,000 cuft/day of hydrogen at STP, approximately half of which would be consumed by the fuel cells and half of which could be compressed and stored.

\subsection{Hydrogen Purification System}

\subsubsection{Purification by Drying and CO2 Removal}

From Table 3.1.2 it can be seen that the gas stream from the PROX is approximately $70 \%$ hydrogen, $11 \%$ water and $18 \% \mathrm{CO} 2$ with trace amounts of methane and oxygen. The high hydrogen content and essentially zero nitrogen content is due to the fact that reforming reaction chosen for the initial reforming stage is the endothermic steam methane reforming reaction. 


$$
\mathrm{H}_{2} \mathrm{O}+\mathrm{CH}_{4} \rightarrow 3 \mathrm{H}_{2}+\mathrm{CO}
$$

rather than the exothermic partial oxidation reaction

$$
\frac{1}{2} \mathrm{O}_{2}+\mathrm{CH}_{4} \rightarrow 2 \mathrm{H}_{2}+\mathrm{CO}
$$

In many reformer designs, the two reactions operate in tandem in an autothermal reactor (ATR) [34][35]. The advantage is that the energy from the partial oxidation reaction can be directly utlilized to support the steam methane reforming reaction. The disadvantage is that oxygen must be supplied in the form of air, which adds nitrogen to the process. Since nitrogen is inert, it ends up in the reformate stream and must be removed to purify the hydrogen. In the simulated reformer, the steam methane route was chosen for the reason that the reformer stream does not contain nitrogen.

Table 3.2.1 shows the composition of the reformate from the PROX. As can be seen, the composition after water and $\mathrm{CO} 2$ removal has a purity of over $99 \%$. Although this purity is not sufficient for operating an automotive fuel cell, it is acceptable for storage for later operation of the minigrid fuel cell system.

Table 3.2.1 PROX outlet composition

\begin{tabular}{|l|c|c|c|}
\hline $\begin{array}{c}\text { Component, } \\
\text { mol\% }\end{array}$ & $\begin{array}{c}\text { PROX } \\
\text { OUT }\end{array}$ & $\begin{array}{c}\text { PROX } \\
\text { OUT } \\
\text { (DRY) }\end{array}$ & $\begin{array}{c}\text { PROX OUT } \\
\text { (CO2 } \\
\text { REMOVED) }\end{array}$ \\
\hline $\mathrm{H} 2 \mathrm{O}$ & 11.28 & - & - \\
\hline $\mathrm{CH} 4$ & 0.26 & 0.30 & 0.37 \\
\hline $\mathrm{H} 2$ & 70.69 & 79.68 & 99.52 \\
\hline $\mathrm{CO}$ & 0.00 & 0.00 & 0.00 \\
\hline $\mathrm{CO} 2$ & 17.69 & 19.93 & - \\
\hline $\mathrm{O} 2$ & 0.08 & 0.09 & 0.11 \\
\hline
\end{tabular}

Water removal by thermal swing adsorption and $\mathrm{CO}_{2}$ removal by acid gas scrubbing are processes currently used in industry. At the flow rates in the proposed system, an acid gas scrubber and a thermal swing zeolite drying unit are approximately the same complexity as a small pressure swing adsorption unit, with the disadvantage that a liquid waste stream is generated from the $\mathrm{CO}_{2}$ scrubber.

\subsubsection{Purification by Pressure-Swing Adsorption (PSA)}

The PSA process is based on the principle that adsorbents are capable of adsorbing more impurities at a higher gas-phase partial pressure than at a lower partial pressure. The impurities are adsorbed in a fixed-bed adsorber at high pressure and then rejected as the system pressure "swings" to a lower level. Hydrogen is essentially not adsorbed. The ability to completely adsorb impurities allows the production of a hydrogen product with very high ( $>99.9$ vol-\%) purity. Figure 3.2.1 shows a PSA system block diagram. 


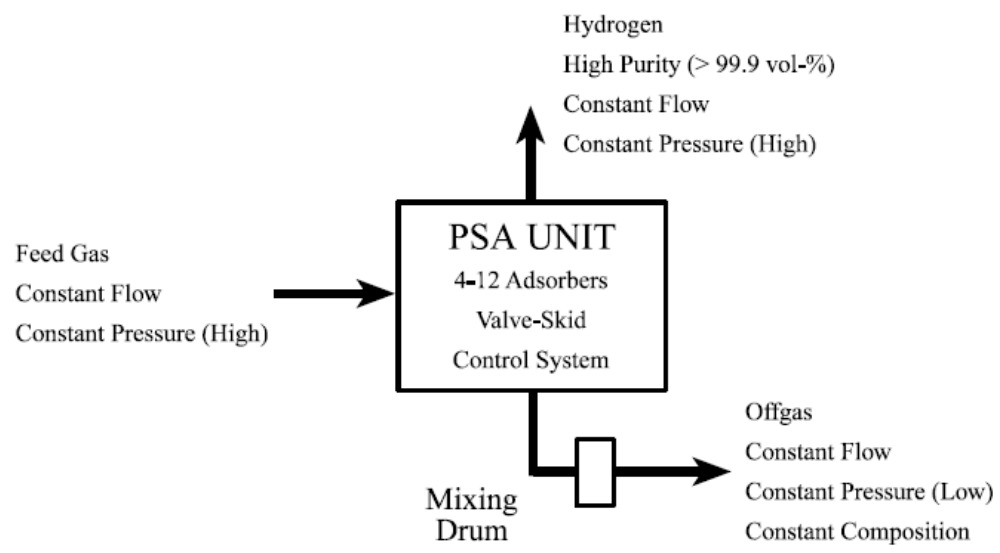

Figure 3.2.1 PSA system block diagram [36].

The feed gas from the reformer enters the unit and is sequentially passed through multiple fixed adsorption beds filled with zeolite. At the outlet of each bed, the hydrogen concentration increases. The impurities are rejected at low pressure from the offgas stream. A complete pressure-swing cycle consists of five basic steps:

- Adsorption

- Cocurrent depressurization

- Countercurrent depressurization

- Purge at low pressure

- Repressurization

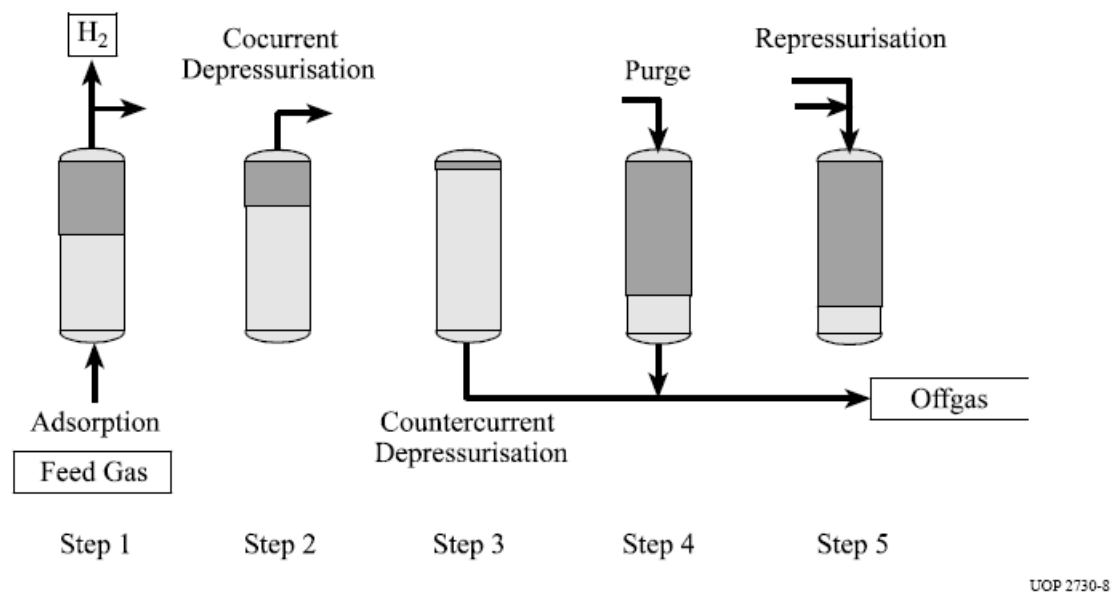

Figure 3.2.2 Multistage PSA process [36]. 
Figure 3.2.2 shows a schematic of a typical multibed PSA system. Pressurization and depressurization are accomplished by means of a series of connecting valves. Much care must go into the design to preserve pressure differentials in such a way that energy need not be added by compression between stages.

\section{Adsorption (Step $1 \rightarrow 2$ )}

The feed gas is introduced at the high adsorption pressure, impurities are adsorbed, and highpurity hydrogen is withdrawn as product. Flow is normally in the upward direction. When an adsorber has reached its adsorption capacity, it is taken off-line, and the feed is automatically switched to a fresh adsorber. This practice maintains constant feed and product flows.

\section{Cocurrent depressurization (Step $2 \rightarrow 3$ )}

To recover the hydrogen trapped in the adsorbent void spaces in the adsorber, the adsorber is depressurized from the product side in the same direction as the feed flow (cocurrent), and highpurity hydrogen is withdrawn. This cocurrent depressurization takes place in typically one to six discrete steps. The hydrogen is used internally in the system to repressurize (equalize) and purge other adsorbers.

\section{Countercurrent depressurization (Step $3 \rightarrow 4$ )}

The saturated adsorber is then generated in a series of steps. After the hydrogen recovery steps are complete, the impurity fronts have migrated to the top of the adsorbent bed, and the bed has no remaining capacity. The bed is then partly regenerated by depressurizing towards the feed end, and the desorbed impurities are rejected to the PSA offgas.

\section{Purge at low pressure (Step $4 \rightarrow 5$ )}

The adsorbent is then purged with high-purity hydrogen (taken from another adsorber on cocurrent depressurization) at constant offgas pressure to further regenerate the bed.

\section{Repressurization (Step $5 \rightarrow \mathbf{1}$ )}

The adsorber is then repressurized with hydrogen prior to being returned to the feed step. The hydrogen for repressurization is provided from the cocurrent depressurization (step 2 above) and with a slipstream from the hydrogen product. When the adsorber has reached the adsorption pressure, the cycle has been completed, and the adsorber is ready for the next adsorption step. PSA hydrogen purification is a relatively mature process that has been in use in industry since 1966. Several companies offer turnkey PSA systems for hydrogen purification. The system description and diagrams in this report were taken from publications by UOP, a major manufacturer, installer, and supporter of hydrogen purification PSA equipment [36].

\section{Feed and Offgas Pressure}

ASPEN simulation of a PSA process is a complex procedure and is highly dependant on operating pressure. The pressure drop from feed to product is relatively small, and the product is available at a pressure about 10 psi lower than the feed. This parameter has the strongest influence on hydrogen recovery. The lower the offgas pressure, the higher the hydrogen recovery possible, and the lower the investment costs for a fixed product rate. A ratio of at least 4 to 1 is typically required between the absolute feed pressure and the absolute waste pressure. Table 3.2.2 summarizes the design parameters from the simulation. 
Table 3.2.2 Summary of PSA parameters

\begin{tabular}{|c|c|}
\hline $\begin{array}{c}\text { Number of } \\
\text { Adsorbers }\end{array}$ & 4 \\
\hline $\begin{array}{c}\text { PSA inlet pressure, } \\
\text { psi }\end{array}$ & 100 \\
\hline $\begin{array}{c}\text { PSA offgas } \\
\text { pressure, psi }\end{array}$ & 15 \\
\hline $\begin{array}{c}\text { H2 pressure to } \\
\text { storage, psi }\end{array}$ & 90 \\
\hline $\begin{array}{c}\text { H2 volume to } \\
\text { storage, cuft/hr }\end{array}$ & 15,000 \\
\hline H2 purity, \% & 99.9997 \\
\hline
\end{tabular}

The hydrogen is of sufficient purity to utilize as fuel for the minigrid system and as commercial fuel for automotive use. The product pressure is not sufficient for high density storage, however, and must be compressed.

\subsection{Hydrogen Compression and Storage System}

Storage of hydrogen presents a number of technical challenges, since hydrogen is the lightest element, and as such, has the lowest density. Three storage techniques were investigated for use with the reformer system: mechanical compression and storage in a pressure vessel, liquefaction, and storage and compression using metal hydride systems.

\subsubsection{Mechanical Compression and Vessel Storage}

The flow rate from a single reformer is approximately $15,000 \mathrm{cuft} / \mathrm{hr}$ at $90 \mathrm{psi}$ from the PSA outlet. At $5000 \mathrm{psi}$, the required storage volume per hour would be approximately $270 \mathrm{cuft}$. The required size of a cylindrical tank to contain 24 hours of production at 5000 psi would be $10 \mathrm{ft}$ in diameter by $80 \mathrm{ft}$ in length. ASPEN simulation indicates that adiabatic compression would consume approximately $10 \%$ of the energy realized from the hydrogen. Mechanical compressor efficiency would be approximately $75 \%$, with a combined thermodynamic efficiency of approximately $35 \%$.

\subsubsection{Liquifaction}

Liquid storage densities for hydrogen are attractive, and at $71 \mathrm{~kg} / \mathrm{m}^{3}$, offer storage densities approximately 30 times as high as gas phase storage at 5000psi. ASPEN simulations indicate that the liquefaction process is extremely energy intensive, with a Carnot efficiency of approximately 7\%. Actual plant operation data from Linde Kryotechnik AG indicates that the liquefaction process consumes a minimum of $30 \%$ of the energy available from the hydrogen. For a fixed minigrid system, there is no compelling advantage to liquid storage. The added energy cost and necessity to handle and transport cryogenic materials make on-site liquefaction of hydrogen unattractive.

\subsubsection{Metal Hydride Compression and Storage}

Hydride compression is an absorption-based system that uses the properties of reversible metal hydride alloys to compress hydrogen. Hydrogen is absorbed into an alloy bed at ambient temperature and, subsequently, is released at elevated pressure when the bed is heated. 
Compression energy can be supplied by hot water and, for the very high pressures being considered for on-board hydrogen storage, at a fraction of the energy cost of mechanical compression [37].

A metal hydride compressor is actually a Carnot-cycle heat engine. The reported efficiency is approximately $50 \%$ of Carnot efficiency, which is based on the difference between a hot energy source for hydrogen adsorption and a cold energy source for heat rejection. In the reformer system described above, the hot water source from the reformer is available at approximately $90 \mathrm{C}$ and cooling water is available at approximately $30 \mathrm{C}$. Carnot efficiency for this temperature difference is approximately $15 \%$, so a metal hydride compressor would operate at an efficiency of about 7\%[38]. Although this efficiency is much lower than mechanical compression, the heat energy from a reformer is essentially "free" and cannot be utlilzed to generate steam and is difficult to reclaim in any way other than for heating water for domestic use.

There is some experimental work that indicates that compression and purification can be simultaneously done by utilization of metal hydrides. DaCosta and Golben reported the use of a metal hydride based compression system that can compress and purify hydrogen with significant energy cost reduction over mechanical compression [38]. The researchers reported results from a pilot-scale compressor and test stand that demonstrated hydride compression to 8,000 psia with a clear path to 10,000 psia. The system was built and is being operated to determine the extent to which a hydride compressor can both tolerate and remove impurities from the hydrogen stream.

The compressor includes three purification techniques: passive purification for $\mathrm{H} 2 \mathrm{O}$ and $\mathrm{O} 2$, elevated temperature desorption for $\mathrm{CO}$ and $\mathrm{CO} 2$, and inert gas venting for $\mathrm{N} 2$ and $\mathrm{CH} 4$. Competitive analysis of mechanical and hydride compression to 5,000 psia indicates that hydride compression energy cost is $60 \%$ less than mechanical compression [39].

Although metal hydride based storage and compression of hydrogen has been around for over 20 years, commercialization is only recently emerging. Ergenics, a division of HERA USA Inc. in Ringwood, NJ is currently developing and marketing a series of products. In the application of the proposed minigrid reformer system, however, the flow rates and volumes involved are at least an order of magnitude higher than the current state of the technology [40].

\subsection{Summary}

Based on the simulation results and data obtained from the GenSys $5 \mathrm{~kW}$ fuel cell system, the following recommendations are made.

\subsubsection{Reformers}

Two steam methane reformers should be utilized, each with supply capacities and flow rates indicated in Table 3.4.1

Table 3.4.1 Reformer electrical supply capacity and maximum flow rates.

\begin{tabular}{|c|c|c|c|c|}
\hline AC Pwr & CH4 & H2 & CH4 & H2 \\
\hline $\mathrm{kW}$ & $\mathrm{lbmol} / \mathrm{hr}$ & $\mathrm{lbmol} / \mathrm{hr}$ & $\mathrm{cuft} / \mathrm{hr}$ & $\mathrm{cuft} / \mathrm{hr}$ \\
\hline 300 & 20 & 48 & 7,190 & 17,260 \\
\hline
\end{tabular}




\subsubsection{Purification}

Purification will be performed by 4-stage PSA. Outlet purity will be a minimum of $99.999 \%$ with $<10 \mathrm{ppm}$ CO. Primary pressure to the PSA will be 100psi. Product pressure will be $90 \mathrm{psi}$.

\subsubsection{Compression and Storage}

Two underground storage tanks should be used, each with a diameter of $10 \mathrm{ft}$ and a length of $80 \mathrm{ft}$. Hydrogen reformate from the PSA system will be pressurized to 5000psi with a mechanical multistage compressor. Tank storage capacities will each be 24 hours of hydrogen supply to the minigrid at full rated power. At full capacity, the tanks will hold approximately $500 \mathrm{~kg}$ of hydrogen.

\section{Smart Energy Management of FC Application and Energy Conservation 4.1 Energy Conservation Algorithm}

In year four of the GIFCO project, the focus of energy management shifted from managing power for residential fuel cell power plant operation to energy conservation. Based on previous year data and observations, heating elements are the largest consumer of power in a typical allelectric home, and offer the most opportunities for conservation. The electric hot water heater and HVAC system are the target appliances of the algorithm, based on the typical temperature and schedule based management algorithms currently employed worldwide. The algorithm developed in year four focuses on demand based management, rather than schedule or temperature based management typically applied to these appliances. Radiance collected water flow and temperature data for the project in an all-electric home that is occupied by a dual income family with no children. The data spans 21 days and is in 15 second intervals. The DAQ used to collect the data is shown in Fig. 4.1.1.

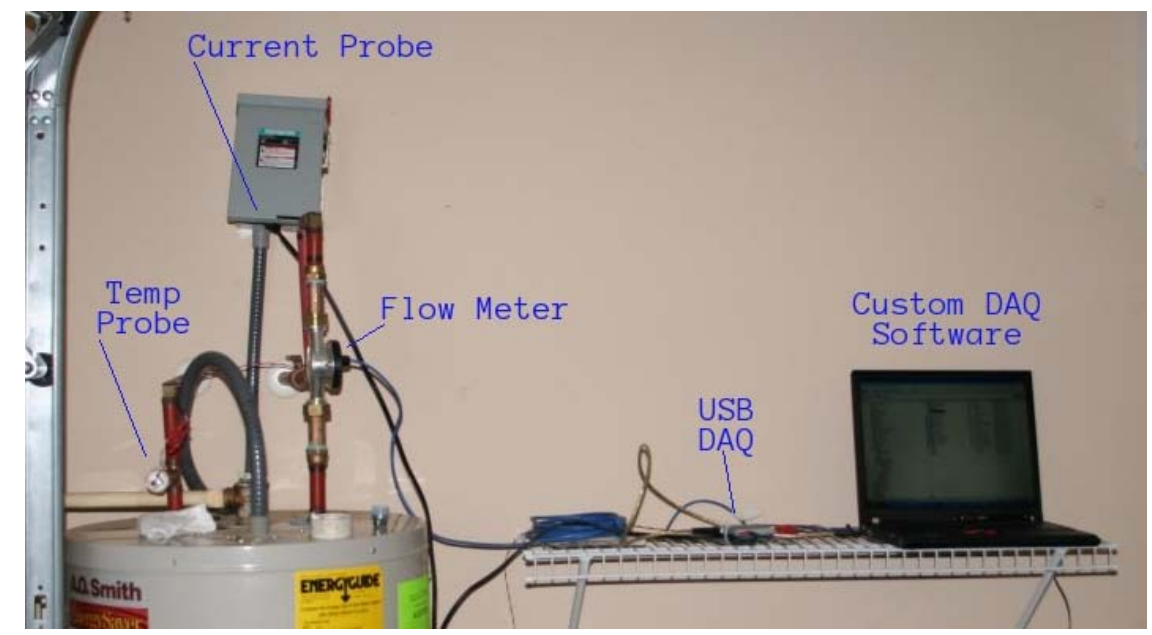

Fig. 4.1.1 DAQ System

After analyzing the data collected, Radiance designed the conservation algorithm shown in Fig. 4.1.2. The algorithm determines demand for water based on real-time conditions (water flow), and based on probability of water flow, which is generated by a neural network. A back- 


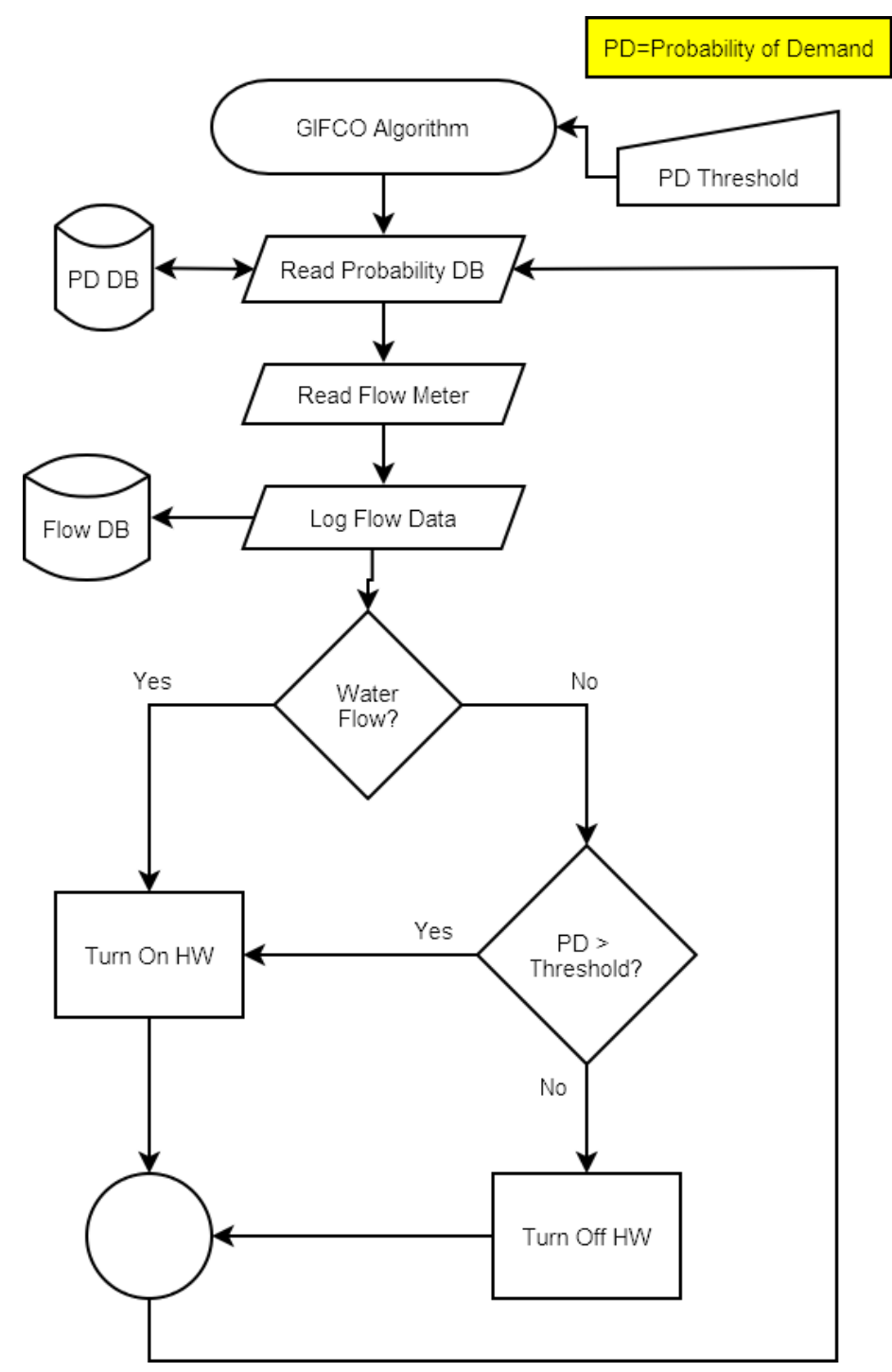

Fig. 4.1.2: Energy Conservation Algorithm.

propagation neural network consisting of two inputs, time of day and day of week, and one output, flow. The network is designed to train each day, using the most recent 21 days of water flow data, averaged into 15 minute intervals. This data is stored on the controller in an SQL database, which is populated during normal operation of the run-time algorithm. Each night, at midnight, a scheduled process runs that cleans up the database, deleting old records, and generates a training set for the neural network. The neural network runs, and the results are stored in the database. The neural network has one hidden layer that consists of a variable 
number of neurons. Between four and six neurons gives the best balance of training speed vs. accuracy. The output is a number between zero and one, and represents the probability of demand for water in \%. The neural network is depicted in Fig. 4.1.3.

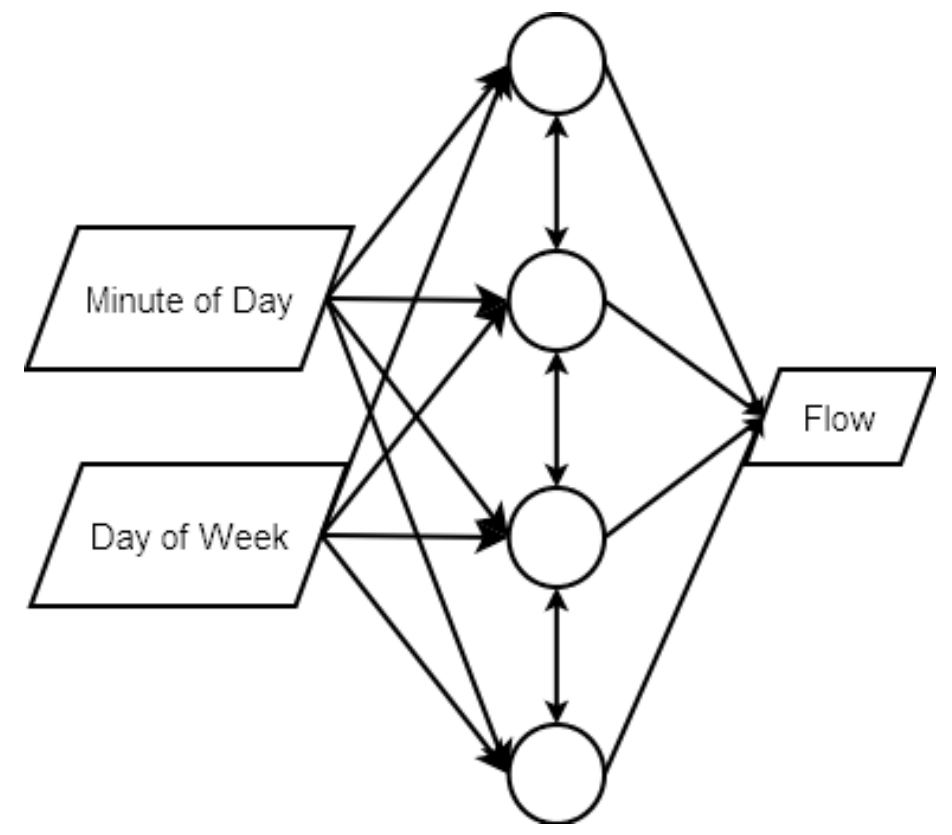

Fig. 4.1.3: GIFCO Neural Network.

\subsection{Energy Conservation Hardware Development}

Radiance designed a custom hardware controller to run the management algorithm that had the following goals:

- Linux operating system

- Ease of software development

O Ease of administration

O Security

O Stability

○ Network connectivity

- flexible I/O

$\bigcirc$ to accommodate multiple inputs/outputs

O future expansion

- low power

O can run from batteries

- high performance

○ $400 \mathrm{mHz}$ processor with floating point emulation

○ High volume data handling 
Radiance accomplished the above goals by using a Gumstix ${ }^{\mathrm{TM}} \mathrm{SBC}$ as the basis for the controller, and then designing a custom controller interface board and relay board around the Gumstix. The Gumstix is a Linux based computer based on an Intel PXA 255 processor, 64MB of Strata flash memory, and 16MB of SDRAM. A block diagram of the GIFCO controller is shown in Fig. 4.2.1.

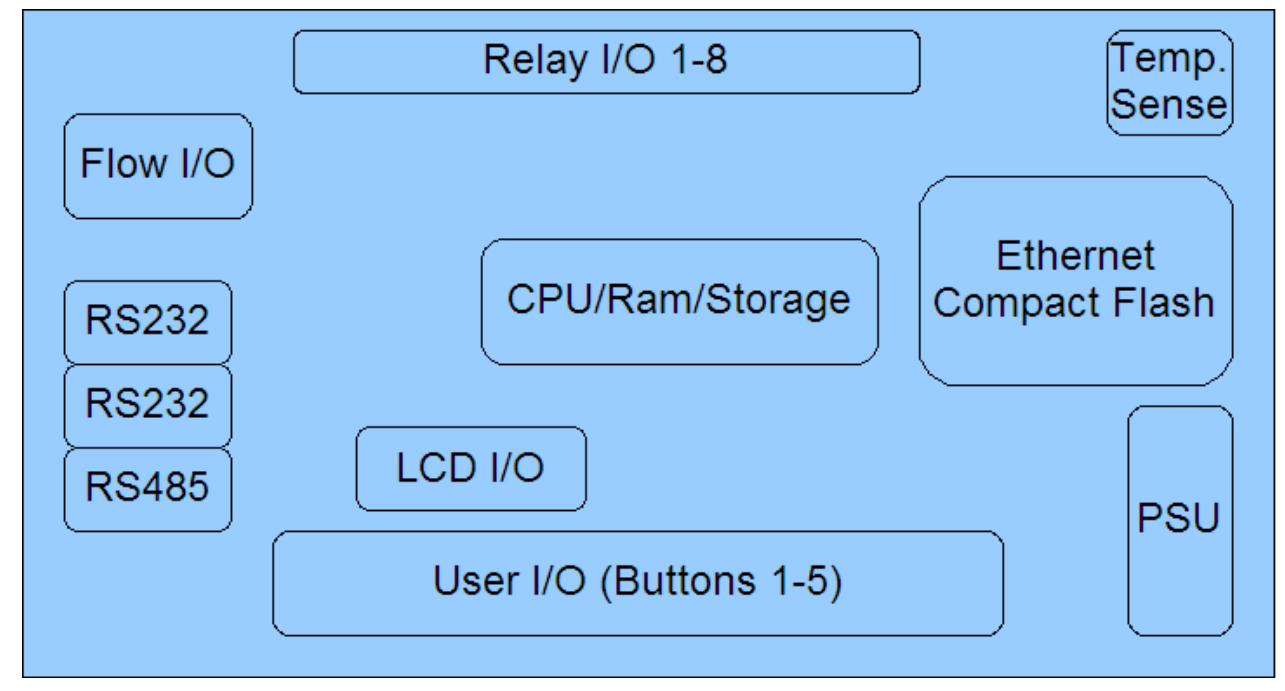

Fig. 4.2.1 Controller Block Diagram.

The complete GIFCO controller system is depicted in Fig 4.2.2. The controller reads the water flow meter (A Flo-Cat/Sea Metrics SEB-075), which outputs a square wave pulse proportional to water flow. The flow meter outputs 174 pulses per gallon of water flowed. The rate of flow is determined by the following formula:

$$
G P M=\frac{60}{t} / 174
$$

where $\mathrm{t}=$ time between pulses. The power to the hot water heater is controlled by a high power contactor, which is controlled by a solid state relay, which is in turn controlled by one of the eight small relays on the GIFCO controller board. The system also is designed to control and manage the HVAC system in a home, but due to time and budget constraints, only the hot water heater control system was implemented. The theory of operation is exactly the same, but substituting $\mathrm{CO} 2$ in the HVAC return air duct for water flow as an indicator for demand. 


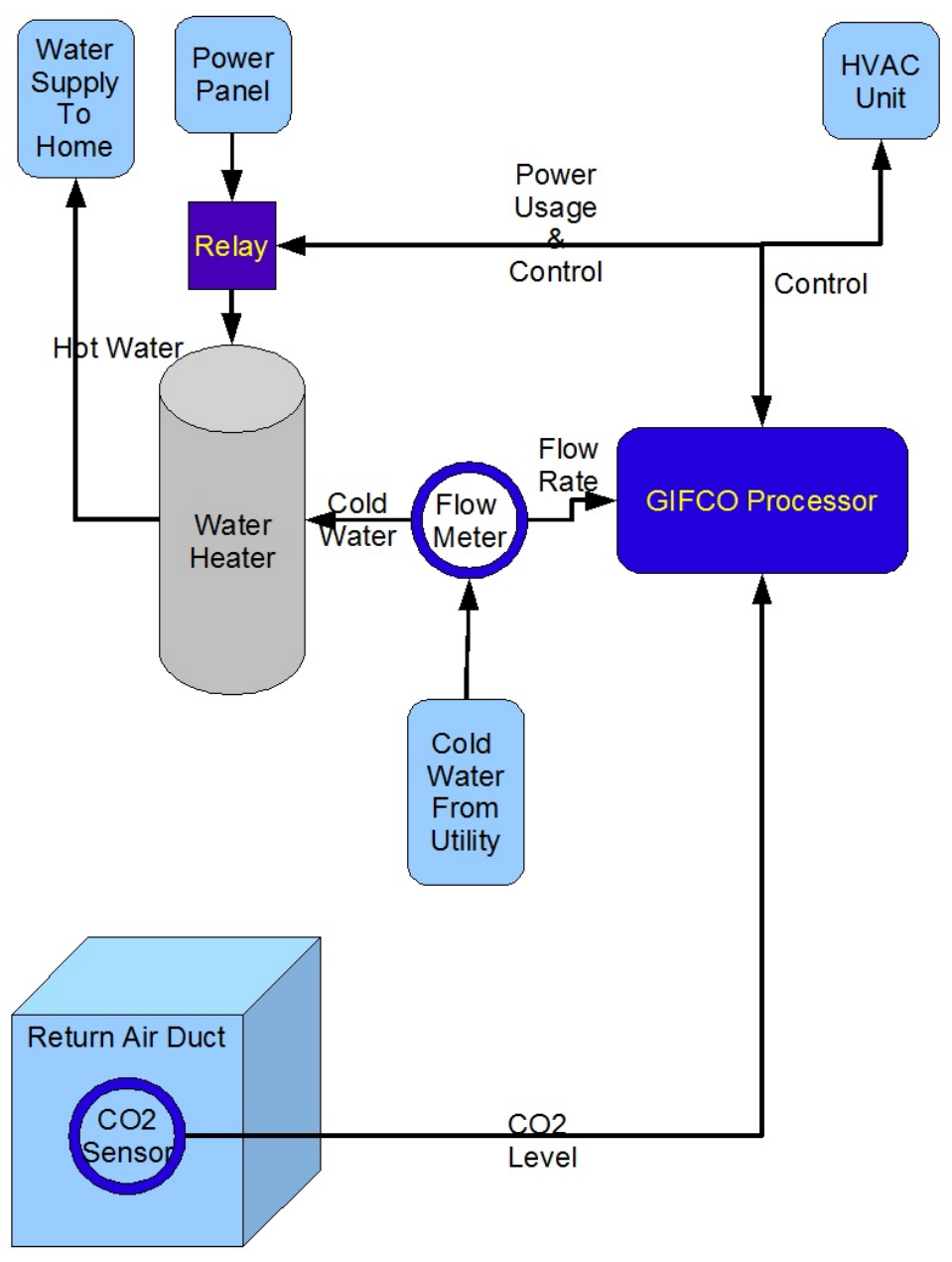

Fig. 4.2.2 GIFCO Controller System.

\subsection{Pilot Program Test and Analysis}

Using the data collected with the DAQ, Table 4.3.1 describes the observations that were made. Based on the data collected, and the associated Probability of Demand (PD), Radiance tuned the algorithm to provide best-case energy conservation, which turns the hot water heater on if hot water will be in demand within 15 minutes. This gives time for the water temperature to recover in a standard electric hot water heater prior to any water being consumed. The PD time interval can be easily tuned to allow faster or slower recovery times. Using this data, potential energy savings while under management by the GIFCO algorithm are listed in Table 4.3.2. 
Table 4.3.1 Data Collection Observations.

\begin{tabular}{|l|l|}
$\begin{array}{l}\text { Cost of } 1 \mathrm{kWh} \text { of power in the state that data was } \\
\text { collected }^{1}\end{array}$ & $\$ .063762 / \mathrm{kWh}$ \\
\hline Data collection period & 21 days $/ 513$ hours \\
\hline $\begin{array}{l}\text { Average power consumption of HW heater used during } \\
\text { data collection: }\end{array}$ & $6.36 \mathrm{~kW}$ \\
$\begin{array}{l}\text { Time power was consumed by HW heater } \\
\text { Time water flowed }\end{array}$ & 76 hours \\
\hline Power consumed by HW heater & 21 hours \\
\hline Cost of power consumed by HW heater & $76 \times 6.36 \mathrm{~kW}=483 \mathrm{kWh}$ \\
\hline $\begin{array}{l}\text { Power consumed when no water was flowing } \\
\text { Cost of power consumed when no water was flowing }\end{array}$ & $483 \times .063762=\$ 30.80$ \\
\hline Power consumed while water was flowing & $59.5 \mathrm{hours} \times 6.360 \mathrm{~kW}=378 \mathrm{kWh}$ \\
\hline Cost of power consumed while water was flowing & 16 hours $\times 6.36 \mathrm{~kW}=101.76 \mathrm{kWh}$ \\
\hline Calculated average power usage per hour & $101.76 \mathrm{kWh} \times .063762=\$ 6.49$ \\
\hline Calculated average power usage per day & $.94 \mathrm{kWh}$ \\
\hline Calculated average power usage per month & $22.59 \mathrm{kWh}$ \\
\hline Calculated average power cost per month & $677 \mathrm{kWh}$ \\
\hline & $677 \mathrm{kWh} \times .063762=\$ 43.17$ \\
\hline
\end{tabular}

Table 4.3.2 Potential Energy Savings using GIFCO management algorithm.

\begin{tabular}{|ll|}
\hline Calculated power usage per month & $\begin{array}{l}16 \mathrm{a}+15 \mathrm{r} \times 6.36 \mathrm{~kW}=197.16 \mathrm{kWh} \\
\mathrm{a}=\text { actual usage, } \mathrm{r}=\text { time spent recovering } \\
\text { thermal losses (pre-demand) }\end{array}$ \\
Calculated power cost per month & $197.16 \times .063762=\$ 12.57$ \\
\hline Calculated net savings per month & $\$ 43.17-\$ 12.57=\$ 30.60$ \\
\hline Calculated net power savings per month & $677 \mathrm{kWh}-197.16 \mathrm{kWh}=479.84 \mathrm{kWh}$ \\
\hline Calculated savings per year & $\$ 30.60 \times 12=\$ 367.20$ \\
\hline Calculated power savings per year & $479.84 \mathrm{~kW} \times 12=5758.08 \mathrm{kWh}$ \\
\hline
\end{tabular}

Note: items labeled calculated were calculated by extrapolating the 513 hours of collected data across 30 days (720 hours). Savings do not account for seasonal variance in HW usage, as the data was collected over a single month in February 2006. 


\section{Neighborhood Level Energy Management}

\subsection{Neighborhood fuzzy controller design}

Based on analysis of the fuzzy logic control algorithm implemented in year 3 of the GIFCO project, Radiance determined that a fuzzy logic based control algorithm was not well suited for NLEM, when energy conservation is the target. The year 3 algorithm served to solve the issue of management at or near the output limit threshold of the PEM based fuel cell power plant (FCPP). In year four, the management focus shifted towards energy conservation. Radiance determined that the ideal neighborhood level control algorithm was the same algorithm that was used in a single home; i.e. a neural network that predicts demand, and manages energy based on demand rather that temperature or a time-based schedule. Since the problem set does not change when the scale of control increases, simply installing the neural network based controller throughout an entire neighborhood is an easy, economical way to save energy. To allow control of peak incident demand for power, an additional check is made in the control loop to determine if peak load shaving has been requested in the neighborhood. This is a signal that is sent out by the utility provider during times of heavy load. These signals could also be sent by the management software of a FCPP. The modified control algorithm is depicted in Fig. 5.1.1. By using the potential savings data from the single home, the potential savings in a 100 home neighborhood are shown in Table 5.1.1.

Table 5.1.1 NLEM cost and power savings.

\begin{tabular}{|l|l|}
\hline $\begin{array}{l}\text { Calculated single home power savings } \\
\text { per year }\end{array}$ & $5758.08 \mathrm{kWh}$ \\
\hline $\begin{array}{l}\text { Calculated single home cost savings per } \\
\text { year }\end{array}$ & $\$ 367.20$ \\
\hline $\begin{array}{l}\text { Calculated 100 Home neighborhood } \\
\text { power savings per year }\end{array}$ & $5758.08 \mathrm{kWh} \times 100=575,808 \mathrm{kWh}$ \\
\hline $\begin{array}{l}\text { Calculated 100 Home neighborhood } \\
\text { power savings per year }\end{array}$ & $\$ 367.20 \times 100=\$ 36,720.00$ \\
\hline
\end{tabular}




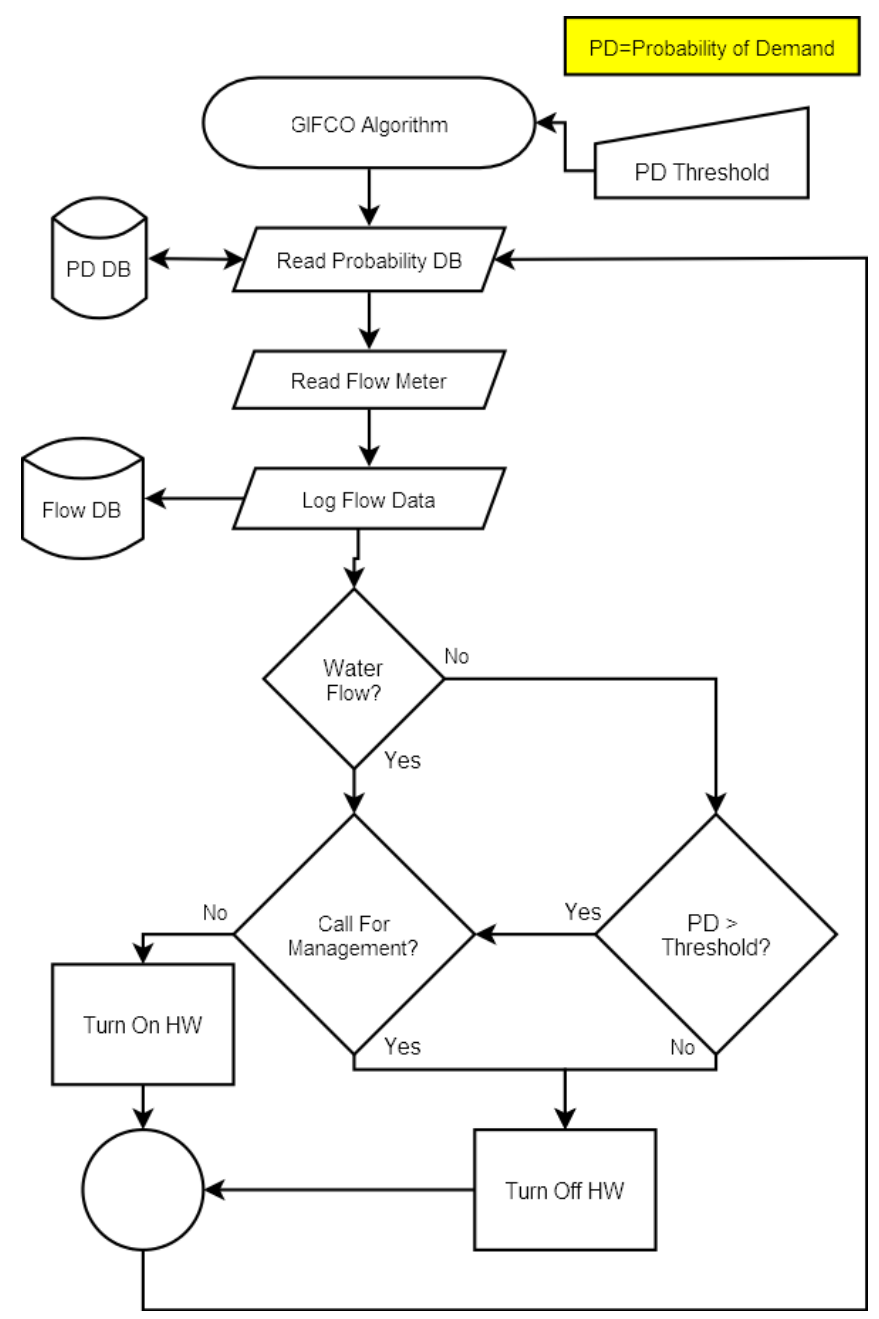

Figure 5.1.1 NLEM Modified GIFCO Algorithm.

\section{Coordination with the Electric Cooperative Industry}

Radiance provided a briefing of energy management techniques used in this project in an attempt to gage the desire of the Electric Cooperative Industry to invest in the technology. Radiance briefed the Vice-President of Marketing for Bowling Green Municipal Utilities on 11 December 2006, and the President of Palmetto Electric on 14 December 2006. The results and comments from those briefings are as follows.

Both organizations are committed, and have been committed for some time, to developing a lowcost solution for managing the demand for electricity use. Up until this point, they have been relegated to a Direct Load Control (DLC) application. DLC techniques provide the consumer with relief from energy costs, but this comes at a sacrifice since controls are applied without 
regard to consumer usage patterns. A technique that accounts for typical consumer usage is preferred. They also indicated that the primary targets for management opportunities are HVAC units and Hot Water Heaters.

They believe that hot water load control, when done properly, should be very low impact, and invisible to the customer. This means both the suppliers and users of electricity will benefit from cost savings that will result from this initiative. Hot water load control systems will contribute to the reduction of consumption thereby reducing peak load usage as well. This will result in savings realized at the Cooperatives as well.

The driving factor for both of these organizations is the price of the technology and associated period for return on investment, both from the consumer and Electric Cooperative perspectives. This will drive their ability to push the technology to market. The consensus is that when any reduction in overall electricity costs is achieved, it creates consumer desire.

\section{Smart Energy Management and Control for FC Based Small Power Application}

Fuel cell, which is one of the environmental-friendly alternative energy sources, can be used in a wide range of applications such as portable power, transportation, and distributed power generation [41]-[43]. In addition to large-scale power production, small fuel cells have recently attracted a lot of attention with some promising results in portable applications [42]. Small fuel cells are intended to replace conventional batteries in portable applications [44]. These fuel cells generally generate power in the range of micro-watt to $150 \mathrm{~W}$. The motivating force behind small fuel cell research is the necessity for higher energy density for portable applications [44]-[46]. For portable applications, the fuel cell should be small and able to operate at ambient conditions (pressure and temperature). The most promising fuel cell technologies for these applications are direct methanol fuel cells and proton exchange membrane (PEM) fuel cells [44]-[46].

PEM fuel cells have many unique features as compared to other types of fuel cells, such as relatively low operating temperature and high energy density [43]. In this part of research, a dynamic model of a PEM fuel cell system is presented for portable applications.

The dynamic modeling of fuel cells has become more important in order to simulate the behavior of physical fuel cells [47]. There are several dynamic fuel cell models reported in the literature [47][54]. Amphlett et. al. [8-10] have used a semi-empirical approach to the activation loss and predicting the voltage output of a Ballard Mark V 35-cell stack. A one-dimensional nonisothermal model has been presented in [51]. The model includes membrane hydration, the reacting gases, phase change of water in the electrodes and an energy equation. The dynamic electrical terminal model of PEM fuel cells was developed in [52]. Padulles et al. proposed a detailed dynamic model for the solid oxide fuel cells for power systems simulations [53]. ElSharkh et al. introduced a dynamic model for a stand-alone PEM fuel cell power plant [54]. Then, Uzunoglu and Alam simulated the PEM fuel cell model described in [54] using Matlab and Simulink for stand-alone residential applications [55].

The purpose of this part of research is to carry out laboratory experiments to determine the dynamic characteristics of a $100 \mathrm{~W}$ PEM fuel cell system for powering different ac or dc 
dynamic loads. In these experiments loads such as light bulbs, and laptop computer are used. The results obtained from the experiments are used to modify the model developed in [54] for portable application the PEM fuel cell.

\section{1 Laboratory Experiments}

Two types of experiment are carried out to determine the FC and load characteristics, namely, the transient and steady state responses. Description of the devices and instruments used in these experiments are as follows:

1. Direct hydrogen, $100 \mathrm{~W}, 16.2 \mathrm{~V}$ fuel cell (Jadoo Power), the fuel cell comes equipped with a two hydrogen storage which last for 3 hours of continuous use at maximum power.

2. Storage oscilloscope

3. 2-Fluke 43B power analyzer

4. Multimeters

5. Dell Inspiron 8000, Laptop computer

6. Bulb panel with different power bulbs

7. dc-ac inverter

\subsubsection{Transient response experiments}

To determine the PEM fuel cell dynamic characteristics, fuel cell is used to feed a dynamic load consists of different power value bulbs. The load is step up and down suddenly while monitoring the transient response of the output voltage from the fuel cell using a storage oscilloscope. The transient response for a load change of zero to $70 \mathrm{~W}$ and from $70 \mathrm{~W}$ to zero are shown in Figs. 7.1.1 and 7.1.2.

\subsubsection{Steady state response experiments}

In these tests two types of load are used such as bulbs panel and laptop computer. The voltage current and power are monitored during load changes. The response of the fuel cell power, voltage and current for an up/down incremental change in the load $(0$ to $70 \mathrm{~W})$ are shown in Figs. 7.1.3 to 7. 1.5.

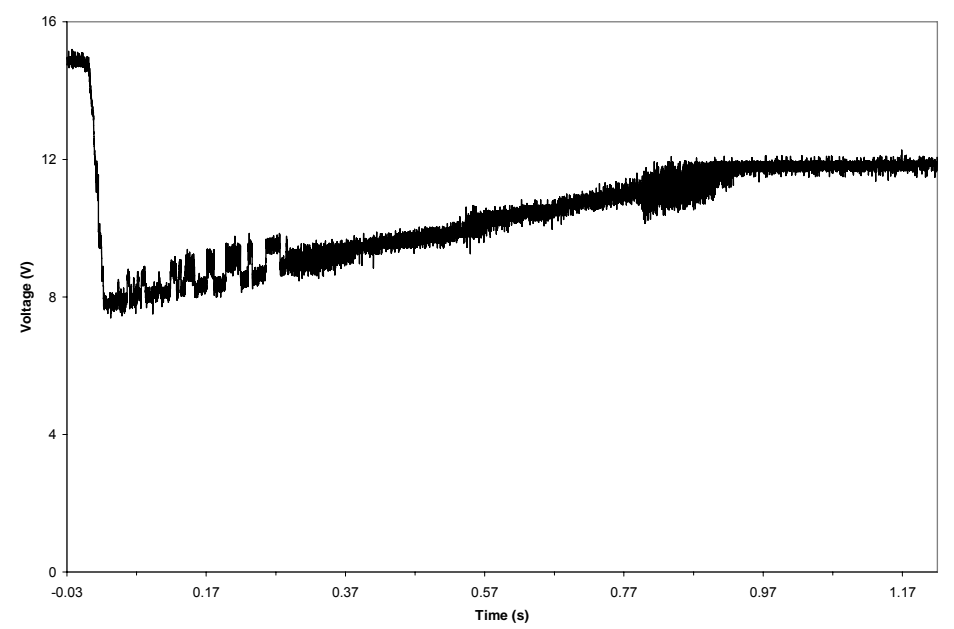

Fig. 7.1.1 Transient response of the fuel cell voltage to a step change in the load. 


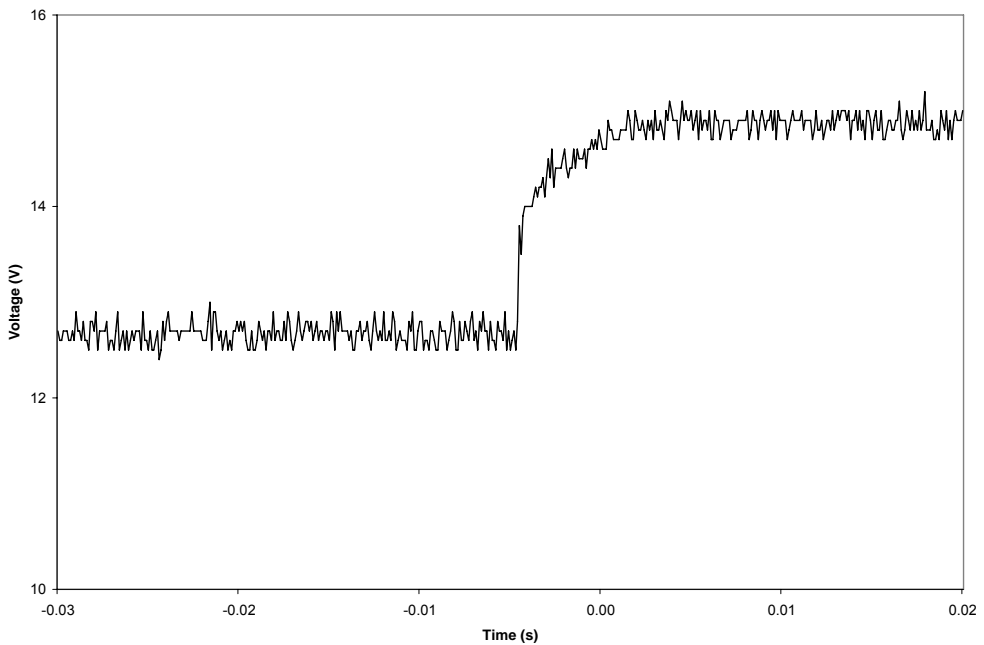

Fig. 7.1.2 Transient response of the fuel cell voltage to a step change in the load.

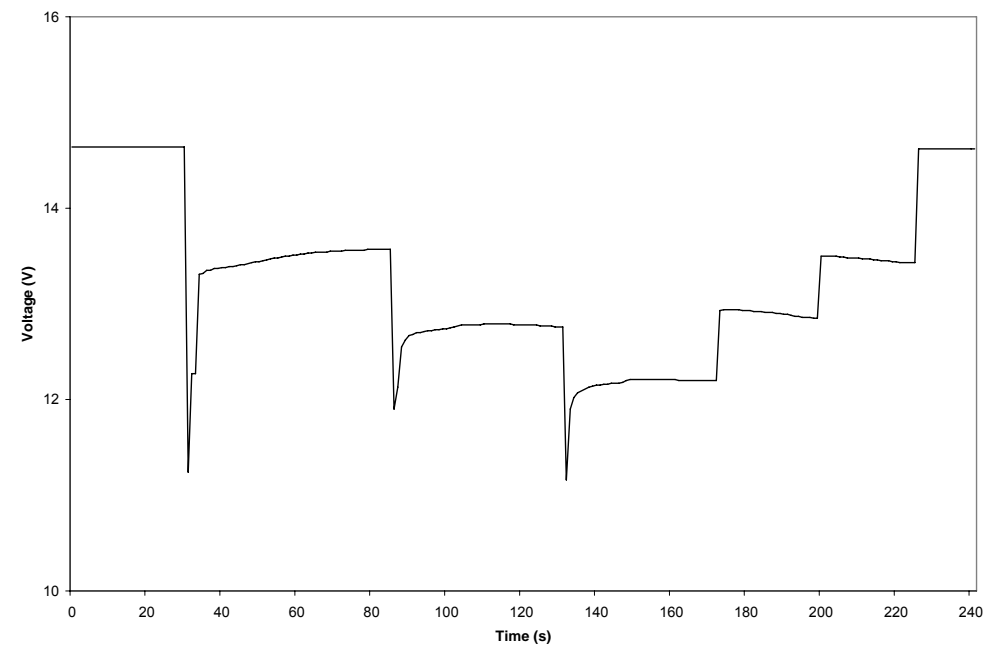

Fig. 7.1.3 Fuel cell voltage response to a step change in the load. 


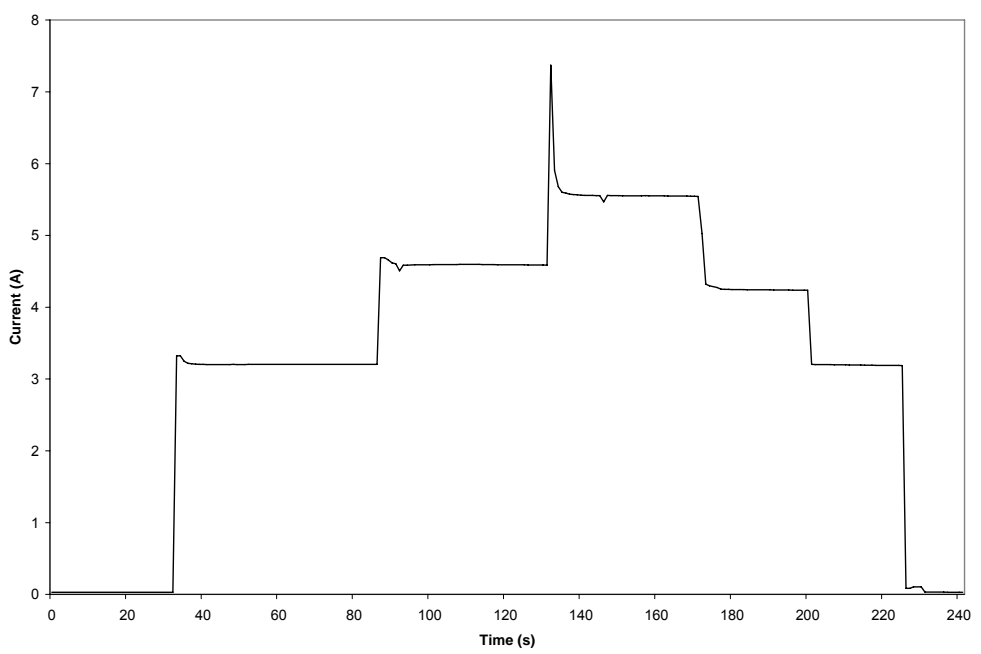

Fig. 7.1.4 Fuel cell current response to a step change in the load.

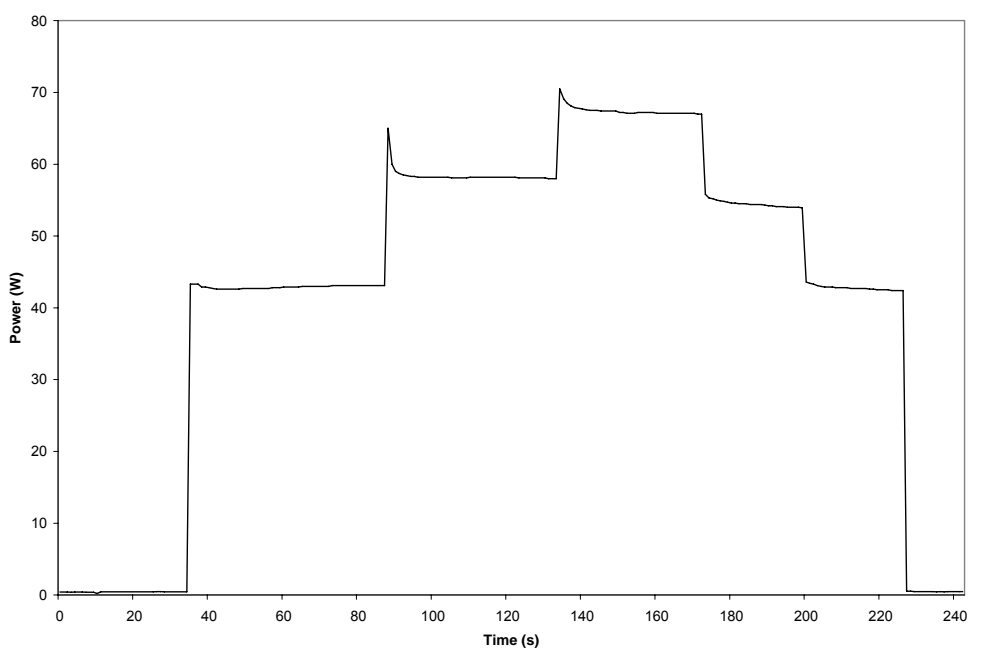

Fig. 7.1.5 Fuel cell power response to a step change in the load.

For the lab top there are three different experiments. The first one is to compare the dc and ac power consumption before and after the laptop adaptor. The responses of the dc and ac power are shown Figs. 7.1.6 to 7.1.7. The second experiment is to monitor the current, voltage and power for the dc side of the adaptor. The responses of the voltage, current, and the power are shown in Fig. 7.1.8 to 7.1.10. In the third experiment the voltage, current, and power at the fuel cell terminal are monitored while a combination of $\mathrm{AC}$ load $(40 \mathrm{~W}$ bulb) and the laptop computer. The responses of the voltage, current, and the power are shown in Fig. 7.1.11 to 7.1.13. 


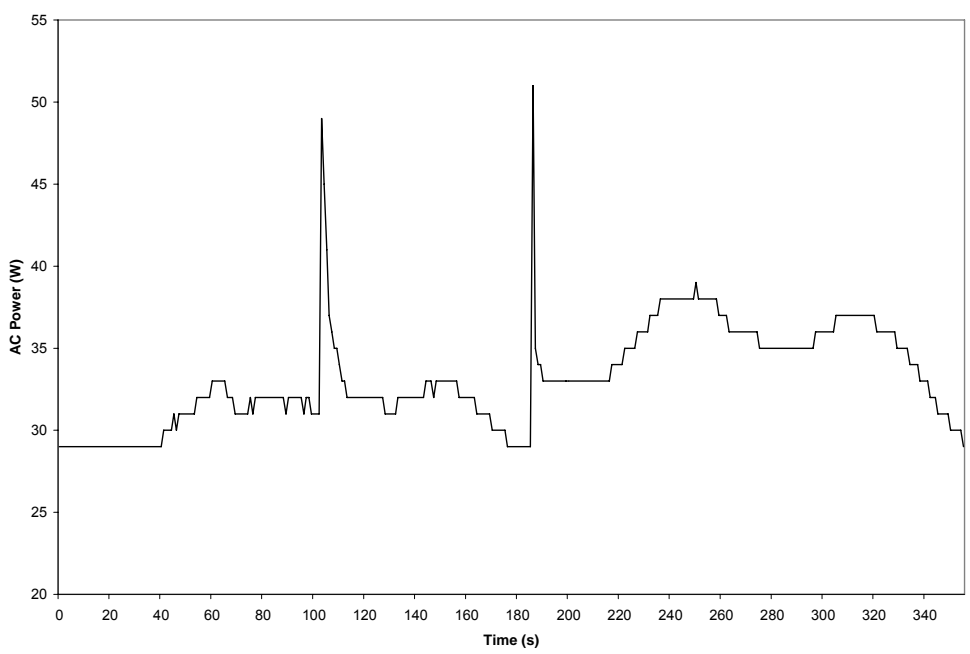

Fig. 7.1.6 AC power response of the laptop computer.

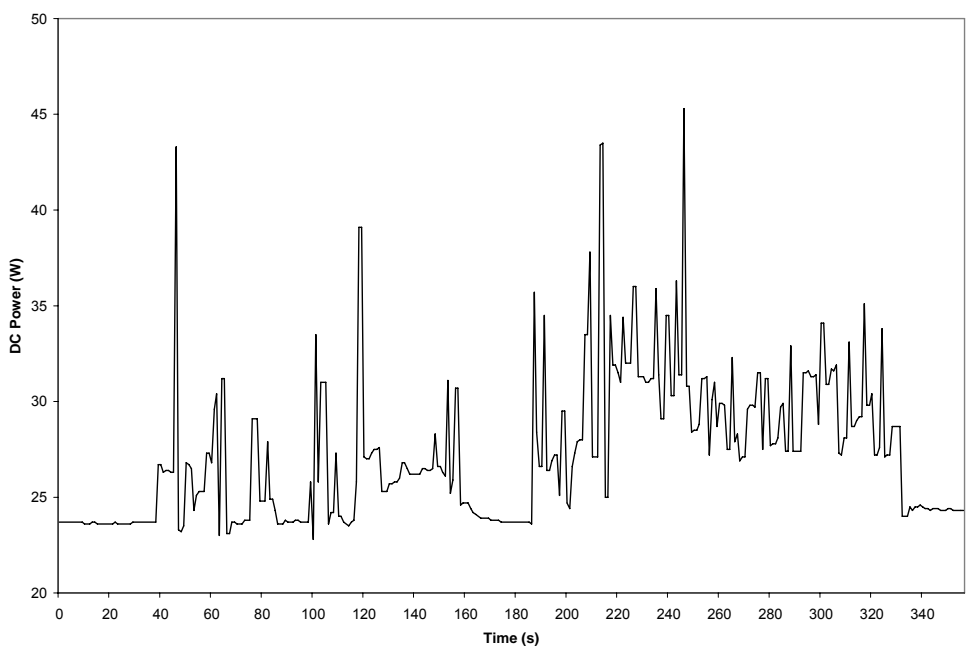

Fig. 7.1.7 DC power response of the laptop computer. 


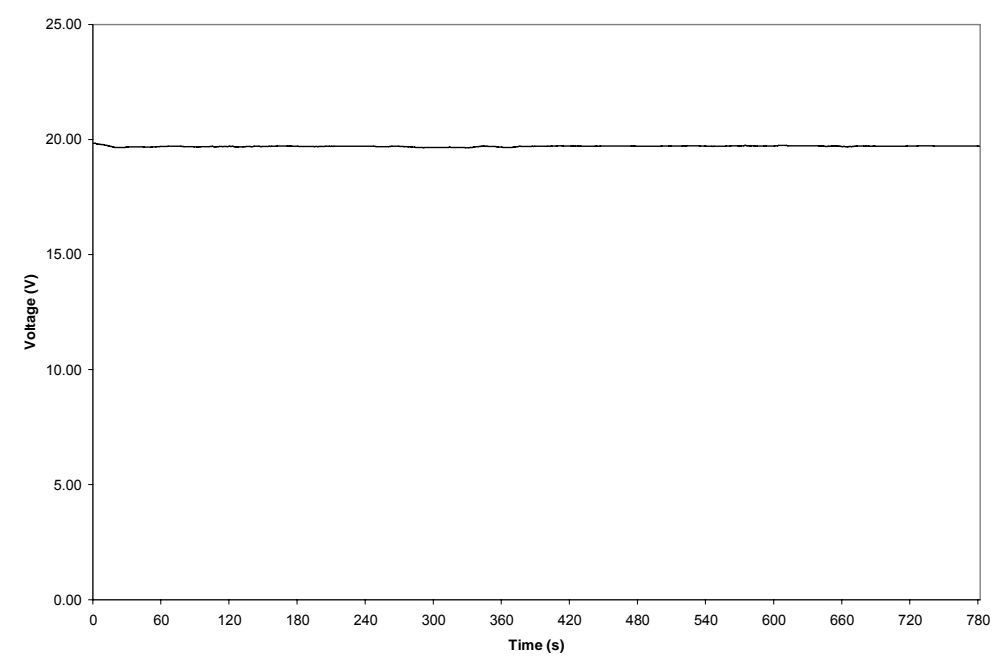

Fig. 7.1.8 Voltage response of the dc side of the laptop computer.

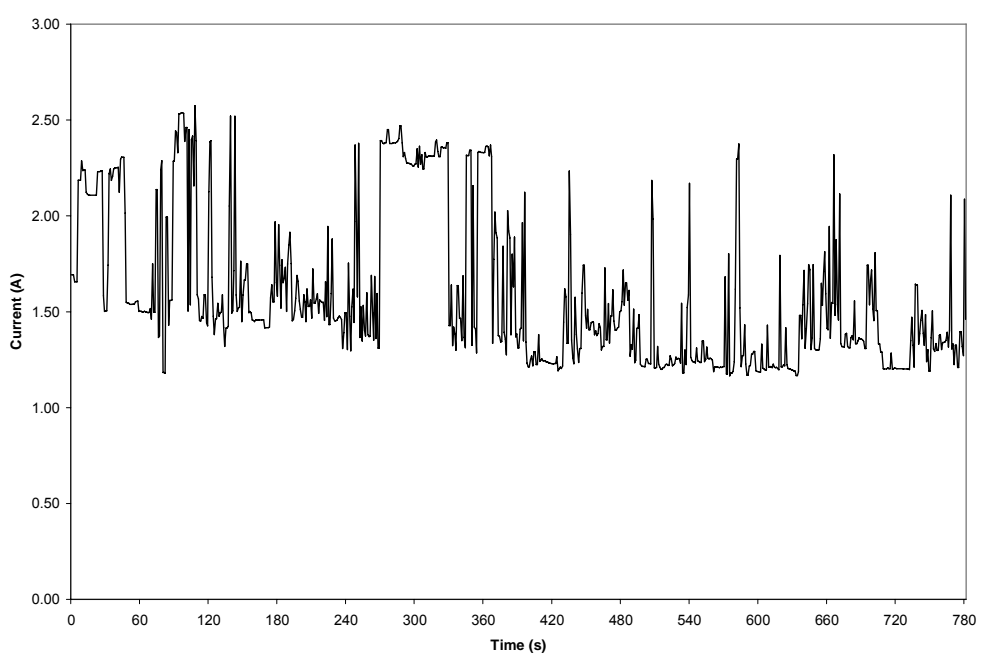

Fig. 7.1.9 Current response of the dc side of the laptop computer. 


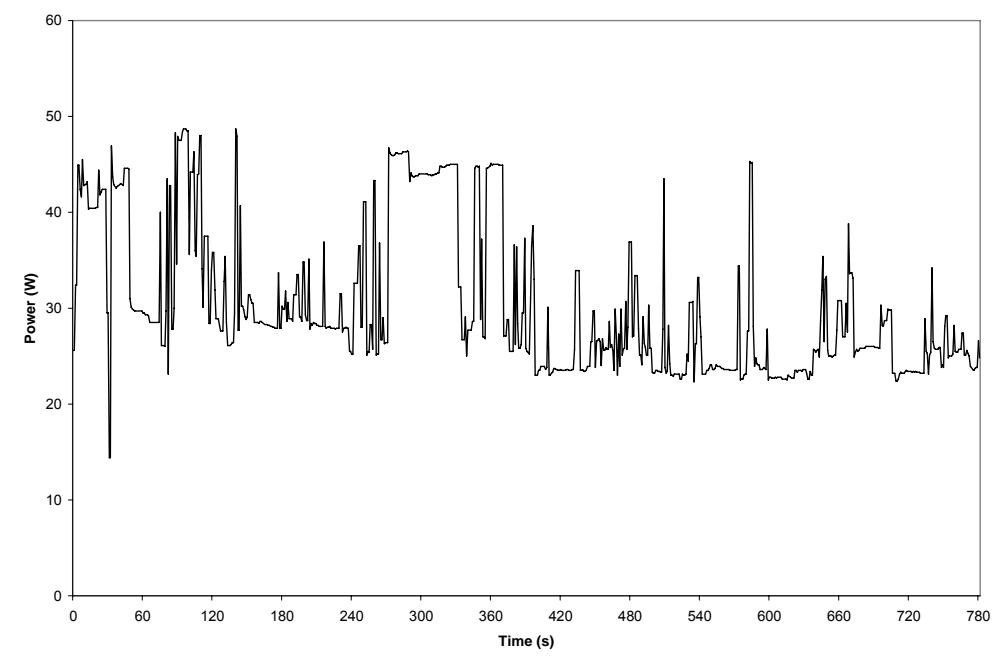

Fig. 7.1.10 Power response of the dc side of the laptop computer.

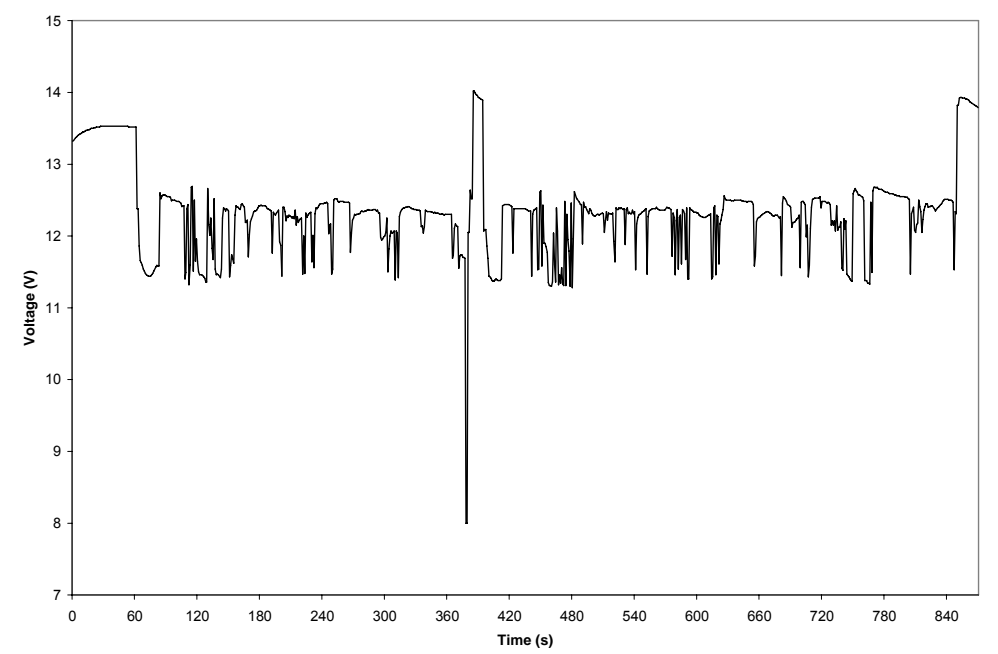

Fig. 7.1.11 Voltage response of the fuel cell output of the laptop computer and $40 \mathrm{~W}$ bulb. 


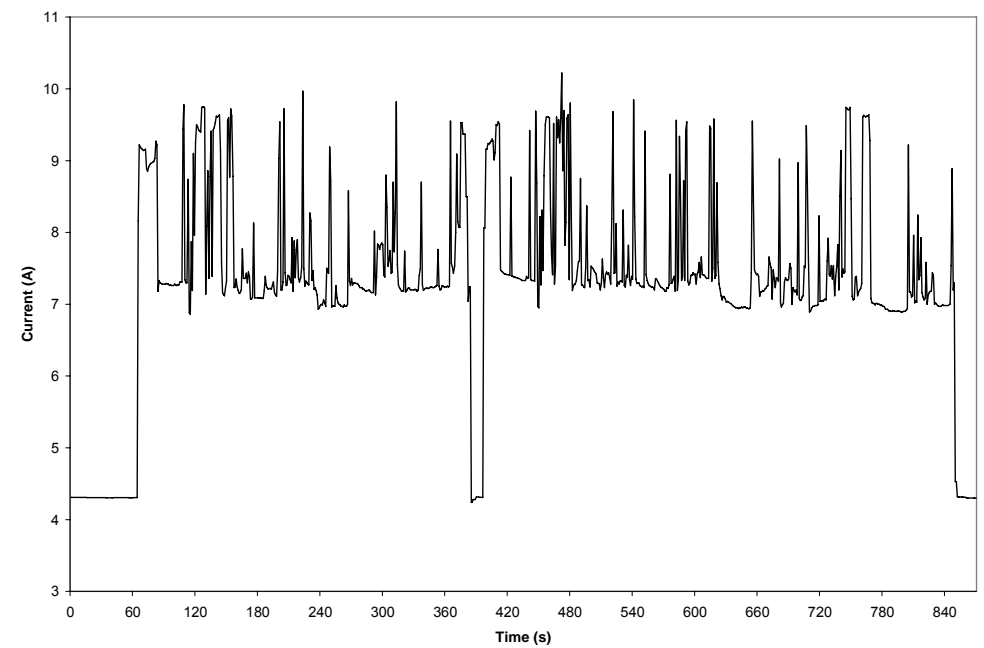

Fig. 7.1.12 Current response of the fuel cell output of the laptop computer and $40 \mathrm{~W}$ bulb.

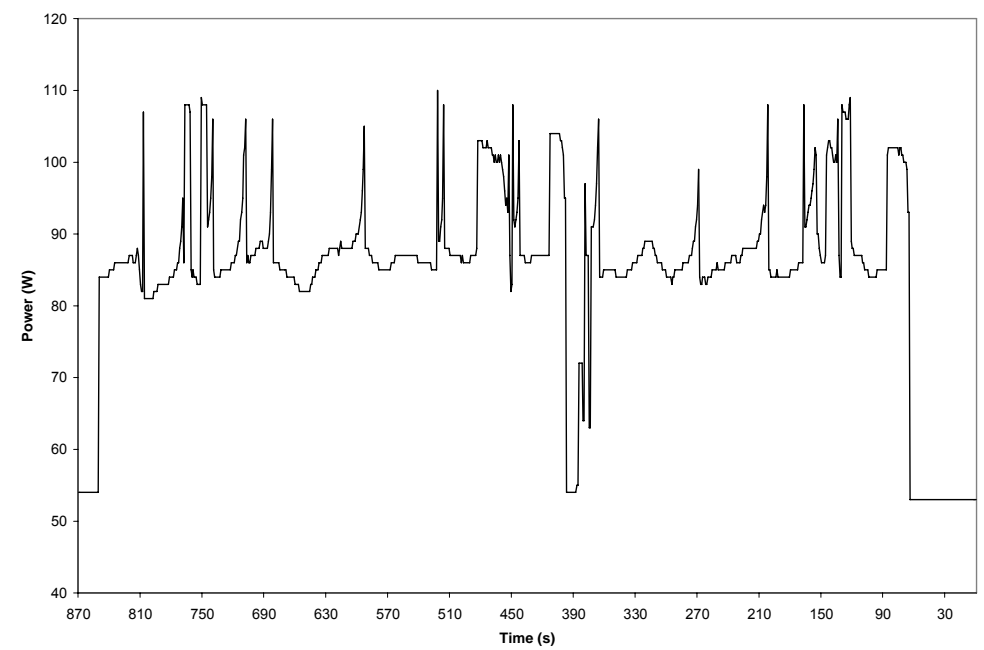

Fig. 7.1.13 Power response of the fuel cell output of the laptop computer and $40 \mathrm{~W}$ bulb.

From the above figures, its clear that the fuel cell can produce about $110 \mathrm{~W}$ for a short time. To test the ability of the fuel cell to provide power close to its limit, a $60 \mathrm{~W}$ bulb is used in parallel with the laptop computer. During startup of the laptop the total power of the laptop and the bulb may reach 130-140 W. Under this situation, the fuel cell reduces the power and turn off the laptop. To use the fuel cell to feed a load in the range of $130-140 \mathrm{~W}$ for a short time a supercapacitor is used. In this experiment, a Maxwell BMOD0110 E016 supercapacitor of 16.2 $\mathrm{V}, 110 \mathrm{~F}$ is used. The capacitor was able to provide the power mismatch between the laptop and the fuel cell output. In this experiment the charging and discharging time and current of the supercapacitor are not controlled. The supercapacitor, fuel cell, and total current are shown in 
Figs. 7.1.14, 7.1.15, and 7.1.16. The supercapacitor power and fuel cell voltage are shown in Figs. 7.1.17 and 7.1.18.

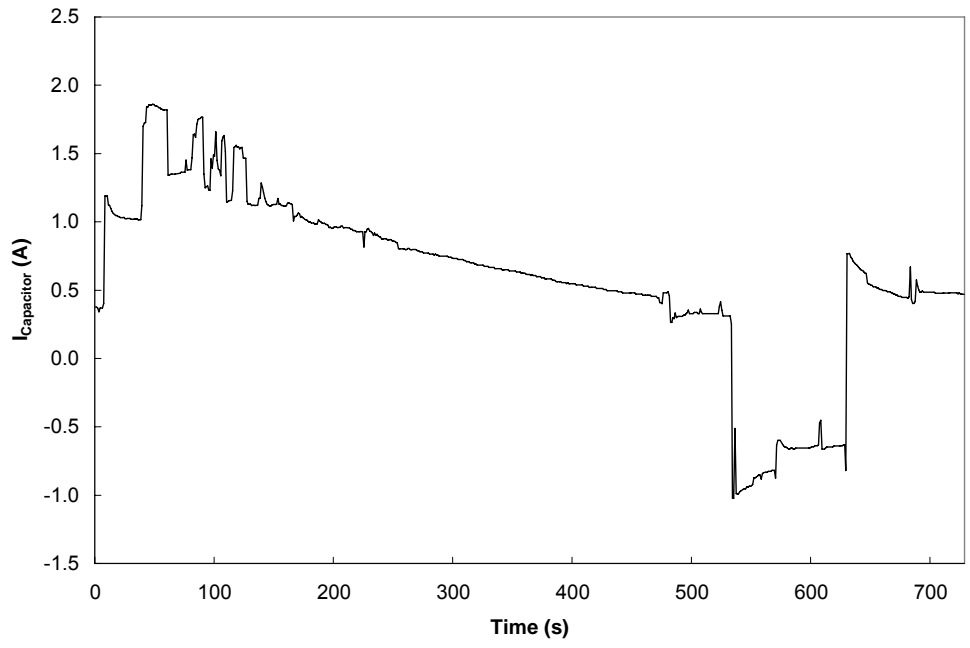

Fig. 7.1.14 Supercapacitor current.

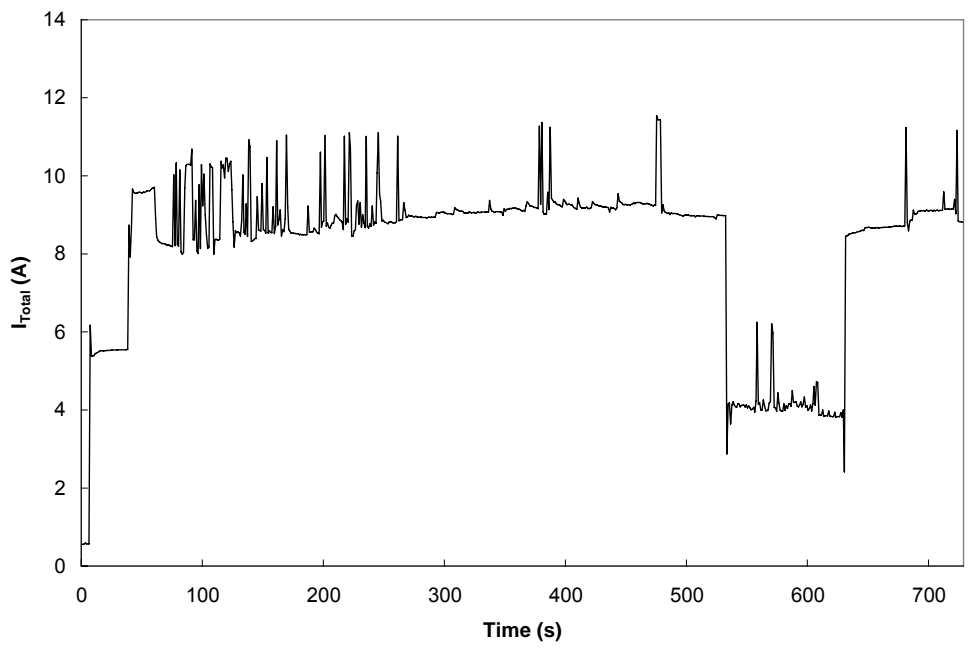

Fig. 7.1.15 Fuel cell current. 


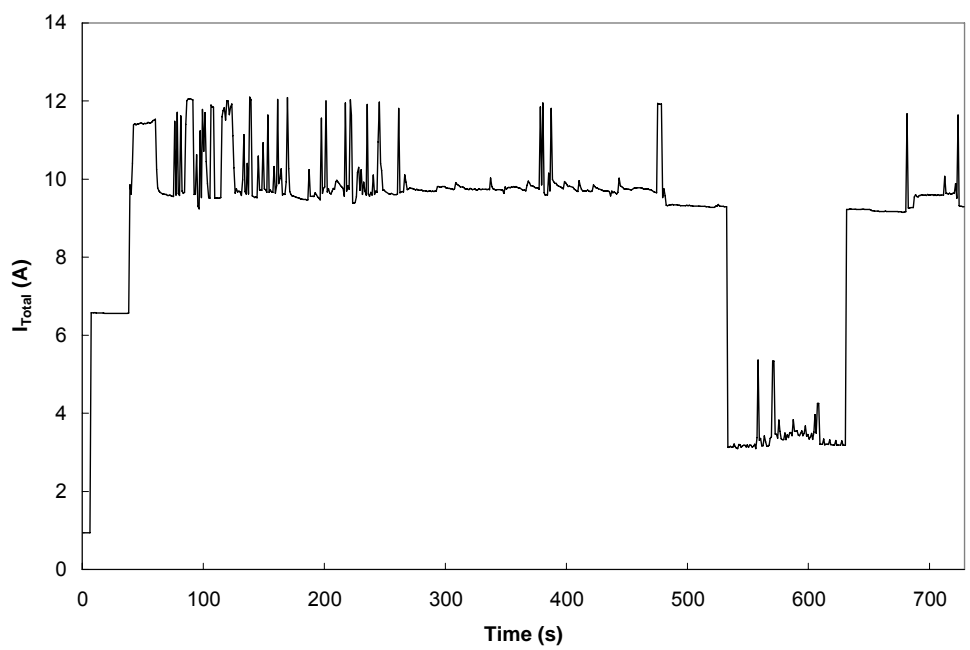

Fig. 7.1.16 Total current.

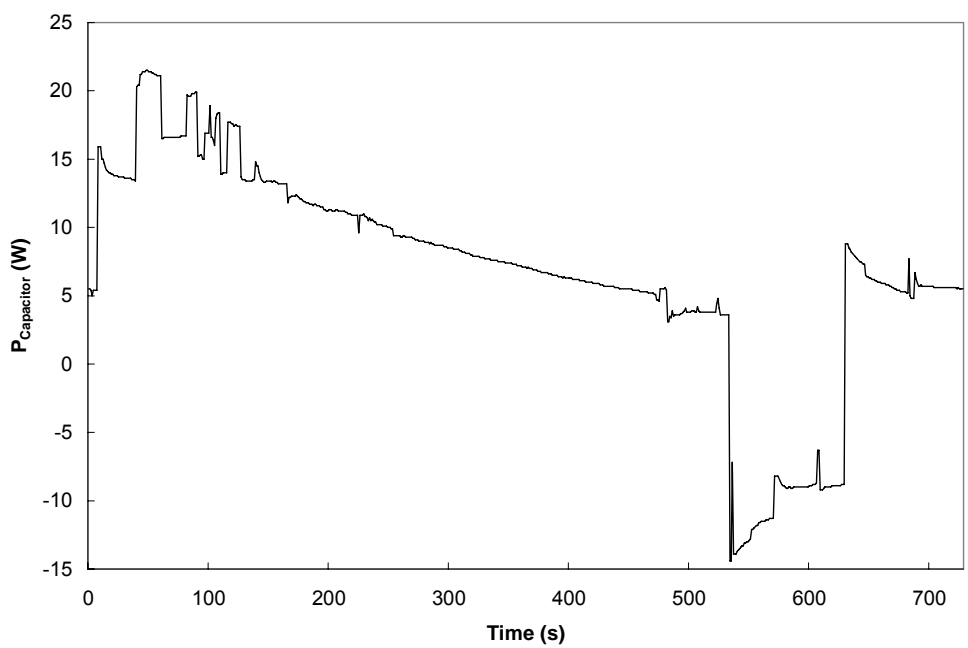

Fig. 7.1.17 Supercapacitor power. 


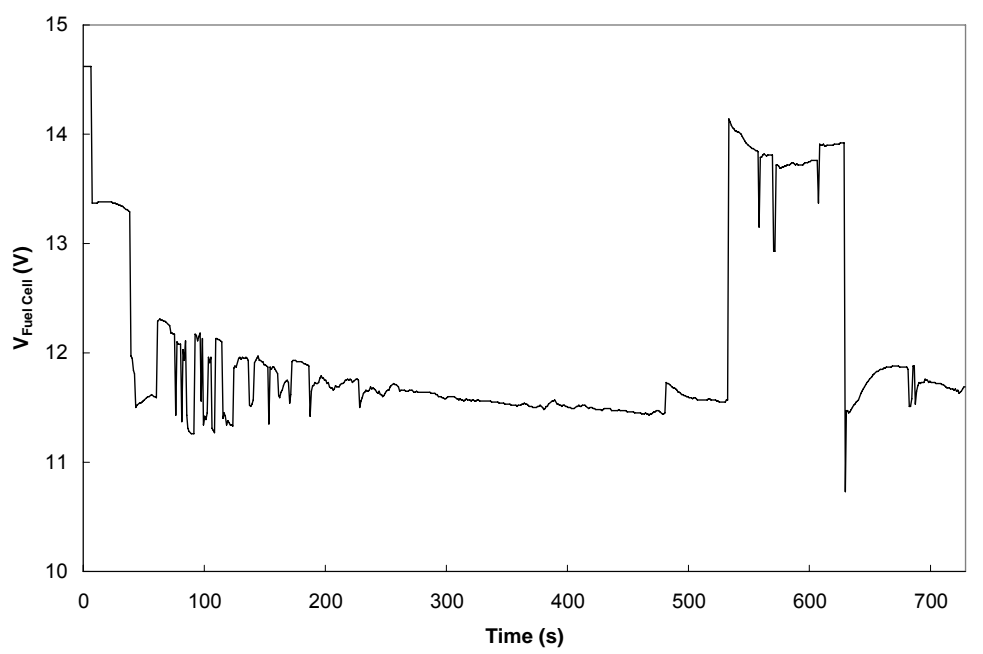

Fig. 7.1.18 Fuel cell voltage.

\subsection{PEM Fuel Cell System Description}

The dynamic model of PEM fuel cells described in [54], [55] is modified for portable applications. The detailed explanation of the dynamic model of the PEM fuel cell system can be found in reference [54], [55]. In this study, the PEM fuel cell model is operated at an ambient temperature $\left(20^{\circ} \mathrm{C}\right)$ and pressure $(1 \mathrm{~atm})$. The PEM fuel cell stack consists of 20 cells. The stack voltage of the PEM fuel cell system is $16 \mathrm{~V}$. A simple block diagram of the PEM fuel cell system dynamic model is given in Fig. 7.2.1. The current delay time constant is assumed as $0.1 \mathrm{~s}$ for a small fuel cell. In the block diagram, the hydrogen input flow for the $100 \mathrm{~W}$ PEM fuel cells system is limited by the saturation block. The hydrogen partial pressure $\mathrm{p}_{\mathrm{H}_{2}}$ can be written as[54], [55]:

$$
P_{\mathrm{H}_{2}}=\frac{1 / k_{\mathrm{H}_{2}}}{1+\tau_{\mathrm{H}_{2}} \mathrm{~S}}\left(q_{\mathrm{H}_{2}}^{\text {in }}-2 k_{r} I_{f c}\right)
$$

where $\tau_{\mathrm{H}_{2}}$ is the hydrogen time constant (s), $\mathrm{k}_{\mathrm{H}_{2}}$ is the hydrogen valve molar constant (kmol/atm $\mathrm{s}), \mathrm{k}_{\mathrm{r}}$ is the modeling constant ( $\mathrm{kmol} / \mathrm{s}$. A), $\mathrm{I}_{\mathrm{fc}}$ is the stack current (A) and $\mathrm{q}_{\mathrm{H}_{2}}^{\text {in }}$ is the hydrogen input flow $(\mathrm{kmol} / \mathrm{s})$. Similar equations for partial pressure of water $\mathrm{p}_{\mathrm{H}_{2} \mathrm{O}}$ and oxygen $\mathrm{p}_{\mathrm{O}_{2}}$ can also be derived using Eq. (1) [54], [55]. The stack output voltage $V_{\text {stack }}$ is expressed as

$$
V_{\text {stack }}=E-B \ln \left(C I_{f c}\right)-R^{\text {int }} I_{f c}
$$

where $\mathrm{E}$ is the Nernst voltage and $\mathrm{R}^{\mathrm{int}}$ is stack internal resistance $(\Omega)$. B and $\mathrm{C}$ are constants to simulate the activation over voltage in the fuel cell system. The Nernst voltage may be written as [54], [55]: 


$$
E=N_{o}\left[E_{o}+\frac{R T}{2 F} \log \left[\frac{p_{\mathrm{H}_{2}} \sqrt{P_{\mathrm{o}_{2}}}}{p_{\mathrm{H}_{2} \mathrm{O}}}\right]\right]
$$

We assume the rated power of this PEM fuel cell system is $100 \mathrm{~W}$. The model parameters of the PEM fuel cells system are updated from references [54], [55] and given in Table 7.2.1. The hydrogen valve constant, the oxygen valve constant and the water valve constant are determined according to reference [43] for the $100 \mathrm{~W}$ PEM fuel cell system. A dc/ac inverter is used to convert the $16 \mathrm{~V}$ dc output voltage to $110 \mathrm{~V}$ ac voltage to serve an ac load.

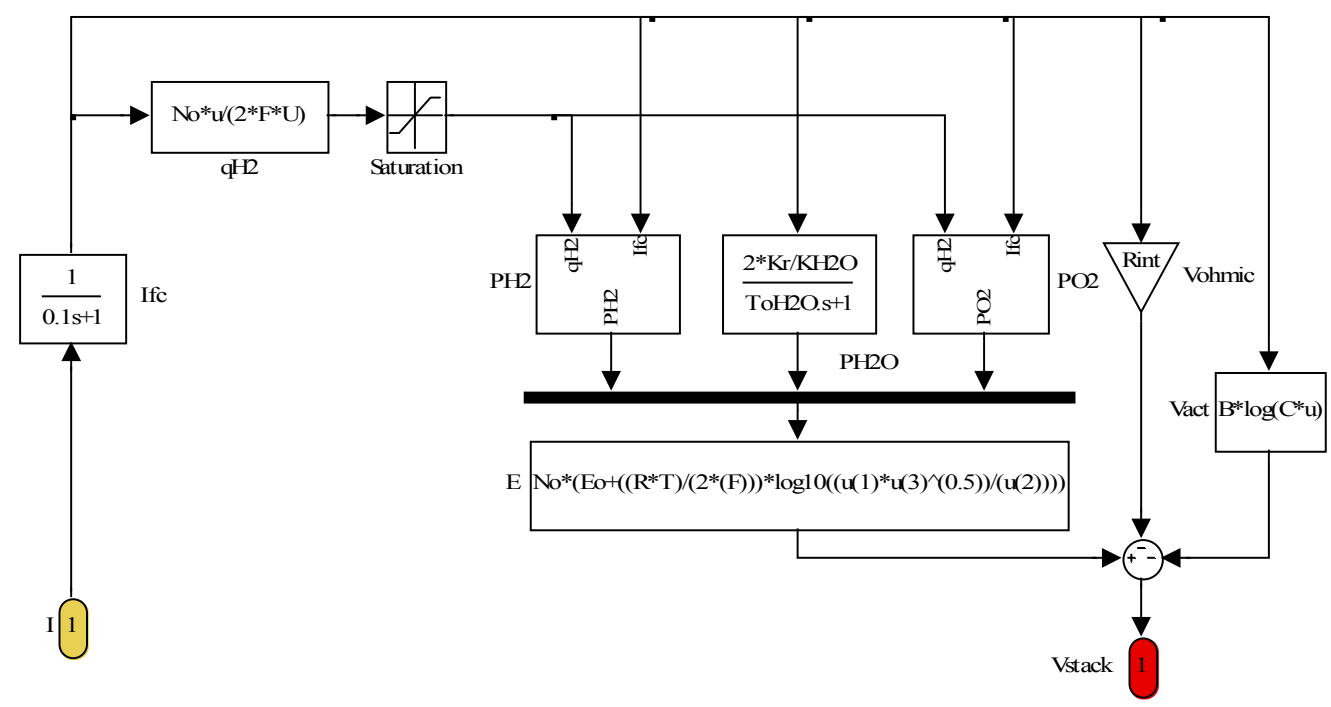

Fig. 7.2.1 A simple block diagram of PEM fuel cell system

\subsection{Simulation Results}

The model of the PEM fuel cell system and experimental results for laptop are simulated using Matlab, Simulink and SimPowerSystems Blockset. The dynamic behavior of the PEM fuel cells system is determined for a simulation time of $300 \mathrm{~s}$. To keep the voltage at the laptop terminal constant a dc/dc boost converter is used.

Figure 7.3.1 shows the change of laptop load currents. The PEM fuel cell provides adequate power to the laptop computer during different operation conditions. The load currents fluctuate between 1.2 A and 2.8 A. Figure 7.3.2 shows the dc power demand of the laptop under different operation conditions. The de power consumption of the laptop is varied between 20 and $40 \mathrm{~W}$. Figure 7.3.3 shows the load voltage of the laptop computer. The PEM fuel cell stack voltage is illustrated in Fig. 7.3.4. It is clearly seen from Figs. 7.3.4 and 7.3.1 that the fuel cell stack voltage drops when the load current increases. Figure 7.3.5 demonstrates the hydrogen flow rate under different operation conditions. The hydrogen flow rate varies according to power demand variations of the laptop computer. 
Table 7.2.1 Parameters in PEM fuel cell system model.

\begin{tabular}{lll} 
Parameter & Representation & Value \\
\hline $\mathrm{N}_{\mathrm{O}}$ & $\begin{array}{l}\text { number of cells in series in } \\
\text { the stack }\end{array}$ & 20 \\
& standard no load voltage & $0.9 \mathrm{~V}$ \\
$\mathrm{E}_{\mathrm{O}}$ & Universal gas constant & $8314.47 \mathrm{~J} /(\mathrm{kmol} \mathrm{K})$ \\
$\mathrm{R}$ & Stack temperature & $293 \mathrm{~K}$ \\
$\mathrm{~T}$ & Faraday's constant & $96484600 \mathrm{C} / \mathrm{kmol}$ \\
$\mathrm{F}$ & stack internal resistance & $1.75 \Omega$ \\
$\mathrm{R}^{\text {int }}$ & Activation voltage constant & $0.04777 \mathrm{~A}^{-1}$ \\
$\mathrm{~B}$ & Activation voltage constant & $0.0136 \mathrm{~V}$ \\
$\mathrm{C}$ & hydrogen time constant & $3.37 \mathrm{~s}$ \\
$\tau_{\mathrm{H}_{2}}$ & hydrogen valve constant & $6.48 \times 10^{-7} \mathrm{kmol} /(\mathrm{s} \mathrm{atm})$ \\
$\mathrm{k}_{\mathrm{H}_{2}}$ & oxygen time constant & $6.74 \mathrm{~s}$ \\
$\tau_{\mathrm{O}_{2}}$ & oxygen valve constant & $3.24 \times 10^{-7} \mathrm{kmol} /(\mathrm{s} \mathrm{atm})$ \\
$\mathrm{k}_{\mathrm{O}_{2}}$ & water time constant & $18.418 \mathrm{~s}$ \\
$\tau_{\mathrm{H}_{2} \mathrm{O}}$ & water valve constant & $6.48 \times 10^{-7} \mathrm{kmol} /(\mathrm{s} \mathrm{atm})$ \\
$\mathrm{k}_{\mathrm{H}_{2} \mathrm{O}}$ &
\end{tabular}

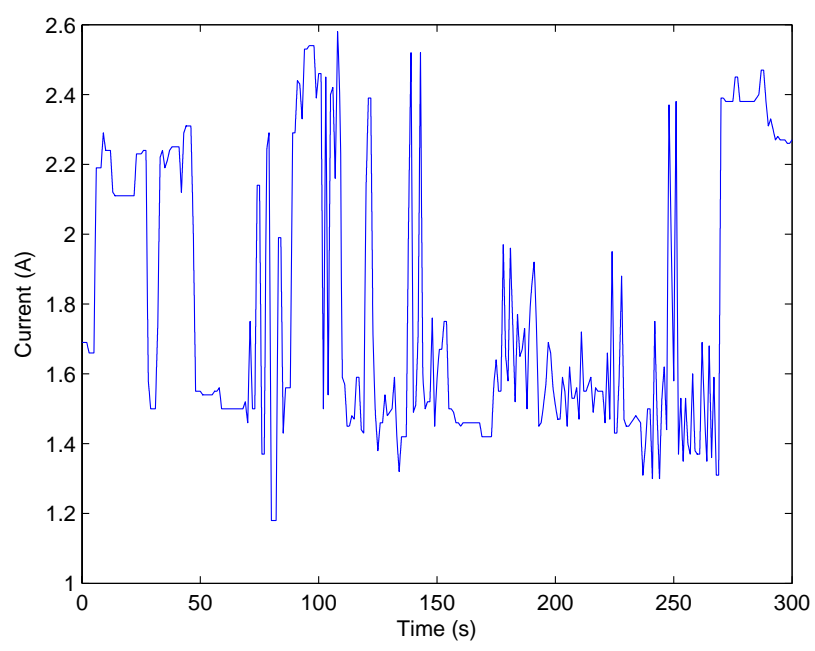

Fig. 7.3.1 Load current under different operation conditions 


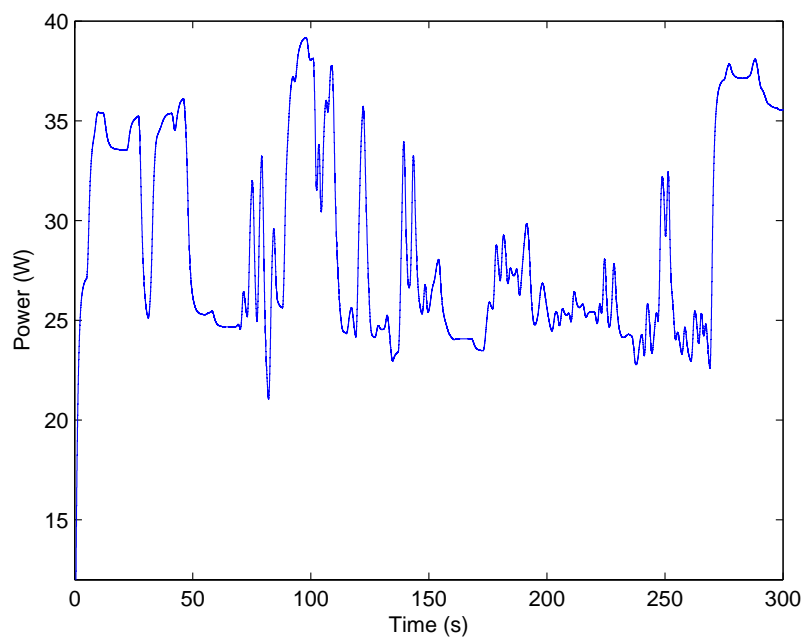

Fig. 7.3.2 Power demand under different operation conditions.

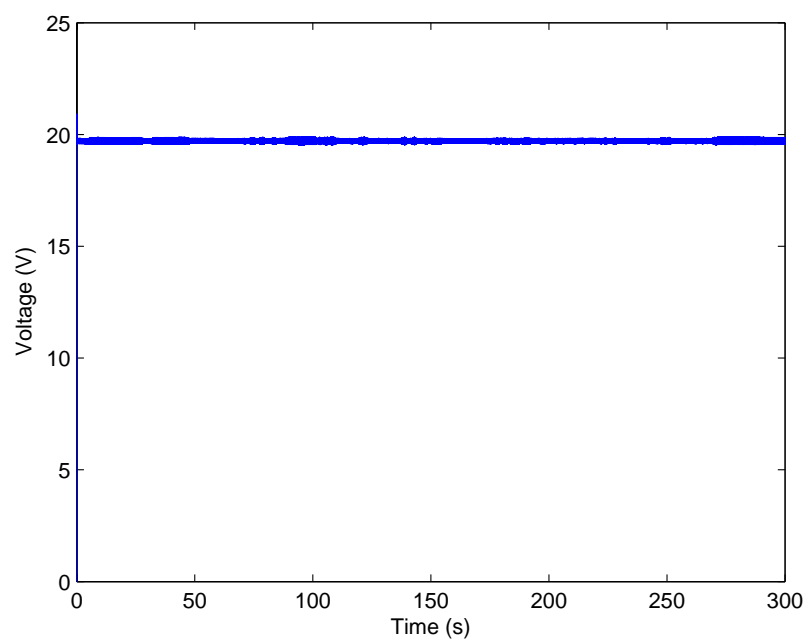

Fig. 7.3.3 Load voltage under different operation conditions. 


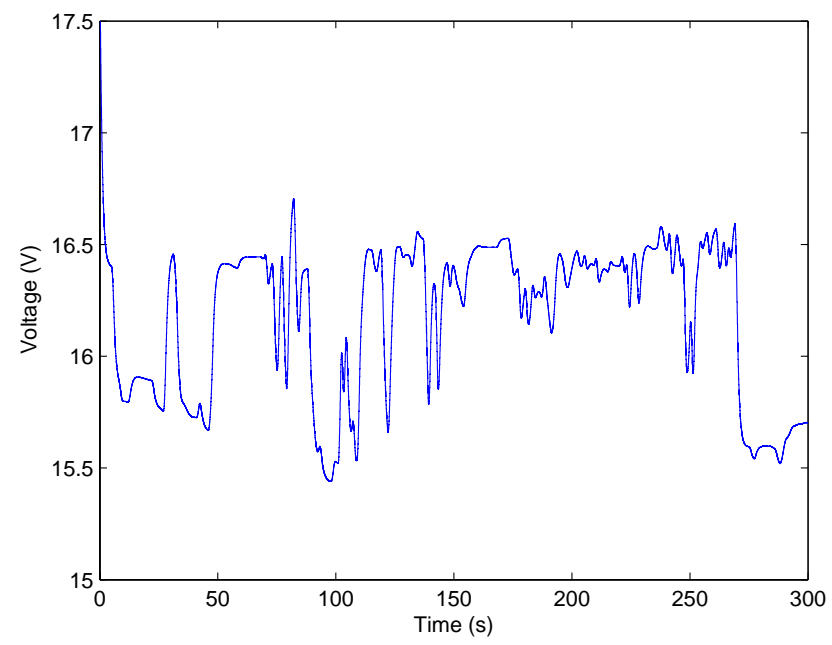

Fig. 7.3.4 Fuel cell output voltage under different operation conditions.

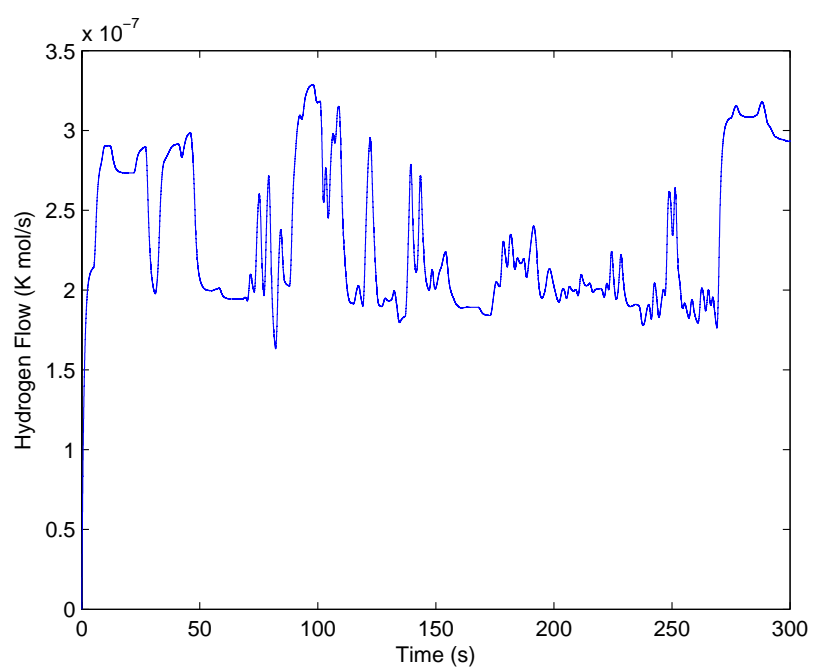

Fig.7.3.5 Hydrogen flow rate under different operation conditions.

Comparing the simulation results in Figs. 7.3.1, 7.3.2, and 7.3.3 to the experimental results in Figs. 7.1.8, 7.1.9, and 7.1.10 shows that the fuel cell model is capable to produce results that are very close to the experimental results.

\subsubsection{Conclusions}

In this research, a 100W PEM fuel cell based system is proposed for powering a laptop computer. The dynamic model of the PEM fuel cell system presented in [54],[55] is modified for portable small power applications, such as a laptop computer. The modeling and simulation are carried out 
using Matlab, Simulink and SimPowerSystems Blockset for portable applications. The experimental results show that a supercapacitor is parallel with the fuel cell will increase the fuel cell ability to provide power more than its full load capacity for a short time. In this case, a control system must be used to control the charging and discharging time. In this research the experimental results are obtained without any control system. The simulation results demonstrated that the power consumption of a laptop varies significantly depending on whether the laptop is operated in the standby state, fully loaded state, operational software state, etc. The fuel cell stack voltage drops when the load current increases. Results show a match between the experimental and simulation results.

\section{References}

[1] Reliability Test System Task Force of the Application of Probability Methods Subcommittee, "IEEE Reliability Test System," IEEE Trans. Power Apparatus and Systems, vol. PAS-98, no. 6, pp. 2047- 2054, 1979.

[2] M. B. Gunes, "Investigation of a Fuel Cell Based Total Energy System for Residential Applications," Master of Science Thesis, Dept. Mechanical Engineering, Virginia Polytechnic Institute and State University, 2001.

[3] NFPA 70 The National Electric Code (c) 2002, National Fire Protection Association, Quincy, MA 02269.

[4] A. J. Wood and B. F. Wollenberg, Power generation operation and control, $2^{\text {nd }}$ Ed., New York: John Wiley and Sons Inc., 1996.

[5] C. K. Pang and H. C. Chen, "Optimal short-term thermal unit commitment," IEEE Transactions on Power Apparatus and Systems, vol. 95, no. 4, pp. 1336-1341, 1976.

[6] S. J. Wang, S. M. Shahidehpour, D. S. Kirschen, I. S. Mokhtar, and G. D. Irisarri, "Shortterm generation scheduling with transmission and environmental constraints using an augmented Lagrangian relaxation," IEEE Transactions on Power Systems, vol. 10, no.3, pp. 1294-1301, Aug. 1995.

[7] T.S. Dillon, K.W. Edwin, H.D. Kochs, and R.J. Taud, "Integer programming approach to the problem of optimal unit commitment with probabilistic reserve determination," IEEE Transactions on Power Apparatus and Systems, vol. 97, pp. 2154-2166, 1978.

[8] J. A. Muckstadt and R. C. Wilson, "An Application of Mixed-Integer Programming Duality to Scheduling Thermal Generating Systems," IEEE Transactions on Power Apparatus and Systems, vol. 87, no. 12, pp. 1968-1978, Dec. 1968.

[9] A. I. Cohen and M. Yoshimura, "A Branch-and-Bound Algorithm for Unit Commitment," IEEE Transactions on Power Apparatus and Systems, vol. 102, no. 2, pp. 444-451, 1983.

[10] S. A. Kazarlis, A. G. Bakirtzis, and V. Petridis, "A genetic algorithm solution to the unit commitment problem," IEEE Transactions on Power Systems, vol. 11, no. 1, pp. 83 - 92, Feb. 1996.

[11] H. Ma, A. A. El-Keib, and R. E. Smith, "A genetic algorithm-based approach to economic dispatch of power systems," IEEE Proceedings, Southeastcon '94, pp. 212 - 216, April 1994.

[12] J. Valenzuela and A. E. Smith, "A seeded Memetic Algorithm for Large Unit Commitment Problems," Journal of Heuristics, vol. 8, no. 2, pp. 173-195, Sept. 1988.

[13] K. A. Juste, H. Kita, E. Tanaka, and J. Hasegawa, "An evolutionary programming solution to the unit commitment problem," IEEE Transactions on Power Systems, vol. 14, no. 4, pp. $1452-1459$, Nov. 1999. 
[14] F. Zhuang and F. D. Galiana, "Unit commitment by simulated annealing," IEEE Transactions on Power Systems, vol. 5, no. 1, pp. 311-318, Feb. 1990.

[15] A. H. Mantawy, Y. L. Abdel-Magid, and S. Z. Selim, "Integrating genetic algorithms, tabu search, and simulated annealing for the unit commitment problem," IEEE Transactions on Power Systems, vol. 14, no. 3, pp. 829-836, Aug. 1999.

[16] Mehmet Burak Gunes, "Investigation of a Fuel Cell Based Total Energy System for Residential Applications," Master of Science Thesis, Dept. Mechanical Engineering, Virginia Polytechnic Institute and State University, 2001.

[17] D. B. Fogel "Evolutionary Computation toward a New Philosophy of Machine Intelligence" $2^{\text {nd }}$ ed, Wiley-IEEE Press, 1999.

[18] T. Back, U. Hammel, H. P. Schwefel, "Evolutionary Computation: Comments on the History and Current State" IEEE Transactions on Evolutionary computation, vol. 1, no. 1, pp. 3-17, April 1997.

[19] V. Miranda, D. Srinivasan, L. M. Proenca, "Evolutionary Computation in Power System," Electrical Power and Energy Systems, vol. 20, no. 2, pp. 89-98, 1998.

[20] P. H. Winston, "Artificial Intelligence" $3^{\text {rd }}$ ed, Addison-Wesley Publishing Company. 1993.

[21] Reliability Test System Task Force of the Application of Probability Methods Subcommittee, "IEEE Reliability Test System," IEEE Trans. Power Apparatus and Systems, vol. PAS-98, no. 6, pp. 2047- 2054, 1979.

[22] G. Kresse and J. Furthmüller, ""Efficiency of ab initio total energy calculations for metals and semiconductors using a plane-wave basis set ", Computational Material Science, vol. 6, pp 15-50, 1996.

[23] G. Kresse and J. Furthmüller, "Efficient iterative schemes for ab initio total-energy calculations using a plane-wave basis set", Physical Review B, vol. 54, pp 11169, 1996.

[24] H. J. Monkhorst and J. D. Pack, "Special points for Brillouin-zone integrations", Physical Review B, vol. 13, pp. 5188-5192, 1976.

[25] F. D. Murnaghan, "The Compressibility of Media under Extreme Pressures", Proc. Natl. Acad. Sci. USA, vol. 30, pp. 244, 1944.

[26] F. Bechstedt, U. Grossner and J. Furthmüller, "Dynamics and polarization of group-III nitride lattices: A first-principles study", Physical Review B, vol. 62, pp 8003-8011, 2000.

[27] M. B. Nardelli, K. Rapcewicz and J. Bernholc, "Strain effects on the interface properties of nitride semiconductors", Physical Review B, vol. 55, pp R7323-R7326, 1997.

[28] L. E. Ramos, L. K. Teles, L. M. R. Scolfaro, J. L. P. Castineira, A. L. Rosa and J. R. Leite, "Structural, electronic, and effective-mass properties of silicon and zinc-blende group-III nitride semiconductor compounds ", Physical Review B, vol. 63, pp. 165210, 2001.

[29] C. Stampfl and C. G. Van de Walle, "Density-functional calculations for III-V nitrides using the local-density approximation and the generalized gradient approximation", Physical Review B, vol. 59, pp. 5521-5535, 1998.

[30] F. Bechstedt and J. Furthmüller , "Do we know the fundamental energy gap of InN?", Journal of crystal Growth, vol. 246, pp. 315, 2002.

[31] C. Xu and S. U. M. Khan, "Photoresponse of Visible Light Active Carbon-Modified-n-TiO Thin Films", Electrochemical and Solid-State Letters, vol. 10, pp. B56-B59, 2007.

[32] S. E. Lindquist and H. Vidarsson, "An rrde investigation of light-induced cathodic currents at polycrystalline $\mathrm{TIO}_{2}$ electrodes in the presence of dioxygen : Part I. The light intensity dependence and the cathodic action spectra", Journal of Molecular Catalysts, Vol. 38, pp $131,1986$. 
[33] J. Larminie, A. Dicks, "Fuel cell systems explained, 2nd edition", John Wiley and Sons, West Sussex, UK, 2003. ISBN 0-470-84857-X

[34] G. Hoogers, editor, "Fuel cell technology handbook", CRC Press, Boca Raton, FL, 2003. ISBN 0-8493-0877-1

[35] John C. Molburg, Richard D. Doctor, "Hydrogen from Steam-Methane Reforming with CO2 Capture," 20th Annual International Pittsburgh Coal Conference, September 15-19, 2003, Pittsburgh, PA.

[36] J. Stöcker, M. Whysall, G.Q. Miller, "30 Years of PSA Technology for Hydrogen Purification,” UOP LLC, 25 East Algonquin Road, Des Plaines, IL 60017-5017, 1998 UOP LLC.

[37] David H. DaCosta, Mark Golben, "Hydride Based Hydrogen Compression," DOE Hydrogen Program, FY 2004 Progress Report, DOE Technology Development Manager: Mark Paster

[38] D. DaCosta, M. Golben. "Advanced Thermal Hydrogen Compression", FY 2003 Progress Report for Hydrogen, Fuel Cells, and Infrastructure Technologies Program Energy Efficiency and Renewable Energy, V-36-V-40. Berkley, CA. www.eere.energy.gov/ hydrogenandfuelcells/

[39] D. DaCosta, M. Golben. "Disproportionation Resistant Alloy Development For Hydride Hydrogen Compression", Proceedings 2002 U.S. Department of Energy Hydrogen Program Annual Review Meeting, Golden, CO, May 6-8, 2002, NREL/CP-610-32405.

[40] Sagnik Mazumdar, M. Ram Gopal, and Souvik Bhattacharyya, "Dynamic Performance Analysis of a Compressor Driven Metal Hydride Cooling System," Journal of Energy Resources Technology, Volume 128, Issue 1, pp. 35-43, March 2006.

[41] J. Larminie, A. Dicks, Fuel Cell Systems Explained, Wiley, Chichester, England, 2003.

[42] W. Vielstich, A. Lamm, H.A. Gasteiger, (Eds), Handbook of fuel cells : fundamentals, technology, and applications, Wiley, Chichester, England, 2003.

[43] F. Barbir, PEM Fuel Cells: Theory and Practice, Elsevier Academic Press, London, UK, 2005.

[44] C. K. Dyer, 'Fuel cells for portable applications', Journal of Power Sources, Vol. 106, No. 1-2, pp. 31-34, 2002.

[45] C.M. Miesse, et. al., 'Direct formic acid fuel cell portable power system for the operation of a laptop computer', Journal of Power Sources, Vol.162, No. 1, pp. 532-540, Nov. 2006.

[46] K. Tuber, M. Zobel, H. Schmidt, C. Hebling, 'A polymer electrolyte membrane fuel cell system for powering portable computers', Journal of Power Sources, Vol. 122, No. 1, pp. 18, 2003.

[47] A. Biylkoglu, 'Review of proton exchange membrane fuel cell models', International Journal of Hydrogen Energy, Vol. 30, No. 11, pp. 1181-1212, 2005.

[48] J.C. Amphlett, R.M. Baumert, R.F. Mann, B.A. Peppley and P.R. Roberge, 'Performance Modeling of the Ballard Mark IV Solid Polymer Electrolyte Fuel Cell I. Mechanistic Model Development', Journal of the Electrochemical Society Vol 142, pp.1-8, 1995.

[49] J.C. Amphlett, R.M. Baumert, R.F. Mann, B.A. Peppley and P.R. Roberge, 'Performance Modeling of the Ballard Mark IV Solid Polymer Electrolyte Fuel Cell II. Empirical Model Development', Journal of the Electrochemical Society Vol 142, pp.9-15, 1995.

[50] J.C. Amphlett, R.F. Mann, B.A. Peppley, P.R.Roberge, and A. Rodrigues, 'A model predicting transient response of proton exchange membrane fuel cells', Journal of Power Sources, Vol. 61, No. 1-2, pp. 183-188, 1996. 
[51] A. Rowe and X. Li, 'Mathematical modeling of proton exchange membrane fuel cells', Journal of Power Sources, Vol. 102, No. 1-2, pp. 82-96, 2001.

[52] S. Pasricha, S.R. Shaw, 'A dynamic PEM fuel cell model' IEEE Trans. on Energy Conversion, Vol. 21, No. 2, pp. $484-4902006$.

[53] J. Padulles, G. W. Ault, and J. R. McDonald, 'An integrated SOFC plant dynamic model for power systems simulation', Journal of Power Sources, Vol. 86, No. 1-2, pp. 495-500, Mar. 2000.

[54] M. Y. El-Sharkh, A. Rahman, M. S. Alam, P. C. Byrne, A. A. Sakla, and T. Thomas, 'A dynamic model for a stand-alone PEM fuel cell power plant for residential applications', Journal of Power Sources, Vol. 138, No. 1-2, pp. 199-204, Nov. 2004.

[55] M. Uzunoglu, M.S. Alam, 'Dynamic modeling, design, and simulation of a combined PEM fuel cell and ultracapacitor system for stand-alone residential applications', IEEE Trans. on Energy Conversion, Vol. 21, No. 3, pp. 767-775, 2006. 